\title{
UPCommons
}

Portal del coneixement obert de la UPC

http://upcommons.upc.edu/e-prints

Aquesta és una còpia de la versió accepted manuscript (AM) d'un article publicat per Taylor \& Francis a la revista Critical Reviews in Solid State and Material Sciences.

URL d'aquest document a UPCommons E-prints:

http://hdl.handle.net/2117/87569

Article publicat / Published paper:

Abt, T., Sanchez-Soto, M. A (2016) Review of the recent advances in cyclic butylene terephthalate technology and its composites. Critical Reviews in Solid State and Materials Sciences. DOI : 10.1080/10408436.2016.1160820 


\section{A review of the recent advances in cyclic butylene terephthalate technology and its composites}

\section{Short title: Recent advances in CBT technology and its composites}

Tobias Abt* and Miguel Sánchez-Soto

Department of Materials Science. Centre Català del Plàstic. Universitat Politècnica de Catalunya, BarcelonaTech (UPC). C/Colom 114, E-08222 Terrassa, Spain.

\section{Abstract}

Cyclic butylene terephthalate $\left(\mathrm{CBT}^{\circledR}\right)$ oligomers are a relatively new class of material and are capable of polymerizing in an entropically-driven ring-opening polymerization into high-molecular-weight polymerized $\mathrm{CBT}(\mathrm{pCBT})$ in very short times, i.e. within minutes. The most important feature of CBT is its very low, water-like melt viscosity prior to polymerization which gives rise to an excellent impregnation of fibrous reinforcements in contrast to conventional, high viscous thermoplastic resins. This opens up new possibilities in the thermoplastic composite production since thermoplastic-based composites show some advantages over thermoset-based ones. Specifically, they have a higher toughness and impact strength and they can be welded, postformed and recycled due to their thermoplastic nature. CBT has the potential to substitute thermoset matrices in fibre reinforced composites and may solve some of the today's recycling issues associated with thermoset-based 
composites. Moreover, the low melt viscosity of CBT enhances the dispersion of nano- or conductive particles and can yield superior nano- and conductive composites. This article reviews the recent advances in processing-structureproperty relationship, physical and chemical modification of $\mathrm{pCBT}$, as well as the preparation of fibre reinforced pCBT composites, $\mathrm{pCBT}$ nanocomposites and conductive pCBT composites.

Keywords: Cyclic butylene terephthalate; pCBT; ring-opening polymerization; thermoplastic composite; nanocomposite, conductive polymer composite.

*Corresponding author: Tobias Abt, Tel: +34 937837 022, Fax: +34 937841827 , e-mail: tobias.abt@upc.edu.

\section{Contents}

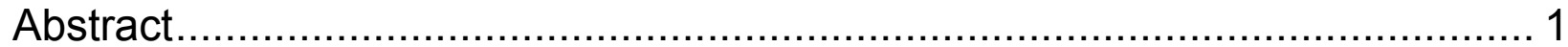

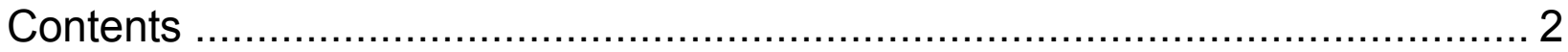

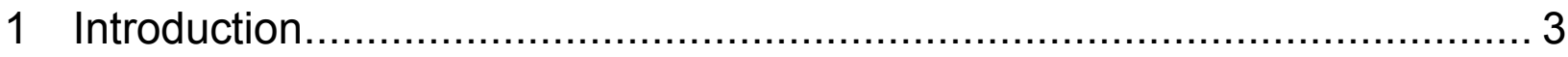

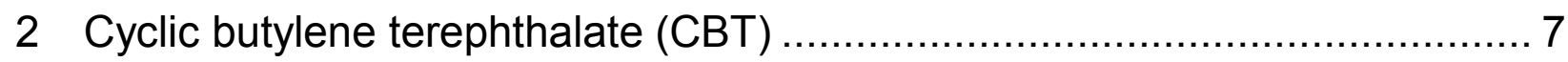

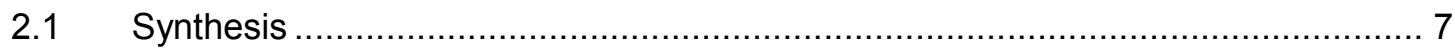

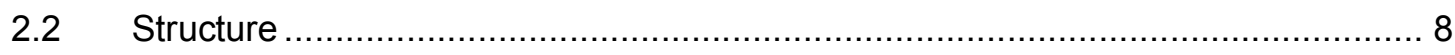

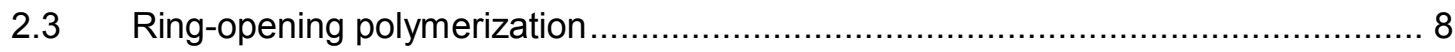

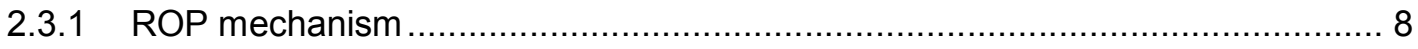

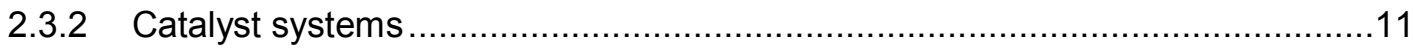

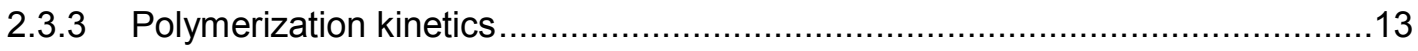

2.3.4 Modeling of polymerization kinetics ............................................................ 15

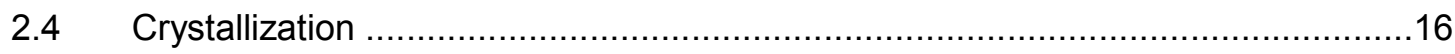

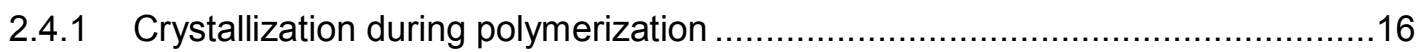

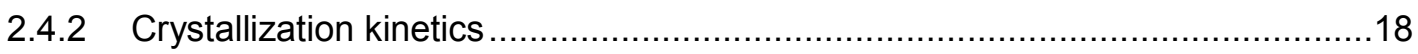

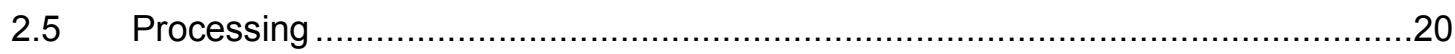

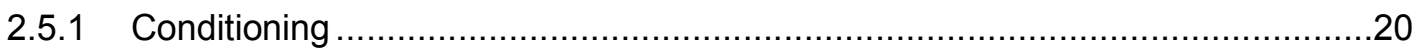

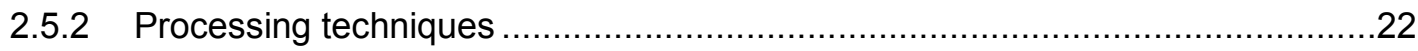




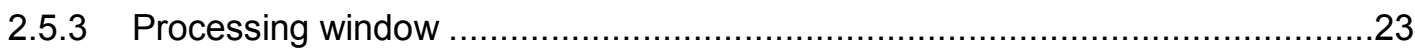

3 Polymerized cyclic butylene terephthalate (pCBT) ............................... 25

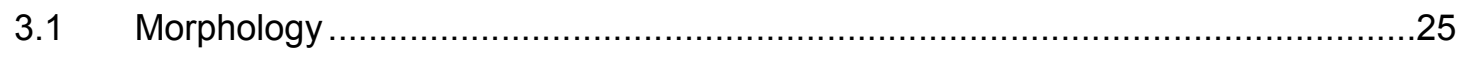

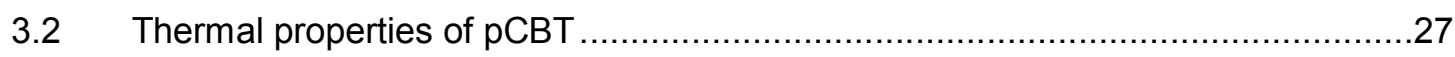

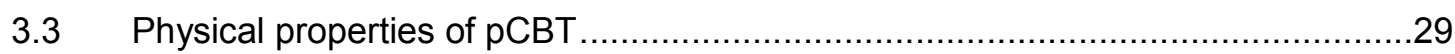

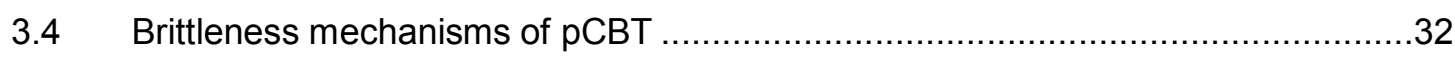

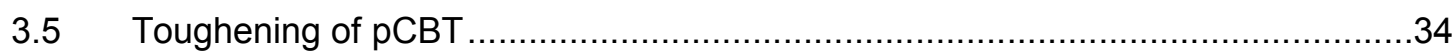

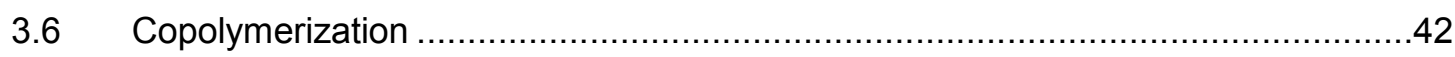

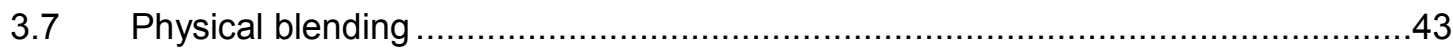

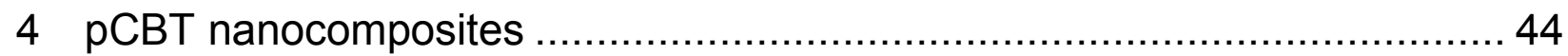

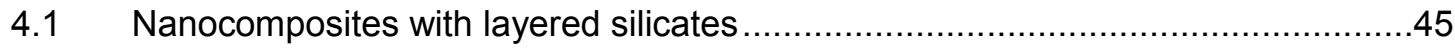

$4.2 \quad$ Nanocomposites with carbon nanotubes....................................................... 47

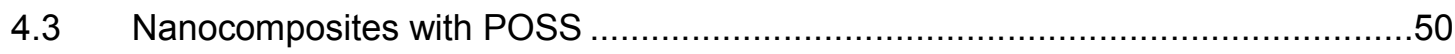

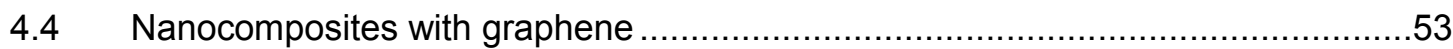

5 Fibre-reinforced pCBT composites ................................................ 56

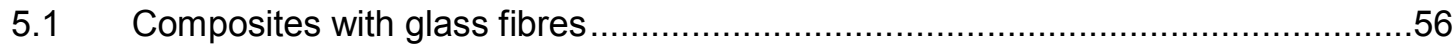

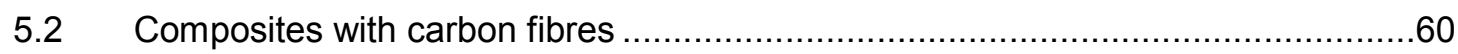

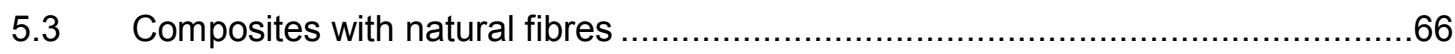

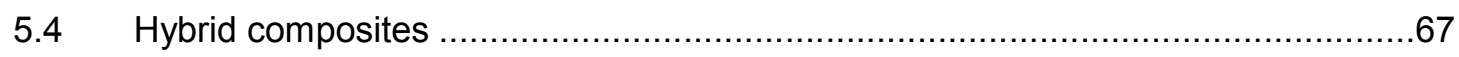

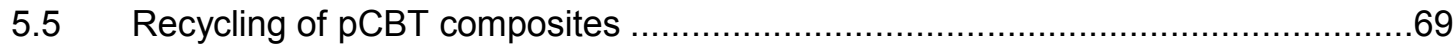

5.6 Applications of pCBT composites................................................................

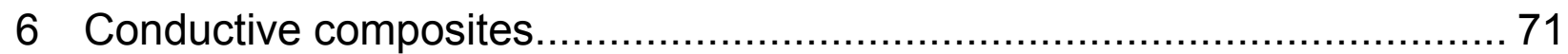

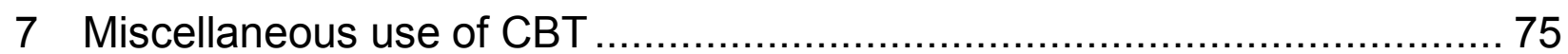

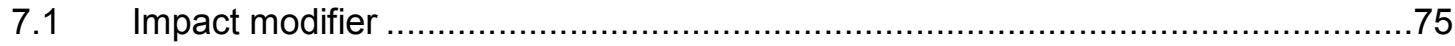

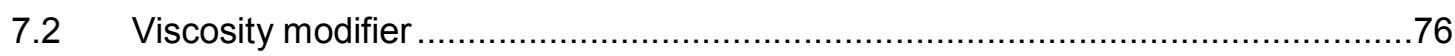

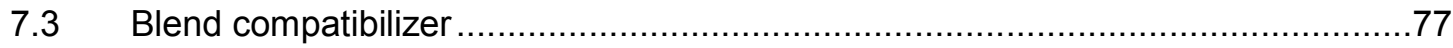

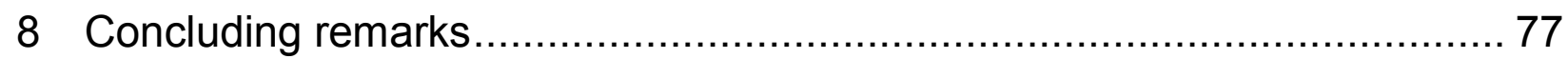

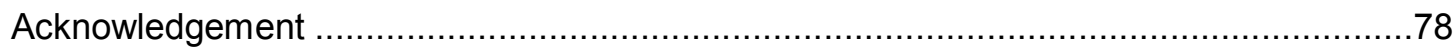

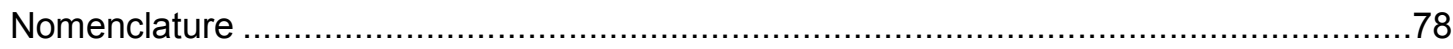

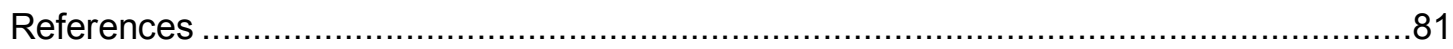

\section{Introduction}


Macrocyclic oligomers (MCOs) have been gaining interest in recent years because they are starting materials for entropically-driven ring-opening polymerizations. The ring-opening polymerization route is very attractive since high-molecular-weight polymers can be obtained in very short times, i.e. in the order of minutes. Ringopening polymerization (ROP) is a polymerization mechanism in which cyclic molecules are opened into linear monomers or oligomers and subsequently bonded into high molecular weight polymers without generating by-products. Cyclic oligomers of condensation polymers have been known for many years. They are formed in small amounts during the condensation polymerization of many polymers, typically less than $2 \mathrm{wt} . \%$, along with the high molecular weight linear chains. ${ }^{1-3}$ The formation of these cyclic oligomers is due to statistical reasons; they are formed either under kinetic conditions or in their equilibrium concentration from melt polymerization. ${ }^{4}$

In the 1930s Carothers and co-workers ${ }^{5-6}$ were the first who prepared aliphatic cyclic oligomeric esters and carbonates by distillative depolymerization of linear polyesters. East and Girshab ${ }^{7}$ extracted cyclic oligomers from poly(butylene terephthalate) (PBT) and quantitatively determined them by high pressure liquid chromatography (HPLC). Most of the early work was only of academic interest which was due to the fact that syntheses were inefficient and purification of products was always necessary. Moreover, most of these oligomers have high melting points, sometimes even higher than their polymeric counterparts, which limits their melt processing. ${ }^{1,4,8}$ Since then, many cyclic oligomers of different polymers have been extracted and characterized by several researchers. The systematic synthesis and subsequent ring-opening metathesis polymerization of macrocyclic polyesters were first developed by Brunelle and his research group in the late 1980s at the General Electric Corporation. ${ }^{1}$ They initially explored macrocyclic polycarbonates (PC) but also developed the reactive processing of poly(ethylene terephthalate) (PET) and 4 / 107 
PBT. The CBT technology passed on in 1999 to the Cyclics Corporation, USA, and is currently marketed under the tradename Cyclics ${ }^{\circledR}$.

Among the various existing MCO families, cyclic oligoesters, especially cyclic butylene terephthalate oligomers are promising. Polymerized CBT (referred to as pCBT to distinguish from conventional PBT obtained by polycondensation reaction) is structurally equal to PBT, a semicrystalline polyester and important engineering thermoplastic. PBT is characterized by rapid crystallization kinetics, high stiffness and strength, high toughness at low temperatures and good processability. Due to these properties, PBT is widely used in the fields of electronics, automotive, telecommunication, machine components as well as food and medical applications. ${ }^{3,}$ 10

Nowadays, other important research fields in polymer science are nanocomposites and fibre reinforced polymer (FRP) composites. FRPs are gaining importance as structural materials because of their better strength-to-weight and stiffness-to-weight ratios as compared to steel or aluminium. FRPs consist of a polymer matrix which may be a thermoset or thermoplastic polymer and a variety of reinforcements such as glass, carbon, aramid or natural fibres. On one hand, thermosets are commonly employed for composite production due to their straightforward processing. On the other hand, thermoplastics show some advantages over thermosets, namely a higher toughness and impact strength, faster manufacturing without releasing harmful volatiles as well as the possibility of welding, postforming and recycling due to their thermoplastic nature. ${ }^{11}$ The possibility of recycling is an increasingly important argument for thermoplastic composites (TPCs) in many markets, especially in the automotive sector. A TPC part can be grinded into fine particles at the end of its life cycle. The ground material (together with virgin 
polymer) can then be injection moulded into new short fibre reinforced parts which then also can be recycled at the end of their life cycle.

However, the main disadvantage in the production of TPCs is the need for high processing temperatures and pressures due to the high melt viscosity of the thermoplastic matrix which often results in products with poor fibre impregnation and high void content. ${ }^{11}$ The viscosity of thermoplastics during melt processing is orders of magnitude higher than that of thermosets, namely $10^{3}$ to $10^{6} \mathrm{~Pa} \cdot \mathrm{s}$ for thermoplastics versus 1 Pa.s or lower for thermosets. ${ }^{12}$ Impregnation can be improved by reducing the flow lengths of the thermoplastic matrix by intimate mingling of the reinforcement and the matrix prior to composite production. Nevertheless, this results in more expensive semi-finished products. On the other hand, fibre wet-out can be improved using reactive processing of TPCs. The fibre reinforcement is impregnated with low viscosity mono- or oligomeric precursors. The latter are then in situ polymerized after impregnation. Moreover, the low viscosity of the precursors allows for processing routes which are traditionally used in thermoset processing, such as vacuum infusion or resin transfer moulding. CBT exhibits a water-like melt viscosity and is thus a promising matrix material for the reactive processing of TPCs using liquid composite moulding techniques. ${ }^{13}$ Similarly, the low viscosity of the melted oligomers is advantageous for the production of polymer nanocomposites with improved properties since nanofiller distribution and dispersion is typically enhanced by reducing the matrix viscosity. ${ }^{14}$ Moreover, the intercalation and exfoliation of layered nanofillers such as organoclay or graphene is also enhanced if the matrix viscosity is decreased. ${ }^{15-16}$

In this review article the recent advances in the processing-structureproperties relationship of pCBT obtained by different processing routes is critically reviewed. Physical and chemical modification of CBT, pCBT micro- and $6 / 107$ 
nanocomposites with different types of reinforcement, continuous fibre reinforced pCBT composites as well as conductive pCBT composites are addressed and discussed.

\section{2}

\section{Cyclic butylene terephthalate (CBT)}

\section{$2.1 \quad$ Synthesis}

Condensation polymerization is a step growth mechanism which involves intermolecular reactions between monomer, oligomer or polymer end groups. Nevertheless, for statistical reasons, intramolecular reactions between the end groups of the same molecule occasionally occur if the polycondensation is carried out at high concentrations, leading to cyclic oligomers. Unfortunately, conventional bulk condensation polymerization yields only small amounts of cyclic oligomers. Direct synthesis of cyclic oligomers as major products can be achieved using conditions of high dilution, pseudo-high dilution, polymer supported synthesis or cyclodepolymerization of linear high-molecular-weight polymers. Cyclo-depolymerization (CDP), also known as ring-closing depolymerization, uses linear polyesters to form cyclic oligomers and thus is a suitable technique for the recycling of polyesters. The cyclic formation mechanism via CDP is basically a transesterification mechanism and is simply the reverse of an entropically driven ring-opening polymerization. ${ }^{17}$ The synthesis of cyclic oligomers has been reviewed by several researchers ${ }^{1,3-4, ~ 8, ~ 13, ~ 18-21 ~}$ over the years and more recent review articles covering this topic have been published by Hodge. ${ }^{22-23}$ Cyclics Corporation produces the CBT oligomers as a 
mixture of dimer, trimer and larger cyclic oligomers via depolymerization of commercial $\mathrm{PBT}^{9,24}$ and various patents are filed for this process (see for instance Refs. $^{25-26}$ ).

On the other hand, the cyclic dimer of CBT has been isolated from the extracts of the marine bacterial strain Cytophaga sp. AM13.1, although in very low yield ${ }^{27}$. This makes the CBT dimer the first cyclic terephthalic acid ester extracted from a natural source.

\subsection{Structure}

The structure of CBT oligomers is displayed in figure 1. CBT is a mixture of oligomers having two to seven repeat units, i.e. ranging from cyclic dimer to cyclic heptamer ${ }^{28}$. An oligomer mixture has the advantage of melting point reduction, since pure, discrete cyclic have relatively high melting points. CBT softens at $140{ }^{\circ} \mathrm{C}$ and is completely molten at $160-190{ }^{\circ} \mathrm{C}$, whereas the pure cyclic dimer melts at $196{ }^{\circ} \mathrm{C}^{1}$ and the pure cyclic tetramer melts at $248{ }^{\circ} \mathrm{C}^{7}$. This results in an initial melt viscosity of $0.02 \mathrm{~Pa} \cdot \mathrm{s}$ at $190{ }^{\circ} \mathrm{C}^{29}$, whereas the dynamic viscosity of conventional PBT at 250 ${ }^{\circ} \mathrm{C}$ was reported to be around $1000 \mathrm{~Pa} \cdot \mathrm{s} .{ }^{30}$

\subsection{Ring-opening polymerization}

\subsubsection{ROP mechanism}


Ring-opening polymerizations are essentially the reverse of cyclo-depolymerizations. Both ROP and CDP are equilibration processes where the ester linkages are repeatedly broken and re-formed. Contrary to CDP however, reactions between oligomers are favoured over cyclizations in ROP because the equilibration is carried out at high oligomer concentrations. ROP exhibits some advantages over conventional step-growth polymerization, namely higher molecular weights (up to 300 $\mathrm{kg} / \mathrm{mol}$ ) can be more readily achieved. Contrary to that, conventional step-growth polymerization typically yields molecular weights of $40-60 \mathrm{~kg} / \mathrm{mol}^{3}$ Since in ringopening polymerizations the broken bonds are simply re-formed, no exotherms or volatile organic compounds (VOCs) are released. The final molecular weight of the polymer solely depends on the molar ratio of cyclic oligoesters to linear end groups. Examples for linear end groups are a linear catalyst, humidity or remaining linear oligomers present in the system. ${ }^{1,19}$ The molecular weight can rise quickly to a high value and since ROP is an equilibration process, the molecular weight dispersity is expected to be 2.0 .

Despite the numerous advantages, entropically-driven ring-opening polymerizations also have drawbacks. For instance, as the polymerization proceeds, the molecular weight and the viscosity rise which in turn can seriously slow down the polymerization. This means that the polymerization temperature (referred to as $T_{P}$ ) should at least exceed $T_{m}$ of the polymer in order to keep the viscosity low. Moreover, in the case of certain high performance polymers the high polymerization temperatures can lead to undesired side reactions. Another problem is that some small cyclics present in the cyclic oligomer families of some high performance polymers have very high melting points and very poor solubilities in the molten larger cyclic oligomers. Consequently, the small cyclics might not become fully incorporated into the linear polymer. 
The ring-opening polymerization mechanism of CBT is displayed in figure 2. Although many types of compounds were reported to initiate the ROP of cyclic oligoesters, certain tin and titanium initiators were found to be most effective. ${ }^{28}$ The role of the different available catalyst systems for the ROP of CBT will be discussed more in detail in the following section. The ring-opening polymerization mechanism has been explained by various researchers ${ }^{28,}{ }^{31-32}$ and comprises initiation and propagation steps. The catalyst is thought to operate by Lewis acid activation of a CBT ester group via complexation and then transferring an alkoxide ligand. This results in an active species which has a functional group originating from the initiator as the end group. Propagation proceeds by coordination of another cyclic oligomer to the active species, followed by insertion of the cyclic into the metal-oxygen bond by rearrangement of the electrons. The process is repeated and more cyclics are successively added to the propagating linear polymer chain. The propagation reactions continue until all cyclics are depleted and the ring-chain equilibration becomes degenerate. In this case, the initiator becomes built into the polymer, which is not terminated unless quenched. $4,28,31$

Cyclic oligomers exhibit almost no ring strain due to their large size. Consequently, the polymerization is almost thermoneutral which leads to complete equilibration of ester groups. In other words, initiation, propagation, and chain transfer have nearly the same rates. ${ }^{4}$ Since the number of bonds in the linear polymer is essentially the same as in the starting oligomers and since the oligomers are not significantly strained, there is little or no change in enthalpy related to the equilibration. The conversion from cyclics to polymer is therefore mainly driven by the change in entropy. This means that the cyclic oligomers have only limited translational entropy as well as limited available conformations ('conformational strain') owing to their $10 / 107$ 
cyclic nature. However, there is a significant increase in conformational entropy (although there is only a modest change in translational entropy) when the rings open. ${ }^{17}$ Three factors control the final degree of conversion from cyclics to polymer during ROP:28

i) purity of the monomers

ii) complete mixing of the initiator and oligomers before ROP causes the viscosity to increase to the point where mixing is inefficient

iii) polymerization at a high enough rate that polymerization is essentially complete before crystallization occurs

\subsubsection{Catalyst systems}

Tripathy and associates ${ }^{33}$ studied the effects of different catalysts and polymerization temperatures on the ROP of CBT. They melt blended CBT oligomers and catalyst at $160{ }^{\circ} \mathrm{C}$ and conducted the ROP at $185-205^{\circ} \mathrm{C}$. The used catalysts were cyclic stannoxane (I), butyltin chloride dihydroxide (II), and tetrakis-(2-ethylhexyl) titanate (III); their chemical structures are shown in figure 3.

The extent of polymerization was analyzed by monitoring the change in light transmittance intensity at several temperatures of polymerization, ranging from 185 to $205^{\circ} \mathrm{C}$. Since the ROP was conducted below the pCBT melting temperature, it was assumed that crystallization followed polymerization (for the chosen $T_{P}$ ). The crystallization resulted in the loss of light intensity due to scattering from 
heterogeneous clusters of pCBT crystals. The authors reported that cyclic stannoxane was the fastest catalyst and completed the in situ polymerization within 2-3 $\min$ at polymerization temperatures of $165{ }^{\circ} \mathrm{C}$ and above. On the other hand, about 15 min of induction time, which is desired for RTM processes, was reported for butyltin chloride dihydroxide and tetrakis-(2-ethylhexyl) titanate. Furthermore, gel permeation chromatography (GPC) was used to find the conditions for the highest possible conversion and highest molecular weight; results are shown in table 1.

Initiator (III) gave the highest molecular weight among all used initiators, and the molecular weight remained the same irrespective of $T_{P}$. The pCBT samples obtained using catalysts (II) and (I) have the lowest and the intermediate molecular weights, respectively (c.f. table 1). When cyclic stannoxane (I) was used as initiator, no decrease in molecular weight was observed with increasing catalyst level because no end groups were introduced. ${ }^{28}$ The ROP of CBT initiated with cyclic stannoxane is a ring-expansion mechanism which results in a macrocyclic $\mathrm{pCBT}$, as shown in figure 4. Macrocyclic pCBT is referred to as c-pCBT in order to distinguish it from linear pCBT.

Although the above results demonstrate that butyltin chloride dihydroxide (II) results in a relatively low molecular weight, the commercially available one-component CBT $160^{\circledR}$ resin contains 0.45 wt. \% butyl tin chloride dihydroxide as catalyst. ${ }^{34}$ The two-component CBT $100^{\circledR}$ resin is provided with the same catalyst in form of Fascat ${ }^{\circledR}$ $4105^{35}$ 


\subsubsection{Polymerization kinetics}

The polymerization kinetics of CBT mainly depends on the type and amount of catalyst as well as on the processing temperature and has been studied by various techniques. Hakmé et al. ${ }^{36}$ investigated the in situ monitoring of the ROP of CBT by dielectric sensing under isothermal conditions at different processing temperatures. Small electrical sensors were therefore introduced in the processing tool. The conductivity signal reflected the local viscosity of the molten CBT and decreased when the polymerization progressed or when the fraction of the amorphous phase decreased during crystallization. Therefore the change in conductivity depended on the increase of molecular weight but was also influenced by pCBT crystallization during or after polymerization. The electrical conductivities as measured by dielectric sensing are illustrated in figure 5.

It was found that simultaneous polymerization and crystallization occurs below 200 ${ }^{\circ} \mathrm{C}$, whereas polymerization is followed by crystallization above $200{ }^{\circ} \mathrm{C}$, and only polymerization occurs above $220{ }^{\circ} \mathrm{C}$. Therefore it can be assumed that the processing conditions affect the crystal morphology (the influence of the morphology on the final properties of pCBT will be discussed later). At $220^{\circ} \mathrm{C}$ only polymerization occurs, hence the small conductivity decrease was only related to the viscosity increase during the molecular weight build-up. At $210{ }^{\circ} \mathrm{C}$ the same small decrease related to the polymerization was observed, followed by another conductivity decrease related to the crystallization of the pCBT. Unfortunately, dielectric sensing could not distinguish between the polymerization and crystallization when they 
occurred simultaneously at temperatures below $210^{\circ} \mathrm{C}$. Therefore, this technique is suitable only to some extent to measure the polymerization kinetics of CBT.

In a more recent study, Zhang and associates ${ }^{37}$ investigated the correlation between the ROP of CBT and crystallization of pCBT. CBT was isothermally polymerized for 30 min during DSC scans performed at various temperatures ranging from $190{ }^{\circ} \mathrm{C}$ to $230{ }^{\circ} \mathrm{C}$. Crystallization during polymerization occurred when $T_{P}$ was below $204{ }^{\circ} \mathrm{C}$. Polymerization and crystallization were gradually separated with the increase of $T_{P}$ from $204^{\circ} \mathrm{C}$. Only polymerization took place above $212^{\circ} \mathrm{C}$. In other words, the crystallization-derived properties of $\mathrm{pCBT}$ are determined by the isothermal stage when $T_{P}$ is below $204{ }^{\circ} \mathrm{C}$ where the main crystallization of pCBT has finished. On the contrary, when $T_{P}$ is above $204{ }^{\circ} \mathrm{C}$, crystallization of $\mathrm{pCBT}$ occurs mainly in the cooling stage. Uniform crystal size distributions were found when polymerization and crystallization occurred simultaneously below $204{ }^{\circ} \mathrm{C}$. With the increase of $T_{P}$ above $204{ }^{\circ} \mathrm{C}$, crystal size distributions became wider and led to more and more obvious double melting peaks during a DSC second heating scan.

GPC is a more direct technique which measures the amount of unreacted oligomers as well as the amount of pCBT polymer; therefore the degree of conversion $\alpha$ can be determined. Steeg and co-workers ${ }^{30}$ studied the polymerization kinetics of CBT from over 200 single GPC measurements performed under isothermal conditions as well as from rheological measurements; results are depicted in figure 6 . It can be seen that reasonable degrees of conversion $(\alpha>0.8)$ are only achieved when CBT is polymerized at temperatures of $170{ }^{\circ} \mathrm{C}$ and above. Lower temperatures yield only partially polymerized $\mathrm{pCBT}$ and the ROP is considerably slower as compared to higher temperatures. 


\subsubsection{Modeling of polymerization kinetics}

The polymerization kinetics can be also assessed by rheological measurements. Chen et al. ${ }^{31}$ used a rheometer as a chemical reactor to monitor the ROP of CBT initiated by butylchlorotin dihydroxide. The authors found that both the complex viscosity and the modulus variation could be efficiently used to determine the degree of polymerization. Figure 7 illustrates the variation of the complex viscosity of CBT polymerized at different temperatures and also the modelled polymerization kinetics deduced from the rheological measurements.

They concluded from the viscosity measurements that it takes about $35,16,14$, and 9 min to reach the plateau at $220,230,240$, and $250{ }^{\circ} \mathrm{C}$, respectively (c.f. figure 7 a). The complex viscosity, elastic and viscous modulus during the polymerization served to build up a method to determine the molecular weight and polymer concentration variation versus the reaction time. Additionally, they developed polymerization kinetics equations in order to simulate the polymerization process (c.f. figure $7 \mathrm{~b}$ ). These equations could fit the molecular weight variation calculated by viscoelastic functions at arbitrary temperature. By fitting the molecular weight variation with kinetics equations, polymerization rate constants were determined at various temperatures. The authors reported that the molecular weight increased faster with increasing temperature due to the high polymerization rate and it took a shorter time to reach constant values. As the temperature increased, it took approximately 30,13 , 12 , and 7 min for $M_{w}(t) / M_{w}(\infty)$ to reach steady values, respectively. This suggested that the weight average molecular weight did not change after that time. The trend is 
consistent with the results evaluated from the time evolution of complex viscosity in figure 7 a. Nevertheless, the polymerization time based on molecular weight in figure $7 \mathrm{~b}$ is systematically shorter as compared to the one from viscosity measurements.

Steeg et al. ${ }^{30}$ measured conversion and viscosity of CBT using GPC and rheometer. The authors derived and optimized an Arrhenius-based conversion model from GPC results in order to predict the conversion of CBT under isothermal conditions. The results were validated and optimized by means of isothermal rheological measurements and the results of the modelling, shown in figure 8 , were generated that predict conversion and dynamic viscosity for every thermal condition.

\subsection{Crystallization}

One of the main advantages of CBT over other reactive systems is that there are generally two processing routes, namely polymerization below or above the melting temperature of $\mathrm{pCBT}\left(\approx 225^{\circ} \mathrm{C}\right)$. In the latter case the ROP of CBT takes place in the molten state. Hence polymerization and crystallization are separate processes and the processing is non-isothermal. If the ROP is conducted below the $T_{m}$ of pCBT, namely below $200{ }^{\circ} \mathrm{C}$ as stated in Ref. ${ }^{36}$, then crystallization during polymerization is possible and processing can be performed isothermally.

\subsubsection{Crystallization during polymerization}


According to Wunderlich ${ }^{38-39}$, crystallization during polymerization can be either simultaneous or successive.

In the first case both processes are truly simultaneous, i.e. a mobile oligomer is added to the growing pCBT crystal and both covalent bonds (due to the ROP) and secondary bonds (due to crystallization) are set at the same time. In the second case, polymerization is followed successively by crystallisation before polymerization is completed. The described scenarios result in different morphologies. While separate polymerization and crystallization usually produces folded chain lamellar crystals, crystallization during polymerization can produce fibrillar extended chain crystals, as schematically shown in figure 9.

Zhang and co-workers ${ }^{40}$ described simultaneous polymerization and crystallization more in detail. Molten CBT undergoes ring-opening and chain propagation which results in living chain ends due to the built-in initiator, as schematically shown in figure 10 and discussed in section 2.3. Subsequently, the propagated chains crystallize preferentially but the living chain end connected with the metal atom of the catalyst cannot be accommodated in the crystal lattice of pCBT due to their incompatible lattice parameters. ${ }^{39,} 41$ The dangling living ends remain hanging off the surfaces of the crystal nuclei, which the authors termed as "living crystal seeds". Recently ring-opened oligomers (which are still amorphous) do not need to move long distances towards to the fronts of crystal growth and can directly fold on the surface of these living crystal seeds according to the intramolecular crystal nucleation model.

Harsch and co-workers ${ }^{42}$ studied the polymerization and crystallization of CBT by fibre Bragg grating (FBG) and normal force measurements under isothermal 17 / 107 
conditions at 170 and $190{ }^{\circ} \mathrm{C}$, respectively. Unfortunately, FBG and normal force measurements were only capable of sensing the crystallization-induced shrinkage but not the polymerization. The results from FBG and normal force measurements suggested that crystallization of pCBT is of stochastic nature and occurs in two steps; i.e. primary and secondary crystallization. They concluded that the polymerization is highly advanced or even completed before the crystallization starts. The primary crystallization rate is higher than the secondary one and was found to be higher at higher temperature. The activation energy of the primary crystallization was found between 80 and $150 \mathrm{~kJ} / \mathrm{mol}$ by adopting an Arrhenius equation. This activation energy, estimated for the crystallization of in situ polymerized CBT, is far below that measured for pCBT crystallizing from the melt. The pCBT polymerized at a temperature of $190{ }^{\circ} \mathrm{C}$ had somewhat higher crystallinity and larger crystallite sizes than the pCBT polymerized at $\mathrm{T}=170{ }^{\circ} \mathrm{C}$, as determined by wide-angle $\mathrm{X}$-ray scattering (WAXS) and differential scanning calorimetry (DSC) analysis.

\subsubsection{Crystallization kinetics}

Lehmann and Karger-Kocsis ${ }^{43}$ studied the crystallization kinetics of in situ polymerized CBT and conventional PBT by DSC both under isothermal and nonisothermal conditions. The used materials were PBT B6550 and PBT B4520, two commercial PBT resins as well as two CBT resins, CBT-XB3-CA4 and CBT160. They have a slightly different composition, namely CBT160 contains more tetramer than CBT-XB3-CA4. The crystallization was analysed by adopting Avrami, Ozawa and Kissinger methods for the isothermal and non-isothermal crystallizations, 
respectively. Crystallisation kinetics under isothermal conditions for various modes of nucleation and growth can be approximated by an Avrami equation: ${ }^{44-45}$

$$
\mathrm{X}_{t}=-\exp \left(-k t^{n}\right)
$$

where $X_{t}$ is the relative crystallinity at different crystallization times $t, n$ is the Avrami exponent and depends on the mechanism of nucleation and the form of crystal growth. The Avrami rate constant $k$ is the crystallization rate constant related to nucleation and growth parameters; and it depends on the shape (e.g. sphere-, discor rod shaped ${ }^{46}$ ) of the growing crystallites. Equation 1 can be linearised which yields

$$
\log \left(-\ln \left(1-\mathrm{X}_{t}\right)\right)=n \log t+\log k
$$

The plot of $\log \left(-\ln \left(1-X_{t}\right)\right)$ against logt is referred to as the Avrami plot and is depicted in figure 11.

From this plot, the Avrami constants $n$ and $k$ can be obtained as the slope of the straight line and the intersection with the y-axis, respectively. ${ }^{43}$ An Avrami exponent of $n \approx 3$ was found for polymerized CBT160 which corresponds to spherical crystal growth. Polymerized CBT XB3-CA4 exhibited an Avrami exponent of $n \approx 2$, indicating two dimensional plate-like crystal growth. The crystallisation half times of polymerized CBT160 were in the range of $0.5-1.5 \mathrm{~min}$ for isothermal crystallization at $190-195$ 
${ }^{\circ} \mathrm{C}$, respectively, and increased with crystallization temperature. Slightly longer crystallisation half times were found for polymerized CBT XB3-CA4. The authors assumed that the molecular weight of pCBT XB3-CA4 was higher than that of pCBT160. This was deduced by the fact that the crystallisation half times increased with increasing crystallisation temperature stronger for $\mathrm{pCBT}$ XB3-CA4 than for the pCBT160.

Similarly, Wu et al. ${ }^{47}$ used DSC analysis to study the isothermal crystallization kinetics of pCBT polymerized at $230{ }^{\circ} \mathrm{C}$ and crystallized at $190-215{ }^{\circ} \mathrm{C}$. They analysed the crystallization kinetics and regime using the Avrami theory and the Hoffman and Lauritzen theory. The Avrami exponent ranged from 2.46 to 2.82, which was related to combined heterogeneous nucleation with a change in the spherulitic morphology. For an Avrami exponent $n$ above 2.73, three-dimensional spherulitic morphology growth incorporated with boundary crystals was found at lower crystallization temperatures. The Avrami exponent decreased to 2.46 for crystallization temperatures greater than $200{ }^{\circ} \mathrm{C}$, which corresponded to the disappearance of the boundary line and the irregular growth of the highly disordered spherulites was lost. The equilibrium melting temperature and glass transition temperature of pCBT were reported to be $257.8^{\circ} \mathrm{C}$ and $41.1^{\circ} \mathrm{C}$, respectively.

\subsection{Processing}

\subsubsection{Conditioning}


The final molecular weight of the PCBT depends on the amount of linear end groups (e.g. humidity) present during polymerization. For this reason, a consequent drying of the CBT prior to processing is crucial. Steeg ${ }^{48}$ studied in cooperation with Cyclics Europe $\mathrm{GmbH}$ the conditioning of CBT granules and powder. They dried the CBT in a circulating air oven at 80 and $100{ }^{\circ} \mathrm{C}$ and measured then the CBT water content over drying time via Karl-Fischer-titration (c.f. figure 12 a). It was stated that a CBT water content of $<200$ and $<125$ ppm results in a molecular weight of $>100$ and $>150$ $\mathrm{kg} / \mathrm{mol}$ of the final $\mathrm{pCBT}$, respectively. The lower limit of $125 \mathrm{ppm}$ was reached after $1.5 \mathrm{~h}$ drying time at $100^{\circ} \mathrm{C}$. When vacuum was added, this limit was already reached after $30 \mathrm{~min}$. On the other hand, it took $5 \mathrm{~h}$ to reach a water content of $200 \mathrm{ppm}$ at a drying temperature of $80^{\circ} \mathrm{C}$. Moreover, it was pointed out that excessive drying times (>36 h) lead to decreasing molecular weight and degree of conversion, probably due to catalyst inhibition.

In a further step, the water absorption of CBT was measured. First, CBT was dried in the circulating air oven at $100{ }^{\circ} \mathrm{C}$ for $5 \mathrm{~h}$. Then the dried CBT was conditioned in ambient atmosphere with a relative humidity of $60 \%$ and the water uptake was measured again using Karl-Fischer-titration. The results are shown in figure $12 \mathrm{~b}$; hatched areas indicate the two humidity limits with corresponding achievable molecular weights, as mentioned above. Since powder particles exhibit a much higher surface-to-volume ratio as compared to pellets, the former adsorb humidity much faster. From a processing point of view, CBT powder exceeds the lower humidity limit of 125 ppm already after 4 min, whereas CBT pellets can be processed without the risk of catalyst inhibition even after being exposed to high humidity for 2 h. 


\subsubsection{Processing techniques}

A variety of reactive processing routes can be used for TPC production with CBT and the interested reader is referred to the following reference ${ }^{11}$ and the references therein. Most of these processing routes belong to the group of liquid composite moulding (LCM). The reactive processing of continuous fibre reinforced $\mathrm{pCBT}$ composite parts can be achieved by structural reaction injection moulding (SRIM), vacuum infusion (VI), also known as vacuum-assisted resin infusion (VARI), thermoplastic resin transfer moulding (TP-RTM) and resin film infusion (RFI) which is similar to prepreg production for thermoset composites using prepreg hand lay-up. RFI can be further enhanced using vacuum assistance. ${ }^{49-51}$ CBT-impregnated prepregs can be prepared by either sprinkling CBT powder on the reinforcement or by soaking the reinforcement in a solution of dissolved CBT with subsequent solvent evaporation. Furthermore, CBT can also be processed by compression moulding and pultrusion. The most important innovation is injection moulding (IM) of cyclic oligomers since cost effective mass production of functional lightweight components using automated IM has not been possible until now. ${ }^{52}$ The very low melt viscosity of cyclic oligomers allows high injection speeds at low injection pressures, the latter minimizing the risk of fibre preform displacement or distortion in the mould. ROP takes place in the mould which is operated at elevated temperatures. Possible reactive systems for high speed polymerization during injection moulding include anionic PA6, PA12, PC, PET and CBT oligomers, although some of these systems require variothermic process control or long reaction times. Solid caprolactam was first processed and injected using a reciprocating screw and a modified non-return 
valve at the Fraunhofer Institute for Chemical Technology, Pfinztal, Germany in cooperation with IM machine maker Engel Austria $\mathrm{GmbH}$. The injection unit of the IM machine was tilted at $30^{\circ}$ to the horizontal in order to prevent the oligomer melt from running back down the gap between the barrel and screw flights into the feed zone. Engel Austria tested a near mass production ready manufacturing cell. One part of the process is the automated preform production, where laser cut glass fabric layers are placed on a stack in the manufacturing cell and fetched by a linear robot equipped with needle grippers. The first fabric layer is directly placed on the heated core and the following fabric layers are sprayed with a binder being fixed on the core by needles. Teflon rollers spread the fabrics out and the contour is thermally fixed. In a next step a six axis robot removes the preform and places it in the oil heated mould of the IM machine. A silicone profile runs around the mould and holds the preform in the desired position and provides a seal for the mould. Then the mould is closed and the cavity is filled within $2 \mathrm{~s}$. After polymerization the part is demoulded by the robot arm and passed on to the subsequent trimming process. This technique paves the way to the mass production of highly cost-effective thermoplastic fibre reinforced composite parts having integrated stiffening and functional elements with advantages in respect of overall energy efficiency, welding and recyclability.

\subsubsection{Processing window}

Generally, the reactive processing of TPCs is targeted on direct impregnation of fibre reinforcements without the need for intermediate processing steps. A number of 
requirements have been defined for achieving direct fibre impregnation with a liquid matrix. ${ }^{11,41,53-54}$

i) The viscosity of the liquid matrix during impregnation is very low, i.e. $\eta \leq 1$ Pa.s.

ii) After impregnation, the matrix can be physically or chemically solidified in a reasonably short time.

iii) The polymerization reaction should not produce any by-products.

iv) The matrix should exhibit good physical properties after solidification in order to obtain composite parts with good mechanical properties.

v) Polymerization and crystallization should not produce large exotherms since they may create hot spots and hence result in through-the-thickness property variations.

The processing window can be defined as the time for the molten CBT to reach a viscosity of $1 \mathrm{~Pa}$.s. Therefore, the processing window is mainly governed by the polymerization kinetics. Mohd Ishak and co-workers ${ }^{29}$ used rheological measurements to determine the melt viscosity increase with time and used the rheological data as an indirect tool to estimate the impregnation and apparent polymerization times; depicted in figure 13.

A phase angle of almost zero indicated the total transformation of the polymerized CBT into a solid phase via crystallization and a tangent could be drawn to the phase angle curve. An apparent polymerization time could then be obtained from the intersection of the tangent to the curve; whereas the impregnation time was simply 
the time when viscosity reached 1 Pa.s. A drastic reduction was found in the apparent polymerization time when the testing temperature increased from 150 to $170{ }^{\circ} \mathrm{C}$. They assumed a rapid ring-opening polymerization at high temperatures due to the short apparent polymerization times for temperatures $170^{\circ} \mathrm{C}$ and above. At a temperature of $210^{\circ} \mathrm{C}$, the viscosity limit of $1 \mathrm{~Pa} \cdot \mathrm{s}$ was already reached after around $1 \mathrm{~min}$, whereas the same viscosity was reached after almost $1 \mathrm{~h}$ at a low temperature of $145^{\circ} \mathrm{C}$.

\section{Polymerized cyclic butylene terephthalate (pCBT)}

\subsection{Morphology}

The morphology of thermoplastics significantly influences their physical properties. This is also reflected in the matrix-governed properties of TPCs, such as transverse and shear properties, fracture toughness or fibre-matrix interface. ${ }^{55}$ For PBT, two different morphologies have been identified both on the unit cell level and on the spherulitic level. On the unit cell level, two triclinic polymorphs are known to exist (c.f. figure 14). The $\alpha$-crystal with gauche-trans-gauche conformation of the butylene moiety is the stable form under standard conditions, whereas the $\beta$ form with all-trans conformation develops only under stretching of unoriented crystals ${ }^{10,56-59}$ or during crystallization at pressures above 2000 bar ${ }^{60}$. This $\alpha$ to $\beta$ crystal transition is completely reversible when the stress is removed. ${ }^{56-57,59,61}$ 
On the spherulitic level, two types of spherulites can be distinguished in PBT. Stein and Misra ${ }^{62}$ studied the morphology of PBT crystallized from the melt at various temperatures using small-angle light scattering (SALS), polarized light microscopy (PLM) and WAXS analysis. The two types of spherulites depend on the crystallization conditions. The usual type has its maltese cross parallel to the polarizers in PLM analysis and is formed at high temperatures or slow cooling rates, which results in increased spherulite size and crystallinity with increasing crystallization temperature. In contrast, the unusual type has its maltese cross at $45^{\circ}$ to the polarizers in polarizing microscopy and is formed at low crystallization temperatures or fast cooling rates.

Analogously, Wu et al. ${ }^{47}$ studied the isothermal crystallization morphology of pCBT polymerized at $230{ }^{\circ} \mathrm{C}$ using PLM. The PLM morphologies of pCBT corresponding to the crystallization temperature range of $190-215{ }^{\circ} \mathrm{C}$ are illustrated in figure 15. Four typical morphologic features of pCBT were reported; usual negative spherulite, unusual spherulite coexisting with boundary crystals, mixed birefringence spherulite coexisting with boundary crystals, and highly disordered spherulitic crystallites, corresponding to the crystallization temperature spectrum.

Parton et al. ${ }^{63}$ examined the morphologies of PBT, pCBT isothermally processed at $190{ }^{\circ} \mathrm{C}$ and reprocessed $\mathrm{pCBT}$ (referred to as RP-pCBT); their respective morphologies obtained by transmission electron microscopy (TEM) are shown in figure 16 .

It is apparent from figure $16 \mathrm{~b}$ that $\mathrm{pCBT}$ samples exhibited a microstructure with well defined, thicker and nicely oriented lamellae as compared to PBT. The transition from crystalline to amorphous regions is more pronounced and sharp in the pCBT $26 / 107$ 
samples, which might indicate a reduction of tie molecules. Miller ${ }^{64}$ stated that the tie molecule density is influenced by simultaneous polymerization and crystallization. Parton et al ${ }^{41,63}$ assumed that the transesterification catalyst of pCBT which remains in the polymer might also influence the amount of tie molecules. The catalyst molecules cannot be included into the polymer crystal, but probably concentrate at the surface of the growing crystals. Such a local transesterification enhancement may drastically decrease the amount of tie molecules owing to the mechanical tensions arising from packing density differences at the crystal boundaries.

\subsection{Thermal properties of pCBT}

The thermal properties of CBT and PCBT have been studied by various researchers using DSC analysis, see for instance refs. ${ }^{29,} 31-32,41,47,63,65-68$ Mohd Ishak and coworkers ${ }^{66}$ compared the thermal properties of injection moulded PBT (denoted as IMPBT), CBT as well as pCBT isothermally polymerized at $190{ }^{\circ} \mathrm{C}$ during compression moulding (referred to as ISP-PBT); the corresponding thermograms are depicted in figure 17.

As can be seen from figure 17 a, CBT oligomers exhibited a broad melting range from about $120-170{ }^{\circ} \mathrm{C}$ together with a melting peak at $142{ }^{\circ} \mathrm{C}$, as confirmed by other researchers. ${ }^{68-69}$ The broad melting range has been ascribed to the different melting temperatures of the oligomers present in the CBT. ${ }^{28}$ The ROP of CBT occurred during the first heating scan and a small pCBT melting peak was observed at $226^{\circ} \mathrm{C}$. However, the related melting enthalpy was insignificant. It was assumed that the reason for the absence of crystallization (and subsequent melting) during the first 27 / 107 
heating is of kinetic origin. CBT undergoes crystallization during polymerization in the temperature range of $170-200{ }^{\circ} \mathrm{C}$, as discussed in section 2.3.3. However, no evidence of any exothermic process linked with the polymerization or crystallization was detected. In contrast, ISP-PBT and IM-PBT exhibited a broad endotherm with a single melting peak at 228 and $224^{\circ} \mathrm{C}$ and a heat of fusion of 71 and $50 \mathrm{~J} / \mathrm{g}$ during first heating, respectively. The relatively higher melting temperature and enthalpy of ISP-PBT is due to the different crystalline structure of the resulting PBT. More specifically, isothermal polymerization of CBT below $T_{m}$ of pCBT leads to the formation of big, perfect crystals having a higher lamellar thickness, as was discussed by Parton. ${ }^{41}$

Mohd Ishak et al. showed in an earlier publication ${ }^{29}$ that the heating rates play an important role in the exothermic process during the first heating of CBT. They found that at a much lower heating rate of $0.5 \mathrm{C} / \mathrm{min}$, the $\mathrm{DSC}$ thermogram showed a prominent exothermic peak at $195{ }^{\circ} \mathrm{C}$ which corresponded to the crystallization of pCBT. It was concluded that high DSC heating rates hinder the crystallization of pCBT and consequently cause the missing melting peak. Regarding the first heating of ISP-PBT and IM-PBT, both samples showed a distinct polymer melting peak although ISP-PBT exhibited a higher melting enthalpy. This indicated that complete polymerization and crystallization of ISP-PBT have taken place during compression moulding.

Figure $17 \mathrm{~b}$ shows the DSC second heating scans of CBT (polymerized during the first heating scan), ISP-PBT and IM-PBT. A broad endotherm with two melting peaks was observed for all samples. The double melting behaviour was ascribed to the melting of small and defective crystals, followed by their immediate recrystallization into more stable structures and their subsequent melting. This was confirmed in a further work $^{67}$, where the authors used modulated DSC (MDSC) to $28 / 107$ 
study the polymerization of CBT. They found that the onset of double melting of pCBT was strongly affected by the polymerization route, i.e. ROP below or above the melting temperature of $\mathrm{pCBT}$. During cooling, the glass transition was observed at 40 ${ }^{\circ} \mathrm{C}$. Moreover, the authors could show that the polymerization of CBT is non athermic. The heat of polymerization derived from the non-reversing DSC trace was found to be around $22 \mathrm{~J} / \mathrm{g}$, but was overlapped with the endothermic melting of CBT at $140{ }^{\circ} \mathrm{C}$. Therefore, the apparently athermic ROP is the result of polymerizationrelated exothermic and melting-related endothermic effects.

\subsection{Physical properties of pCBT}

The morphology and resulting physical properties of pCBT are strongly influenced by the processing route. Various researchers prepared unreinforced pCBT; an excerpt of the physical properties is presented in table 2 with focus on different processing methods and polymerization conditions.

Parton and associates ${ }^{63}$ studied the influence of the processing conditions of a thermoplastic RTM process on the properties of pCBT. One sample was isothermally processed at $190{ }^{\circ} \mathrm{C}$ (i.e. simultaneous polymerization and crystallization) whereas another sample was polymerized at $230^{\circ} \mathrm{C}$ and then crystallized at $190^{\circ} \mathrm{C}$. The two samples were compared to injection moulded PBT. The authors reported that pCBT was brittle in contrast to conventional PBT, irrespective of the processing route. As shown in fig. 18, PBT did not break in flexural tests but showed a yield point, whereas pCBT broke in a brittle manner. Simultaneous polymerization and crystallization of CBT at $190{ }^{\circ} \mathrm{C}$ yielded an even more brittle and weaker pCBT. Both pCBT190 and pCBT230 exhibited a higher modulus than PBT due to the markedly higher degree of $29 / 107$ 
crystallinity relative to PBT. Molecular weight and residual oligomer content were quite similar in all three samples. Both PBT and pCBT were reprocessed using injection moulding in order to decrease the degree of crystallinity, which in turn typically increases the toughness. As can be seen from table 2, the crystal fraction of RP-pCBT decreased to a similar level as PBT. Consequently, failure strain increased as the strength decreased. The latter might be attributed to the pronounced molecular weight reduction of RP-pCBT due to the reprocessing step. This reduction was also observed for PBT but to a much lesser extent.

Baets $^{70}$ also used a TP-RTM process for the isothermal polymerization of CBT at $190{ }^{\circ} \mathrm{C}$ and obtained similar results, i.e. a brittle pCBT (c.f. table 2).

Several authors ${ }^{64,71-73}$ employed compression moulding (CM) for the in situ polymerization of $\mathrm{CBT}$ at 240 and $250{ }^{\circ} \mathrm{C}$ with subsequent non-isothermal melt crystallization. Due to the latter, one might expect a less crystalline but tougher pCBT. While the pCBT crystal fraction was indeed lower than the ones obtained from TP-RTM, the pCBT was equally brittle. This is in contrast to the results in ref. ${ }^{63}$, where it was stated that crystallization of the melt (i.e. reprocessing of $\mathrm{pCBT}$ ) yields a relatively tougher $\mathrm{pCBT}$.

Miller et al. ${ }^{64}$ used cyclic stannoxane as initiator of the ROP and obtained a macrocyclic c-pCBT. The crystal fraction and the molecular weight of c-pCBT were considerably higher than the ones of its linear counterparts. The higher molecular weight is due to the absence of linear end groups (coming from the initiator) during the ROP. Similarly, c-pCBT had a higher modulus as compared to PBT. Nevertheless, the macrocyclic c-pCBT exhibited an exceptionally low strength and failure strain.

Zhang and co-workers ${ }^{40}$ polymerized CBT in a three neck flask under nitrogen atmosphere and then quenched the flask in ice water. Samples for tensile testing $30 / 107$ 
were prepared by solution casting (SC). Stiffness and strength of solution casted pCBT were found to be inferior to the ones of pCBT prepared by other processing methods (c.f. table 2).

\section{Influence of morphology}

Ludwig and Eyerer ${ }^{74}$ discussed the influence of the processing conditions on morphology and deformation behaviour of PBT. Injection moulded samples were crystallized at mould temperatures of 60 and $118^{\circ} \mathrm{C}$ and using sample thicknesses of 3 and $5 \mathrm{~mm}$, respectively. The low mould temperature led to unusual spherulites, whereas the higher one resulted in usual or mixed type spherulites. Tensile tests showed an increase in yield stress from $50 \mathrm{MPa}$ for the usual type and $55 \mathrm{MPa}$ for the unusual type spherulite while strain at yield was equal for both types. Slowly cooled PBT exhibited a relatively higher microhardness $\left(148 \mathrm{~N} / \mathrm{mm}^{2}\right.$ versus 138 $\mathrm{N} / \mathrm{mm}^{2}$ ). Zhang and co-workers ${ }^{75}$ also studied the effect of the mould temperature on the mechanical properties during injection moulding of PBT. They found that tensile modulus and strength increased from 2.5 to $2.7 \mathrm{GPa}$ and 54 to $58 \mathrm{MPa}$, respectively, when the mould temperature was increased from 20 to $120^{\circ} \mathrm{C}$. At the same time, failure strain decreased from 198 to $32 \%$.

Analogously, Yu et al. ${ }^{76}$ studied the effect of different crystalline morphologies on the mechanical properties of carbon fibre reinforced pCBT composites. They prepared stacked films of CBT powder and reinforcement, which were then polymerized during compression moulding at $230{ }^{\circ} \mathrm{C}$. The mechanical properties of the pCBT composites were strongly affected by their crystalline morphologies and degree of crystallinity. The sample crystallized at $185^{\circ} \mathrm{C}$ exhibited a relatively low $31 / 107$ 
crystal fraction, which resulted in a spherulitic superstructure with large spherulite/transcrystalline boundary regions. As a consequence, cracks tended to initiate and propagate along these weak spherulite/ transcrystalline boundaries, leading to low mechanical properties. The composite sample crystallized at $210{ }^{\circ} \mathrm{C}$ showed highly disordered spherulitic crystallites without spherulite/transcrystalline boundary lines or boundary crystals, which resulted in somewhat better mechanical properties.

It can be recognized from table 2 that unmodified CBT yields an essentially brittle pCBT, irrespective of processing route, polymerization and crystallization temperature, molecular structure (i.e. linear versus macrocyclic pCBT), molecular weight, degree of conversion, degree of crystallinity or spherulitic morphology. Possible reasons for this brittleness will be discussed in the following section.

\subsection{Brittleness mechanisms of pCBT}

There a number of reasons for brittle behaviour of semicrystalline thermoplastics, namely: ${ }^{28,} 40-41,64,77-78$

- matrix defects such as voids and impurities, acting as stress concentrators

- very large spherulites, also acting as stress concentrators

- high degree of crystallinity

- low amount of intercrystalline tie molecules

- low molecular weight 
While impurities are less likely to occur in the case of a proper processing of CBT, voids may form in thick-walled parts during a pressure-less crystallization due to volumetric shrinkage. The pCBT brittleness has been ascribed to the formation of large spherulites together with a high degree of crystallinity and crystal perfection, which typically leads to a reduction of intercrystalline tie molecules ${ }^{28,41,63-64}$. The brittleness was more severe for simultaneous polymerization and crystallization below the melting temperature of $\mathrm{pCBT}$. Besides the above mentioned reasons for brittleness, some researchers have focussed on the residual CBT oligomers after polymerization. $\mathrm{Wu}$ and Huang ${ }^{32}$ found some residual CBT crystals when the polymerization was performed at $190{ }^{\circ} \mathrm{C}$ in a hot stage. $\mathrm{Xu}$ and co-workers ${ }^{79-80}$ showed that unpolymerized CBT was present in the form of large, well-developed oligomer crystals in a CBT/rubber matrix blend. It is also clear from literature that polymerization below $T_{m}$ might not be high enough to melt all cyclics present in CBT. ${ }^{19-20}$ Zhang et al. ${ }^{40}$ confirmed this assumption when they studied the effects of these residual CBT crystals on the mechanical properties of pCBT. They demonstrated that $\mathrm{CBT}$ oligomer crystals with high melting points could not completely melt at $190{ }^{\circ} \mathrm{C}$ and appeared as well-developed crystals from nano- to micro-scale in the pCBT matrix, highlighted with ellipses in figure 19a.

These crystals served as a self-compatible nucleating agent which reduced the induction time of crystallization during polymerization. Moreover, the crystals acted as stress concentration points and led to the brittleness of $\mathrm{pCBT}$, as schematically shown in figure 20 . The authors speculated that a high degree of crystallization and a perfect crystal structure together with a low density of intercrystalline tie molecules of pCBT is favoured by their so-called living lamellar crystal initiation mechanism, which 33 / 107 
was discussed in section 2.4.1. Furthermore, they stated that the low viscosity of molten CBT may be favourable for entanglement reduction. Besides, polymerization at low temperatures may cause a decrease in the polymerization rate, leading to a low molecular weight. ${ }^{11,19}$

One might expect that a $T_{P}$ above $T_{m}$ with subsequent non-isothermal melt crystallization increases the toughness. However, it was shown by various researchers ${ }^{41,70-72}$ that the obtained pCBT is not significantly tougher (c.f. table 2). Since the ROP was conducted above $T_{m}$, it can be assumed that all CBT oligomer crystals were in the molten state. Therefore, remaining oligomer crystals cannot be the reason for brittleness of $\mathrm{pCBT}$ obtained by a non-isothermal processing route. $A$ possible explanation might be a low molecular weight due to humidity which on one hand inhibits the catalyst ${ }^{1,4,36}$ and on the other hand can cause hydrolysis. ${ }^{81}$

It is known that if the molecular weight is below a critical value or if the polymer contains a large amount of a very low-molecular-weight fraction mixed in with a high-molecular-weight fraction, the polymer will be extremely brittle and will have a lower-than-normal strength. At higher loads or elongations the weak lowmolecular-weight materials may break at considerably lower elongations than the high-molecular-weight polymers. ${ }^{82}$ Although a high molecular weight is obtained when the ROP is conducted under inert atmosphere or in closed moulds in TP-RTM processing, the resulting $\mathrm{pCBT}$ is still brittle. ${ }^{11,63,83}$

\subsection{Toughening of $\mathrm{pCBT}$}


A variety of methods to reduce the brittleness of semicrystalline thermoplastics are available and the chances of brittle failure can be decreased by: ${ }^{83-87}$

- reducing the crystallinity

- $\quad$ adding rubbery polymers

- $\quad$ adding plasticizers

- increasing the molecular weight by chemical modification (chain extension/branching)

- copolymerization with soft segments

- incorporation of nano-particles

Most of these toughening methods have been applied to pCBT; an excerpt of the reported physical properties of toughened pCBT is compiled in table 3.

\section{Reducing the crystallinity}

The large strain plastic deformation in semicrystalline polymers is mainly governed by chain sliding on crystallographic slip planes and the dominant energy-absorbing mechanism is shear yielding. The toughness of semicrystalline polymers decreases with increasing degree of crystallinity and perfection of the crystallites because shear yielding is hindered. An increasing spherulite size lowers the toughness because larger defects and voids are formed, and cracks propagate more easily along the interfaces between bigger spherulites. ${ }^{88}$ Decreasing the degree of crystallinity and thus introducing more tie molecules between adjacent crystals typically increases the 
toughness. This can be achieved by changing the processing conditions, namely by applying a fast cooling after CBT polymerization instead of slow cooling or isothermal crystallization at e.g. $190{ }^{\circ} \mathrm{C}$. Baets and co-workers ${ }^{89}$ developed a non-isothermal production process for basalt fibre-reinforced CBT composites and studied the influence of different cooling rates on the toughness. They found in three-point bending tests that the failure strain increased from $1.8 \%$ for slowly cooled composites to $2.6 \%$ for quench cooled samples. Moreover, fracture toughness mode II tests showed a twofold increase of the crack propagation energy for the quenched samples as compared to slowly cooled samples. The difference in mechanical properties was related to the difference in the degree of crystal perfection.

\section{Adding rubbery polymers}

It is well known that the toughness of semicrystalline polymers can be enhanced by introduction of rubbery particles. They act as stress concentrators and initiate highly energy-absorbing mechanisms, namely massive crazing and shear band formation. ${ }^{88}$

Dell'Olio et al. ${ }^{90}$ studied the impact of reactive and non-reactive additives on the ROP, crystallisation and final crystal structure of pCBT. The authors used DSC and rheological methods and correlated the results with the observed improvements in fracture toughness and tensile properties for both the neat PCBT as well as mode I and II fracture toughness of fibre-reinforced pCBT composites. The non-reactive modifiers were selected $\beta$ nucleants and a ductile thermoplastic, poly(ethylene-coglycidyl methacrylate) (PEGMA). These modifiers were found to have little impact upon polymerization, crystal fraction and crystallization rate and the property 
improvements were modest. The $\beta$ nucleants had little impact upon the tensile properties, while the addition of PEGMA when added at high concentrations of 15-35 wt. $\%$ increased the failure strain up to $290 \%$. Nevertheless, the tensile modulus decreased by more than $100 \%$. Moreover, the fracture toughness remained unchanged for PEGMA-modified PCBT, while the addition of $\beta$ nucleants had a negative effect on fracture toughness.

\section{Adding plasticizers}

Another common method to toughen polymers is to increase the chain mobility by adding a plasticizer. It has been reported that pCBT can be effectively toughened by the addition of tetrahydrofuran (THF) prior to polymerization. ${ }^{91}$ The resultant pCBT was found to be tough, showing a strain at break of well above $100 \%$ in tensile tests. Other matrix properties, such as tensile modulus, tensile strength and glass transition temperature were not significantly altered by the addition of THF. It was found that the presence of THF enhanced the ROP, resulting in an increased molecular weight and a narrowed molecular weight distribution. Apparently, remaining oligomers after polymerization were extracted by the THF and a toughened oligomer-free pCBT was obtained. The samples became brittle after three months when subjected to a temperature of $80{ }^{\circ} \mathrm{C}$. Hence this toughening method is impractical since the toughening action of THF is not permanent. Moreover, the very low melt viscosity of CBT allows for solvent-free processing routes which are preferred over the use of solvents. 


\section{Chemical modification}

Chemical modification is commonly used to improve certain properties of thermoplastics. It exploits the reactions of polymer functional groups with low molecular weight mono-, bi- or polyfunctional compounds. ${ }^{87,}$ 92-96 Polyesters are especially accessible to chemical modification because they bear reactive functional groups in their main chain and chain ends, such as esters, hydroxyls and carboxyls as in the case of e.g. PET and PBT. The chemical modification of polyesters comprises four main techniques: $:^{87,97}$

- controlled degradation to decrease the molecular weight or to produce monomers/oligomers

- capping of carboxylic end groups

- compatibilization of partially miscible polymer blends

- chain extension/branching to increase the molecular weight by coupling of two or more polymer chains

Reactive chain extension of polyesters with low molecular weight bi- or polyfunctional compounds is a suitable technique to improve the toughness, impact strength and hydrolytic stability. ${ }^{87-88}$ The reason therefore is that a higher molecular weight induces more tie molecules between crystallites and spherulites. The reactive agents, socalled chain extenders, are preferably bifunctional and should react readily through an addition reaction without generating any by-products. ${ }^{93-94}$ Inata and Matsumura ${ }^{98-}$ 103 studied a variety of electrophilic chain extenders for polyesters. Among the 
studied compounds, epoxides, isocyanates, oxazolines, and carbodimides were found to be particularly effective. More recently, carbonylbiscaprolactam was found to also be a suitable chain extender for polyesters. ${ }^{104}$ Figure 21 depicts some of the chain extension reactions of these electrophilic compounds with carboxylic end groups.

Systematically increasing the molecular weight of pCBT by adding chain extenders prior to ROP has been considered in patent literature. ${ }^{105-107}$ Our group has shown that reactive chain extension with low molecular weight bifunctional epoxy resins (EP) or isocyanates (NCO) is an effective and straightforward method to toughen pCBT.

In the case of epoxy toughening ${ }^{71}$, CBT/EP dry blends with small amounts (14 wt.\%) of diepoxide were compression moulded in a hot plate press. A sevenfold failure strain was found in tensile tests for an EP content of $2 \mathrm{wt} \%$, compared to that of pristine $\mathrm{pCBT}$, while stiffness and strength remained relatively unaffected by the chain extension reaction (c.f. table 3). GPC analysis confirmed the low molecular weight of unmodified pCBT, a possible explanation for brittleness. It also showed the remarkable increase in molecular weight when 2 or 3 wt.\% epoxy resin was used. The diepoxide substantially reacts with the carboxyl end groups of pCBT in an esterification reaction as shown in figure 21 and yields a predominantly linear polymer, as suggested by proton nuclear magnetic resonance spectroscopy (NMR).

On the other hand, when the epoxy content was higher than 2 wt.\% some gel formation occurred, indicating a partially crosslinked structure of the chain extended pCBT. Thermal analysis of modified pCBT showed a slight decrease in glass transition, melting and crystallization temperature, and degree of crystallinity with increasing EP content. This was mainly attributed to the formation of branching and a minimal plasticizing effect of unreacted epoxy resin after ROP. SEM micrographs $39 / 107$ 
suggested a more favourable adhesion of remaining oligomer crystals to the pCBT matrix when EP was used. The improved adhesion also contributed to the toughness increase of chain extended pCBT.

In a complementary work, Dell'Olio et al. ${ }^{90}$ confirmed that the use of bifunctional epoxy modifiers copolymerized with CBT during ROP is an effective strategy to improve mechanical properties such as fracture toughness, tensile strength and strain to failure of pCBT. The authors melt blended CBT and epoxy resin at $140{ }^{\circ} \mathrm{C}$ for $5 \mathrm{~min}$ without premature polymerization of the CBT. The CBT/EP blends were cooled, ground, dried and then used for sample prduction in a hot plate press operated at $250{ }^{\circ} \mathrm{C}$ for $15 \mathrm{~min}$ followed by $200{ }^{\circ} \mathrm{C}$ for $85 \mathrm{~min}$. The used epoxy resins were bisphenol A diglycidyl ether (DGEBA), butanediol diglycidyl ether (BDDGE) and bis[(glycidyl ether)phenyl)]-m-xylene (BGOP). Dynamic viscosity measurements at $200{ }^{\circ} \mathrm{C}$ showed that the addition of DGEBA and BGOP markedly increased the rate of polymerisation while the BDDGE reduced it. DSC confirmed that the epoxy resins retarded the pCBT crystallization rate and decreased the crystal fraction. Fracture toughness improved by $87 \%, 52 \%$ and $37 \%$ when pCBT was modified with BDDGE, DGEBA or BGOP, respectively. The flexible aliphatic BDDGE epoxy resin imparted the largest improvement in toughness but had the least amount of reaction with $\mathrm{CBT}$ and the least impact upon crystallinity. DGEBA and BGOP exhibited excellent fracture toughness improvement and similarly superior improvements in strength and elongation to failure due to an increased level of reaction with CBT and a greater impact upon the crystal structure. The improvements in fracture properties were attributed to the formation of an inherently tougher epoxy polyester copolymer, delaying crystallisation, reducing overall crystallinity and causing the crystallites to be more disordered, more diffuse and smaller. 
Analogously, the reaction of CBT with three types of isocyanates has also been reported. ${ }^{108}$ The used isocyanates were a bifunctional aromatic type (hexamethylene diisocyanate; HDI), a bifunctional aliphatic type $\left(4,4^{\prime}-\right.$ methylenebis(phenyl isocyanate); MDI) and a polymeric methylene diphenyl isocyanate $(\mathrm{PMDI})$. All reactions took place in a Brabender batch mixer equipped with a torque measuring system at $230{ }^{\circ} \mathrm{C}, 60 \mathrm{rpm}$ and under nitrogen atmosphere to minimise hydrolysis. This type of equipment is quite useful for small-scale CBT processing because it does not only allow continuous mixing during ROP, but also gives useful information about the torque and thus viscosity evolution with time. ${ }^{109}$ Dry blends of CBT and the corresponding amount of each isocyanate $(0.25,0.5,0.75$ and $1 \mathrm{wt} \%$ ) were melt blended for 4 or $7 \mathrm{~min}$, respectively. The isocyanate-modified samples showed a considerable torque increase compared to unmodified CBT, suggesting a higher molecular weight. Gel content measurements prior to compression moulding indicated a linear chain structure for the two bifunctional isocyanate-modified samples, whereas the polyfunctional PMDI-modified PCBT exhibited considerable gel formation at higher NCO contents. All compression moulded samples were completely soluble, indicating that the crosslinked structures in PCBT/PMDI samples changed to linear or branched structures during this second melting. Proton NMR analysis showed that the dominant chain extension reaction mechanism is the formation of thermally stable amide groups. DSC analysis showed a general depression of melting and crystallization temperatures as well as degree of crystallinity. A 22-fold to 28-fold increase in elongation at break was observed in tensile tests when the pCBT contained 0.75 to $1 \mathrm{wt} \%$ isocyanate. Stiffness and strength generally decreased by about $10 \%$ (table 3 ). 
Other strategies to reduce the brittleness of thermoplastics include copolymerization with soft segments as well as well as physical modification with nano-particles and will be discussed in detail in the following sections.

\subsection{Copolymerization}

It is well known that the incorporation of even small amounts $(10 \%)$ of flexible chain segments such as polytetrahydrofuran (polyTHF) in polyester macromolecules results in a decrease in mechanical strength and in an increase in elongation at break. $^{110}$ The copolymer of PBT and polyTHF is known as copoly(butylene terephthalate- $b$-tetrahydrofuran) and belongs to the relatively new material class of thermoplastic elastomers (TPEs). ${ }^{104,}{ }^{110-115}$ Polyether ester elastomers exhibit outstanding elasticity, tear strength, solvent resistance, low-temperature flexibility and strength at elevated temperatures. Due to these properties they were commercialized under the trademark Hytrel ${ }^{\circledR}$ by DuPont in $1972 .^{104,115}$

Analogously, several researchers have copolymerized CBT with poly(ethyleneco-vinyl acetate) $(E V A)^{116}$, poly(vinyl butyral $)^{117}, \varepsilon$-caprolactone ${ }^{68}$, polycaprolactone $(P C L)^{32,118}$, hydroxyl terminated tetrabromobisphenol $A^{119}$, bisphenol $A$ diglycidyl ether ${ }^{119}$ and hydroxylated polydimethylsiloxane. ${ }^{119}$ Nevertheless, only some reports on the mechanical properties of these pCBT copolyesters are available and are summarized in table 3. Conventional PBT does not break in flexural tests but exhibits a yield point ${ }^{63}$ In tensile tests, PBT typically shows a failure strain of $>50 \% .{ }^{120}$ It is apparent from the failure strain in table 3 that in the case of CBT copolymerized with polytetrahydrofuran or PCL, a toughness similar to the one of conventional PBT could 
not be achieved. Copolymerization with $\varepsilon$-caprolactone or EVA resulted in ductile materials which exhibited a yield point, necking, strain hardening and very high failure strains. On the other hand, stiffness and strength drastically decreased. This decrement of mechanical properties together with $T_{g}$ and $T_{m}$ reduction are the major disadvantages of copolymerization with soft segments as a toughening method.

\subsection{Physical blending}

Samsudin et al. ${ }^{121-123}$ prepared blends of CBT and styrene maleimide by solid-state dispersion with compositions ranging from 90 to 10 wt.\% of CBT and subsequent in situ polymerization of CBT within styrene maleimide. It was found that the presence of 30 wt $\%$ and above of styrene maleimide impeded the crystallization of pCBT to such an extent that crystallization could not be detected under the conditions of the DSC experiment. The blend system exhibited a single composition-dependent $T_{g}$, which indicated the presence of miscibility. Furthermore, the negative value of the Flory-Huggins interaction parameter indicated that $\mathrm{pCBT}$ and styrene maleimide were thermodynamically miscible in the melt.

As can be seen from table 3 , the various toughening methods of pCBT allow tailoring the mechanical properties. The latter can range from rubber-like behaviour using copolymerization with EVA or $\varepsilon$-caprolactone to high stiffness and strength together with increased toughness using small amounts of polycaprolactone, epoxies or isocyanates. The physical modification of pCBT with nano-reinforcements will be discussed in the subsequent sections. 


\section{$4 \quad$ pCBT nanocomposites}

Polymer nanocomposites, in which the reinforcement has at least one dimension in the nanometre range, have received increasing interest in the past years. It is well recognised that the behaviour of composites largely depends on interfacial interactions. This means that the smaller the size of the reinforcement, the greater the contribution of interfacial interactions to the composite properties. Thus, a major challenge in the development of high performance nanocomposites is the control of nano-reinforcement dispersion. The mechanical, thermal and physical properties are greatly enhanced by the incorporation of nano-particles of different sizes and aspect ratios, and in thermoplastic matrices they can increase toughness. ${ }^{83-85}$ These improvements can already be obtained with very low nano-reinforcement contents, usually less than 5 wt.\%. Nevertheless, property improvements are typically only observed when the nano-particles are randomly and homogeneously dispersed on a nanoscale level in the polymer matrix. Thus, nanocomposites exhibit unique properties not shared by their micro- and macro-composite counterparts. ${ }^{124-126}$ CBT has been extensively used in nanocomposites due to the low melt viscosity prior to ROP which is advantageous for a good dispersion of the nano-reinforcement. Three types of nanocomposites can be distinguished, depending on how many dimensions of the dispersed particles are in the nanometre range. ${ }^{124}$ 
- two-dimensional (2D) nano-particles (i.e. having one dimension in the nanoscale) such as layered silicates ${ }^{126}$ or graphene nano-platelets ${ }^{127-128}$

- one-dimensional (1D) nano-particles such as carbon nanofibres ${ }^{129}$, carbon nanotubes ${ }^{130}$ or cellulose whiskers ${ }^{124}$

- zero-dimensional (OD) nano-particles such as fullerenes or polyhedral oligomeric silsesquioxane (POSS) molecules ${ }^{131-133}$

\subsection{Nanocomposites with layered silicates}

Layered silicates for the preparation of polymer/layered silicate nanocomposites (PLS) belong to the general family of 2:1 layered or phyllosilicates. ${ }^{126}$ Montmorillonite, hectorite and saponite being the most commonly used. Their crystal structure consists of layers made up of two tetrahedrally coordinated silicon atoms fused to an edge-shared octahedral sheet of either aluminium or magnesium hydroxide. The layers have a thickness of around $1 \mathrm{~nm}$ and lateral dimensions from $30 \mathrm{~nm}$ to several microns or larger, depending on the layered silicate.

Layered silicates are typically rendered organophilic in order to increase the compatibility between the hydrophobic polymer and hydrophilic silicate. This is achieved by ion-exchange reactions with cationic surfactants including primary, secondary, tertiary, and quaternary alkylammonium or alkylphosphonium cations. These ion-exchanged organic surfactants increase the interlayer spacing and lower the surface energy of the inorganic layered silicates which improves intercalation. Three methods for the preparation of PLS are reported: ${ }^{124,126}$ 
- melt intercalation: silicate delamination via shear flow and dispersion in the molten polymer

- in situ intercalative polymerization: swelling of the layered silicate with the liquid monomer/oligomer and subsequent polymerization

- exfoliation adsorption: exfoliation of the silicate layers in a suitable solvent, adsorbing the polymer onto the delaminated sheets and then solvent evaporation

Many researchers studied PBT/organoclay nanocomposites obtained by traditional melt intercalation or in situ intercalative polymerization of PBT monomers. ${ }^{134-138}$ An increasing amount of reports on pCBT/organoclay nanocomposites can also be found. ${ }^{14,65,139-146}$ The low viscosity of molten or dissolved oligomers is utilized to obtain a CBT-intercalated organoclay. Subsequent ROP causes then an increase in interlayer distance along with the disintegration of the layered clay structure, as shown in figure 22. Only few reports on complete clay exfoliation of the final nanocomposites are available, ${ }^{139,}{ }^{146}$ whereas intercalated or flocculated-intercalated structures are more commonly observed. ${ }^{141-145}$ Although the organoclay is successfully intercalated with CBT oligomers or even completely exfoliated before ROP, the silicate layers tend to reorganize due to the low viscosity of the molten CBT during ROP. Thus the exfoliated structure is lost and a flocculated-intercalated structure is obtained after polymerization. ${ }^{142,144-145}$

Tripathy and co-workers ${ }^{144}$ prepared pCBT/organoclay nanocomposites (using Cloisite ${ }^{\circledR} 20 A$ ) with a clay content of 2,4 and 6 wt.\%. CBT oligomers and organoclay were solvent blended for $20 \mathrm{~h}$ and then in situ polymerized. The thermal stability of these nanocomposites was found to increase by $8-10^{\circ} \mathrm{C}$ in nitrogen atmosphere. 
Karger-Kocsis et al. ${ }^{65}$ studied pCBT/organoclay nanocomposites using Cloisite ${ }^{\circledR}$ 30B (referred to as $\mathrm{Cl} 30 \mathrm{~B}$ ) with a clay content of $5 \mathrm{wt} . \%$ by modulated DSC analysis. The organoclay suppressed the crystallization of the PCBT produced during the first heating. However, the second heating suggested that more perfect crystallites were formed in the organoclay modified PCBT. The organoclay also affected the conversion and mean molecular mass of the resulting PCBT which were slightly lower than those of the neat PCBT polymerized under identical conditions. Moreover, they found that the organoclay hinders the cold crystallization of pCBT during the first heating scan. This was confirmed by Lanciano et al. ${ }^{142}$ who suggested that the presence of the montmorillonite shifts the ROP of CBT towards higher temperatures.

Abt et al. ${ }^{147}$ reported the preparation of isocyanate-toughened nanocomposites made from $\mathrm{CBT}$ and $\mathrm{Cl} 30 \mathrm{~B}$ via melt and solvent blending. Ternary blends of $\mathrm{pCBT} / \mathrm{PMDI} / \mathrm{Cl} 30 \mathrm{~B}$ had an intercalated-flocculated structure which resulted in a higher toughness, but also led to a stiffness and strength similar to that of neat pCBT due to an antagonistic effect of organoclay reinforcement and isocyanate toughening. The compatibility between the PCBT matrix and clay was further increased by preparing PMDI-tethered intercalated organoclay. The modified organoclay then exfoliated during ROP and yielded true pCBT/clay nanocomposites. Thermal properties and stabilities were not significantly altered by the organoclay, although some nanocomposites showed a decreased degree of crystallinity. It was concluded that isocyanates can enhance the compatibility between PCBT and nanofiller as well as the degree of exfoliation.

\subsection{Nanocomposites with carbon nanotubes}


Carbon nanotubes (CNT) are materials that can be thought as graphene sheets rolled into a cylindrical shape. ${ }^{148}$ They exist either as single-walled (SWCNT) or multiwalled (MWCNT) types and have gained considerable interest due to their remarkable physical, mechanical and electronic properties as well as a thermal conductivity higher than diamond. ${ }^{149}$ Particularly, their exceptional mechanical properties combined with their low density make CNTs a promising nanoreinforcement and many polymer/CNT nanocomposites including PBT/CNT have been prepared. ${ }^{149-150}$ However, only few pCBT/CNT nanocomposites have been reported in literature.

Romhány et al. ${ }^{151}$ prepared $\mathrm{pCBT/MWCNT}$ nanocomposites by solid-phase high-energy ball milling of CBT with MWCNT with subsequent in situ polymerization during compression moulding. They reported that the MWCNTs did not significantly affect the crystallinity of the isothermally produced pCBT but acted as nucleation agents during crystallization. Dynamic mechanical thermal analysis (DMTA) revealed a reinforcing effect of the MWCNT and an increase of the $T_{g}$ by $4-18{ }^{\circ} \mathrm{C}$. The authors suggested that the increase in $T_{g}$ is probably due to the formation of a transcrystalline-like interphase between MWCNT and pCBT in which the segmental motion of pCBT macromolecules is restricted. The pCBT/MWCNT nanocomposites apparently exhibited an optimum MWCNT content because flexural modulus, strength and Charpy impact strength (CIS) increased by up to $50 \%$ and went through a maximum. Optimum properties were found in the MWCNT range of $0.25-0.5 \mathrm{wt} . \%$.

Baets and associates ${ }^{83-84}$ dispersed small amounts of MWCNTs (up to 0.1 wt. \%) in CBT in order to increase the toughness of pCBT. The addition of 0.05 wt.\% of MWCNTs to pCBT resulted in an increase in stiffness by $30 \%$, strength by $80 \%$ and energy to failure by $30 \%$ while the failure strain was found to slightly decrease. 
However, the molecular weight of pCBT decreased by around $30 \%$ when MWCNTs were present in the blends.

Wu and co-workers ${ }^{152-154}$ synthesized a novel cyclic initiator from dibutyl tin(IV) oxide and hydroxyl-functionalized MWCNTs. This initiator was solvent blended with CBT in THF with the aid of ultrasonification and polymerized. The reaction mechanism of CBT initiated by the MWCNT-supported initiator is depicted in figure 23.

Thermogravimetric analysis (TGA) confirmed a grafting ratio of pCBT on MWCNTs of $59.3 \%$. The pCBT grafted onto the MWCNTs enhanced the interfacial adhesion between the MWCNTs and the PCBT and thus improved the compatibility. The MWCNTs were found to be homogeneously dispersed in the matrix when the content was lower than $0.75 \mathrm{wt} \%$, while higher MWCNT contents resulted in agglomeration. Intrinsic viscosity measurements showed that the molecular weight of the PCBT was not affected when the MWCNT-supported initiator was used. The thermal stability of the nanocomposites also remained unchanged. However, residual carboxyl groups of the MWCNTs facilitated the thermal degradation of the pCBT matrix. On the other hand, a combined Avrami/Ozawa analysis confirmed that the MWCNT-supported initiator acted as nucleation agent and significantly increased the crystallization rate of pCBT due to heterogeneous nucleation. The degree of crystallinity markedly increased with the addition of MWCNTs and the nanocomposites showed a nearly two-fold crystal fraction as compared to that of pCBT. Moreover, the crystallization temperature increased by $14-18{ }^{\circ} \mathrm{C}$ when $0.5-1.5$ wt. $\%$ of MWCNT-supported initiator was used.

$\mathrm{Li}$ and co-workers ${ }^{73}$ prepared pCBT/CNT mat composites. First, CBT was dissolved in chloroform and then a pre-stretched CNT mat was impregnated with the 49 / 107 
solution. After drying, the impregnated CNT mat was compression moulded at $250{ }^{\circ} \mathrm{C}$ for 15 min. Tensile modulus showed a 15-fold increase and the strength was 5 times higher for the composites containing 31 wt.\% of CNT mat while the failure strain decreased by $60 \%$, as compared to neat pCBT. Mechanical properties further increased when the CNT mat content was 64 wt.\% in the composites; modulus and strength were 40 and 9 times higher respectively, while strain at break decreased by 76\%. Similar to randomly dispersed CNTs in pCBT, CNT mat also has a nucleation effect on pCBT as shown by DSC. Multiple crystallization peaks appeared during cooling and the crystallization temperatures increased with increasing CNT mat content.

Kim and associates published a series of papers ${ }^{155-157}$ aimed on the electrical and thermal conductivity of pCBT/MWCNT nanocomposites prepared by a solventfree processing method. Similarly, Noh et al. ${ }^{158-159}$ used a CNT mat to impart conductivity. The conductivity results of these works will be further discussed in section 6.

\subsection{Nanocomposites with POSS}

Polyhedral oligomeric silsesquioxane, commonly referred to as POSS, is a class of 0D-type nano-reinforcement and has attracted a great deal of attention in recent years. The term silsesquioxane refers to molecules, whose chemical structure follows the basic composition of $\mathrm{R}_{n} \mathrm{Si}_{n} \mathrm{O}_{1.5 n} .{ }^{133}$ The R-group, also called the vertex group, may be hydrogen, alkyl, alkylene, aryl arylene, amine, glycidyl among others. These organic vertex groups are responsible for the functionality, solubility, polarity and reactivity of the POSS molecules and can be easily tailored. The interactions and/or $50 / 107$ 
reactions of these organic functional groups with a polymer may result in the nanometric dispersion of POSS into the matrix. ${ }^{131-133}$ The molecular architecture of POSS can be divided into caged structures and non-caged structures as shown in figure 24 a and b, respectively. Non-caged structures can be further classified into random, ladder and partial-cage structures.

Polymer/POSS nanocomposites have been prepared using traditional melt blending routes $^{160-161}$, reactive blending ${ }^{162}$ as well as copolymerization or grafting ${ }^{163-165}$ via reactive R-groups of POSS. POSS has been successfully incorporated in various commodity $^{162,166}$, engineering ${ }^{160,167}$ and high-performance ${ }^{168-169}$ thermoplastic polymers. The incorporation of POSS can lead to dramatic improvements of several properties such as increases in use temperature, oxidation resistance, as well as reductions in flammability and viscosity during processing. ${ }^{131-132,170}$

Many polyester/POSS nanocomposites have been prepared using $\mathrm{PET}^{171-176}$, polycarbonate ${ }^{160-161,177}$ or $\mathrm{PBT}^{178-179}$ as matrix. Similar to other types of nanoreinforcements, synergetic reinforcing effects of POSS were only observed when good compatibility existed. Otherwise aggregation occurred which led to a decrease in mechanical properties.

Only few reports on pCBT/POSS nanocomposites are available. Wan et al. ${ }^{145}$ used aminopropylisooctyl POSS as a surfactant for sodium montmorillonite and incorporated then CBT catalyst into the POSS-modified clay. This POSS-claycatalyst complex was used as initiator of the ROP of CBT and clay exfoliation even at 10 wt. \% of clay loading was achieved. The pCBT/POSS/clay nanocomposite was further used as a masterbatch for conventional PBT. While an increase in stiffness and strength was found for the PBT nanocomposites, no information on the mechanical properties of the PCBT nanocomposites was given. 
Similarly, McLauchlin et al. ${ }^{143}$ prepared a masterbatch of pCBT and POSSmodified clay which was subsequently melt blended with PBT to give nanocomposites containing 3 wt.\% of clay. On one hand, an intercalated/exfoliated morphology with the related increase in stiffness and strength were observed for the PBT nanocomposite. On the other hand, the CBT catalyst present in the masterbatch caused a depolymerization of the PBT.

Abt and co-workers ${ }^{180}$ melt blended pCBT in a batch mixer at $240{ }^{\circ} \mathrm{C}$ with 2.5 and 5.0 wt.\% of Octamethyl-POSS and Trisilanolphenyl-POSS, respectively. The obtained pCBT/POSS nanocomposites were ground, vacuum-dried and then compression moulded at $250{ }^{\circ} \mathrm{C}$ for $5 \mathrm{~min}$. Both POSS types slightly decreased the pCBT melting temperature and the crystal fraction. Octamethyl-POSS somewhat increased the crystallization temperature, thus acting as a heterogeneous nucleation agent, while a small decrease in crystallization temperature was found for the pCBT/Trisilanolphenyl-POSS nanocomposites. TGA analysis showed that the latter POSS type releases chemically or physically bound water at a temperature of 237 ${ }^{\circ} \mathrm{C}$. Therefore it was assumed that hydrolysis took place during processing of the pCBT/Trisilanolphenyl-POSS nanocomposites. Energy-dispersive X-ray spectroscopy showed that a part of the POSS was well dispersed in form of small agglomerations with a size of about $1 \mu \mathrm{m}$ but also larger POSS aggregates with a size of about $10 \mu \mathrm{m}$ were observed. Due to the relatively low thermal stability of the used POSS types as compared to the one of neat pCBT, pCBT/POSS nanocomposites also exhibited a lower thermal stability relative to pCBT.

Wu et al. ${ }^{181}$ reacted trisilanolisooctyl POSS with the butyltin trichloride initiator of CBT. This POSS-Sn initiator was used to prepare pCBT/POSS nanocomposites with up to 20 wt. \% of POSS content. Glass transition temperature and crystallization temperature slightly increased with POSS loading and thermal stability of the 52 / 107 
nanocomposites improved by up to $11^{\circ} \mathrm{C}$. However, molecular weight decreased due to the increasing amounts of catalyst bonded to the POSS.

\subsection{Nanocomposites with graphene}

Graphene (referred to as $\mathrm{G}$ ) is a one-atom-thick layer of $\mathrm{sp}^{2}$-bonded carbon atoms densely arranged in a two-dimensional honeycomb crystal lattice and recently has received enormous attention due to its outstanding mechanical, thermal and electrical properties. $^{127,}{ }^{182-183}$ Graphene can be obtained from graphite intercalation compounds using the Hummers method. ${ }^{184}$ This method involves the oxidation of naturally occurring graphite using a water-free mixture of concentrated sulfuric acid, sodium nitrate and potassium permanganate and yields graphite oxide (commonly referred to as GO) with a $\mathrm{C}: \mathrm{O}$ ratio of approximately $2: 1 . \mathrm{GO}$ is highly oxygenated and bears epoxide, diol, ketone, hydroxyl and carboxyl functional groups on the basal plane and additional carbonyl and carboxyl groups located at the edges of the GO sheets. These functional groups render GO platelets highly hydrophilic, allowing them to readily swell and disperse in water ${ }^{127,}{ }^{182-183}$ but direct exfoliation into non-aqueous solvents or hydrophobic polymer matrices is difficult. ${ }^{185}$ Exfoliated and reduced GO is then obtained by solution-based chemical reduction of $\mathrm{GO}^{183,186}$ or most commonly by thermal shocking. The latter yields thermally reduced graphite oxide (TRGO) which retains some of the oxygenated functional groups originally present on the GO platelets. $^{127}$

Similar to other 2D-type reinforcements such as layered silicates, proper exfoliation and homogeneous dispersion of single graphene sheets in the polymer matrix is crucial for property improvements. ${ }^{127,183,187}$ However, G exfoliation remains 
a major challenge due to the strong $\pi-\pi$ stacking of the $\pi$ orbitals of graphene. ${ }^{182-183}$ Since the high melt viscosity of most thermoplastics complicates exfoliation, $G$ is therefore commonly intercalated/exfoliated by solvents and/or monomers prior to melt blending with thermoplastics. ${ }^{127,} 182-183,185,187-189$ The low melt viscosity of CBT may be favourable for $\mathrm{G}$ exfoliation.

Fabbri and associates ${ }^{189}$ prepared pCBT/G nanocomposites by solvent blending CBT oligomers and $0.5-1$ wt.\% of graphene nano-platelets in THF. Then the solvent was extracted and the dried compound was polymerized during melt blending at $200{ }^{\circ} \mathrm{C}$ for $30 \mathrm{~min}$. Good graphene dispersion was observed but the pCBT molecular weight strongly decreased with increasing $G$ content. Due to this low molecular weight the nanocomposites were too brittle for standard specimen preparation and nano-indentation was performed instead. It was found that the elastic modulus and indentation hardness increased for $\mathrm{G}$ contents lower than 0.75 wt.\%. Moreover, thermal stability in oxygen was improved by up to $20^{\circ} \mathrm{C}$ and all prepared samples were electrically conductive.

Balogh et al. ${ }^{190}$ used melt blending in a batch mixer at $200{ }^{\circ} \mathrm{C}$ and $180 \mathrm{~min}^{-1}$ for 2 min to prepare CBT/G nanocomposites with $G$ contents of $1-5$ wt.\%, without prematurely polymerizing the $\mathrm{pCBT}$. The CBT/G blends were ground, dried and then in situ polymerized during compression moulding at $240{ }^{\circ} \mathrm{C}$ for $10 \mathrm{~min}$. While poor $\mathrm{G}$ dispersion was obtained, it was found that $G$ had a reinforcing effect on pCBT. DMTA storage modulus at room temperature increased by $39-89 \%$ and the heat conductivity was also markedly enhanced. Moreover, $G$ was found to act as nucleating agent because crystallization temperatures and crystal fractions increased by up to $4{ }^{\circ} \mathrm{C}$ and $4 \%$, respectively, for $\mathrm{G}$ contents of $1-5$ wt. $\%$. Graphene incorporation markedly enhanced the heat conductivity but did not alter the thermal stability of pCBT, due to $\mathrm{G}$ agglomeration. 
Chen et al. ${ }^{188}$ prepared pCBT nanocomposites with TRGO by solvent blending in THF, vacuum drying and then polymerization at $200{ }^{\circ} \mathrm{C}$. The rate and degree of CBT polymerization decreased with TRGO content, which was ascribed to the reaction between carboxyl groups of growing pCBT chains and hydroxyl/epoxy groups situated on the surface of TRGO as shown in fig. 25. The pCBT grafted onto TRGO was confirmed by various characterization techniques and the grafting content was found to be up to $53 \%$.

Noh and co-workers published a series of articles ${ }^{191-193}$ dealing with the electrical and thermal conductivity of PCBT/G nanocomposites prepared by a solventfree processing method, which will be further discussed in section 6 .

It is apparent that graphene is difficult to exfoliate and disperse homogeneously in the pCBT matrix. More importantly, it seems that $G$ interferes with the ROP of CBT because the final $\mathrm{pCBT}$ molecular weight was rather low and the reported $\mathrm{pCBT/G}$ nanocomposites were brittle. On the other hand, it is clear from literature that chemical functionalization of graphene is of crucial importance in the synthesis of polymer-graphene nanocomposites with good dispersion. ${ }^{127,182-183,185,187}$ The oxygen-containing functional groups of TRGO can be used to enhance the compatibility of the latter with various polymer matrices via chemical functionalization, ${ }^{127,}{ }^{182}$ for instance with isocyanate compounds. In this chemical functionalization, organic isocyanates react with the hydroxyl and carboxyl groups of graphene oxide to form carbamate and amide functionalities, respectively. The functionalization reduces the hydrophilic character of $\mathrm{GO}$ and effectively prevents restacking of the exfoliated graphene sheets due to reduced $\pi-\pi$ interactions. Moreover, it can be employed for covalent bonding of the polymer chains. ${ }^{185,}{ }^{187}$ This has not yet been reported for $\mathrm{pCBT/graphene} \mathrm{nanocomposites.}$ 


\section{$5 \quad$ Fibre-reinforced $\mathrm{pCBT}$ composites}

So far, continuous fibre reinforced composites made from CBT and glass fibres, carbon fibres, basalt fibres, kenaf fibres and more recently hybrid glass-carbon fibres have been reported. Various reinforcement architectures have been used for pCBT composites, most commonly unidirectional fibres and woven fabrics.

\subsection{Composites with glass fibres}

Glass fibres (commonly referred to as GF) are widely used in composite production due to their principal advantages such as low cost, high tensile strength, high chemical resistance, and excellent insulating properties. Their disadvantages are relatively low tensile modulus and high density, sensitivity to abrasion during handling, relatively low fatigue resistance and high hardness. ${ }^{194}$

Mallon and co-workers ${ }^{195}$ investigated the VARTM and RTM processing of CBT. The authors used a flat heated mould together with a heated delivery system for transporting the molten resin from the melting unit to the mould. The fibre preform was bagged with a high temperature plastic film and sealing tape. Uncatalysed CBT was melted at $165^{\circ} \mathrm{C}$ in a reactor, catalyst was added to the CBT melt and mixing continued for $2 \mathrm{~min}$. The mould was then vacuum-infused and held at $170{ }^{\circ} \mathrm{C}$ for 40 min in order to complete the ROP. In this manner flat panels were moulded using S2 
glass fabric, S2 glass mat and carbon fabrics with fibre volume fractions over $45 \%$ in the case of GF, and up to $64 \%$ in the case of the carbon fabric. A one-dimensional heat transfer analysis was performed and transverse thermal conductivities were estimated to be $0.75 \mathrm{~W} / \mathrm{m} \cdot \mathrm{K}$ and $1.5 \mathrm{~W} / \mathrm{m} \cdot \mathrm{K}$ for glass and carbon fibre beds under vacuum, respectively. Moreover, the heat transfer analysis predicted a $40^{\circ} \mathrm{C}$ temperature drop from the mould surface to the top surface of the fibre preform. An insulating layer placed on top of the preform reduced the temperature drop across the preform to an acceptable value of $10^{\circ} \mathrm{C}$. Comparison of DSC results between pCBT and pCBT composites indicated that the composition of the crystals was different in each case. GPC results revealed that the degree of conversion was only around $65 \%$, suggesting that the mould temperature was too low and the processing time was too short. DMA tests on the moulded glass panels showed that the flexural storage modulus varied from approximately $18 \mathrm{GPa}$ at room temperature to $9 \mathrm{GPa}$ at $150^{\circ} \mathrm{C}$ for the $\mathrm{S} 2$ glass fabric/pCBT composite. For the carbon fabric panels, flexural modulii up to $51 \mathrm{GPa}$ were achieved, with flexural strengths of up to $450 \mathrm{MPa}$.

Parton et al. ${ }^{41,63,69}$ prepared pCBT/GF composites using a lab-scale TP-RTM system. The authors used two different reinforcements; one was a unidirectional noncrimp GF fabric and the other one was a non-crimp fabric which consisted of three plies, $0^{\circ}, 90^{\circ}$ and a random mat. Uncatalysed CBT was melted at $190^{\circ} \mathrm{C}$ in a reactor, then 0.45 wt. $\%$ of a tin-based transesterification catalyst was added to the CBT melt. The latter was then vacuum infused into a closed mould which was preheated to 190 ${ }^{\circ} \mathrm{C}$ and contained the reinforcement. The time for polymerization and crystallization was $30 \mathrm{~min}$. As pointed out earlier, isothermal polymerization and crystallization below $T_{m, p C B T}$ results in pCBT brittleness due to a high crystal fraction and perfection together with a low amount of intercrystalline tie molecules. The mechanical properties of the resulting composites were not affected in fibre dominated $57 / 107$ 
orientations but the transverse strength on the other hand decreased to below the matrix strength due to the brittleness of the matrix (c.f. table 4). The authors showed that the presence of the fibres reduced the degree of conversion of the $\mathrm{pCBT}$. Due to side reactions of the CBT resin with epoxide functional groups present in the sizing, partially crosslinked pCBT was formed. ${ }^{69}$

Baets et al. ${ }^{70,83-84,118}$ employed a lab-scale TP-RTM system to prepare pCBT/GF composites and used different methods to increase the toughness. The addition of 7 wt.\% of polycaprolactone to CBT increased the failure strain to twice that of pure pCBT. Moreover, the impact resistance was more than doubled with the addition of PCL. ${ }^{84}$ The addition of CNTs to CBT increased stiffness and strength, however, the failure strain decreased (table 4). An inhomogeneous distribution of the CNTs in the pCBT/GF composite was found because the CNTs were stuck between the glass fibre bundles.

Mohd Ishak and co-workers ${ }^{66}$ prepared woven GF fabric reinforced pCBT composites at $190^{\circ} \mathrm{C}$ for 30 min during compression moulding. The authors used two approaches; displacement-controlled compression moulding and pressure-controlled compression moulding. The displacement-controlled approach involved downward steps of the upper hot plate from about $10-3 \mathrm{~mm}$ in order to facilitate the macro- and micro-impregnation processes. The pressure-controlled approach involved the application of pressure after $10 \mathrm{~min}$. Similar to what has been reported by other researchers; it was found that the crystallinity of conventional injection moulded PBT is markedly lower than that of $\mathrm{pCBT}$, rendering the latter more brittle. Both tensile and flexural properties as well as inter-laminar shear strength were enhanced when the moulding occurred under pressure-controlled conditions (c.f. table 4). SEM analysis showed uniform fibre dispersion in the matrix, excellent fibre wet-out and good interfacial bonding between the fibres and $\mathrm{pCBT}$.

$58 / 107$ 
Mäder and co-workers studied the adhesion, interphases and failure behaviour of pCBT/GF composites. ${ }^{196}$ The authors used single fibre pull-out test, atomic force microscopy and $\zeta$ potential tests to show that the interfacial bond strengths in pCBT composites depend on the type of sizing formulation. The greatest adhesion strength was achieved using aminosilane sizings with epoxy resin film former. For these sizing systems, cohesive failure occurred and similar values of both interfacial adhesion strength $\left(\tau_{d}\right)$ and fracture energy release rate $\left(G_{i c}\right)$ were obtained, in which $\tau_{d}$ approached the shear yield strength of pCBT. The data indicated highly reactive alkaline amino groups dominating the fibre surface and were available at the interface for adhesional bonds with the PCBT matrix. By increasing the $T_{P}$, the higher mobility of the polymer chains enabled enhanced bond formation and led to improved interfacial parameters.

Durai Prabhakaran et al. ${ }^{197}$ studied the role of the processing on the mechanical properties of GF reinforced pCBT and PBT composites. Three different unidirectional composite laminates were manufactured by vacuum consolidation; a pCBT/GF composite polymerized at $230{ }^{\circ} \mathrm{C}$ and PBT/GF composites made from prepreg tapes as well as from commingled yarns. It was found that the compression modulus and strength of the commingled PBT/GF system displayed the highest values which were significantly higher than the ones observed for the PBT/GF prepreg and the pCBT/GF composite systems. Interestingly, the pCBT/GF system displayed the highest compression strain to failure, namely $1.8 \%$. On the other hand, the PBT/GF prepreg systems displayed higher flexural and interlaminar shear strengths than the commingled PBT/GF and the pCBT/GF systems. Flexural properties of the latter system are shown in table 4. SEM and optical microscopy 
studies revealed that the pCBT/GF systems provided good fibre wetting, but also displayed some voids within the resin.

\subsection{Composites with carbon fibres}

The principal advantages of carbon fibres (referred to as CF) are their exceptionally high tensile strength to weight ratios as well as tensile modulus to weight ratios, very low coefficient of linear thermal expansion which provides dimensional stability, high fatigue strengths and high thermal conductivity. The main disadvantages are their low failure strain, low impact resistance and high electrical conductivity. So far, carbon fibres have been excluded from widespread commercial use due to their high cost. CF-based composites are mostly employed in the aerospace industry, where weight saving is considered more critical than cost. ${ }^{194}$

As already mentioned earlier, $\mathrm{Yu}$ and co-workers ${ }^{76}$ studied the effects of different crystalline morphologies on the mechanical properties of $\mathrm{pCBT/CF}$ composites. Stacked films of CBT powder and reinforcement were polymerized during compression moulding at $230{ }^{\circ} \mathrm{C}$. After $30 \mathrm{~min}$ the composites were quenched to crystallization temperatures of 185,195 and $210^{\circ} \mathrm{C}$, respectively. The mechanical properties of the pCBT composites were strongly affected by their crystalline morphologies and crystal fraction; see table 4 . The sample crystallized at $185^{\circ} \mathrm{C}$ exhibited weak spherulite/transcrystalline boundaries which led to low mechanical properties, whereas the composite sample crystallized at $210{ }^{\circ} \mathrm{C}$ showed highly disordered spherulitic crystallites without spherulite/transcrystalline boundary lines or boundary crystals. Hence, composites crystallized at $210{ }^{\circ} \mathrm{C}$ displayed the best tensile and flexural properties. 
Agirregomezkorta and associates ${ }^{198-202}$ used vacuum infusion to produce woven CF fabric-reinforced pCBT composites and compared them to equally produced epoxy-based composites. The pCBT-based composite presented a higher shrinkage and void content than the epoxy-based one due to the volumetric shrinkage associated with pCBT crystallisation. Impact tests with nominal impact energies ranging from 0.3 to $60 \mathrm{~J}$ showed that the stiffness and the damage threshold of the pCBT/CF were lower than those of the epoxy-based composite. However, the peak load and penetration energy of pCBT/CF was twice of the epoxy/CF composite. The higher energy absorption capability of pCBT/CF was justified by its lower interlaminar shear strength (ILSS), as compared to the epoxy/CF composite. The epoxy-based composite matrix was characterized by a relatively brittle fracture, whereas the thermoplastic nature of the pCBT matrix induced delamination, which in turn improved the energy absorption capability and impact resistance ${ }^{199}$. Moreover, the authors used quasi-static and low energy impact tests and found that the ILSS is strain rate dependent for both composites. All pCBT/CF composites failed by interlaminar shear, whereas epoxy-based samples broke in a mixed mode. The volume damaged during tests was higher in PCBT composites than in epoxy ones. However, the pCBT/CF composite showed a lower ILSS value (namely 19.8 MPa), probably due to its lower tensile strength and higher void content. $^{201}$

Archer and co-workers ${ }^{203}$ produced a three-dimensional woven CF fabricreinforced $\mathrm{pCBT}$ composite using a multi-layer carbon fibre three-dimensional woven angle interlock fabric. The reinforcements were manufactured on a modified textile loom to produce fabrics with fibres orientated in the warp, weft and through-thethickness directions. Thermal and mechanical tests were conducted on the pCBT composite and comparisons were made to an epoxy-based composite with the same $61 / 107$ 
weave architecture (table 4). It was found that a highly crystalline matrix was developed as a result of the standard fabrication process with microcracks formed throughout the matrix. These cracks reduced the tensile strength of the pCBT matrix and caused localised stresses on the specimen surface. Consequently, flexural strength and failure strain of the epoxy-based composite were $46 \%$ and $27 \%$ higher, respectively, as compared to the pCBT-based composite. Moreover, the apparent ILSS of the pCBT-based sample was approximately $10 \%$ lower. Reprocessing and annealing of the pCBT-based laminate reduced the crystallinity of the polymer structure. Although this was expected to improve toughness, it was found to have a detrimental effect on the composite stiffness and led to melting temperature depression.

An increasing amount of work is focussed on improving the mechanical properties of continuous fibre reinforced pCBT composites by applying different toughening methods. Kim and associates ${ }^{204}$ used a novel fast manufacturing process to prepare CF fabric-reinforced pCBT composites. Samples were compression moulded at 250 ${ }^{\circ} \mathrm{C}$ for 2 min using a pressure of $1 \mathrm{MPa}$. Annealing at $200{ }^{\circ} \mathrm{C}$ for $120 \mathrm{~min}$ resulted in improved mechanical properties and thermal stability of the pCBT. The tensile strength of samples compression moulded at $250{ }^{\circ} \mathrm{C}$ for 2 min was $440 \mathrm{MPa}$ whereas that of the sample annealed at $200{ }^{\circ} \mathrm{C} \mathrm{C}$ for $120 \mathrm{~min}$ after compression moulding was $500 \mathrm{MPa}$. In addition, the thermal stability of the annealed composites improved by $10^{\circ} \mathrm{C}$.

Wu et al. ${ }^{205-209}$ proposed a new concept for binding and ex situ toughening of textile reinforced pCBT composites. First, an epoxy preforming binder in powder form was spread onto the surface of tri-axial GF fabrics and then thermally activated in a hot plate press. Three kinds of laminates were prepared. One reference laminate with 62 / 107 
no binder, one laminate with binder as interlayer in textile preforms (simultaneous binding and ex situ toughening concept) and one laminate with binder premixed in molten CBT resin before impregnation of dry textile preforms (in situ toughening concept). The results showed that both in situ and ex situ toughening concept have great potential in toughening of textile reinforced pCBT $_{\text {composites. }}{ }^{208}$ In situ toughening with 2 or 4 wt.\% led to an improvement of about $18 \%$ in flexural strain. The flexural strength was improved by $26.7 \%$ in the case of 4 wt. $\%$ preforming binder while the flexural modulus remained nearly unchanged. As for the ex situ toughened samples, a toughening effect was only observed with 2 wt. \% performing binder in the interply region, which illustrates an excellent toughening performance with an increase of $72.9 \%$ in flexural strain, $69.1 \%$ in flexural strength, and even $8.3 \%$ in flexural modulus respectively. An increase of preforming binder up to $4 \mathrm{wt} \%$ appeared to have a negative influence on the toughening performance and mechanical properties (c.f. table 4). In a further step, the influence of the epoxy preforming binder on the thermal and rheological properties of CBT was studied. ${ }^{209}$ DSC analysis showed that the crystallization temperature and the crystallinity of pCBT during cooling are both found to decrease with increasing filling fraction of preforming binder. The onset of crystallization, the crystallization rate and the crystal structures were influenced due to the addition of preforming binder. Furthermore, the processing time was found to be prolonged.

In a follow-up work, ${ }^{207}$ the authors studied the influence of various commercial preforming binders on the interlaminar fracture properties, namely an epoxy-based binder, an acrylic-based binder and a binder based on a random terpolymer of ethylene, methyl acrylate and glycidyl methacrylate. It was found that the acrylicbased binder showed the best performance in terms of the homogeneity of the pCBT laminate and the magnitude of the final fracture toughness. The mode II fracture $63 / 107$ 
toughness was improved by $124-152 \%$ as compared to the reference laminate without binder.

Abt et al. ${ }^{210}$ prepared toughened CF fabric-reinforced pCBT composites by chemical modification of CBT with small amounts of epoxy resin and isocyanates as chain extenders (in situ toughening concept). Homogeneous CBT/epoxy and CBT/isocyanate blends were prepared by melt blending the components in a labscale batch mixer at low temperatures and high shear rate. Melt blending was stopped before the ring-opening polymerization of CBT could start. The modified CBT was the starting material for carbon fibre fabric-reinforced pCBT composites (fibre content at about 65 wt\%) which were prepared by ROP during compression moulding using a simple powder prepreg method. Interlaminar shear strength, flexural strength, and failure strain of the chemically modified composites increased up to $60 \%$ with respect to unmodified pCBT composites (c.f. table 4). Nevertheless, the flexural moduli slightly decreased due to the toughening effect of the chain extender on the pCBT matrix. Drop weight impact tests revealed that the energy absorption of the modified composites was relatively higher as compared to unmodified pCBT composites. Moreover, critical energy and delamination threshold force were higher for modified composites. It was concluded that toughening of pCBT with epoxy or isocyanates, namely PMDI and $\mathrm{HDI}$, is very effective for improving the mechanical properties, most importantly the toughness of fibre reinforced pCBT composites.

Dell'Olio and associates $^{90}$ prepared pCBT/CF composites modified with different types of epoxy resin (namely DGEBA, BDDGE and BGOP), as already mentioned in section 3.5. Composites were manufactured by sprinkling the CBT powder on the CF reinforcements, vacuum bagging and in situ polymerization during compression moulding at $250{ }^{\circ} \mathrm{C}$ for $15 \mathrm{~min}$ followed by $200{ }^{\circ} \mathrm{C}$ for $85 \mathrm{~min}$. The fracture toughness of the composites increased by factors of 2,3 and 4 when the $64 / 107$ 
composites were toughened with DGEBA, BDDGE and BGOP, respectively, as compared to unmodified pCBT composites. SEM analysis of the fracture surfaces showed tearing and stretching of the matrix, while unmodified pCBT/CF exhibited smooth surfaces without any pCBT elongation.

Kim et al. ${ }^{204}$ suggested a novel fast manufacturing process using high-speed processing at $250{ }^{\circ} \mathrm{C}$ for $2 \mathrm{~min}$. Structure and properties of the composites were altered by thermal annealing and the mechanical properties as well as thermal stability were improved as the remaining CBT oligomers were polymerized further. Annealing at $200{ }^{\circ} \mathrm{C}$ for $120 \mathrm{~min}$ was found to be the best annealing condition for improving the mechanical properties and thermal stability of pCBT due to the improvement in crystallinity. The tensile strength of the composites compression moulded at $250{ }^{\circ} \mathrm{C}$ for 2 min was $440 \mathrm{MPa}$ and that of the ones annealed at $200{ }^{\circ} \mathrm{C}$ for 120 min after compression moulding was $500 \mathrm{MPa}$. In addition, the thermal stability of the annealed composites improved by $10^{\circ} \mathrm{C}$. In a follow-up work, Lee and co-workers ${ }^{211}$ designed and manufactured a microwave plasma equipment in order to improve interfacial bonding and mechanical interlocking between CF fabrics and the pCBT matrix. High-speed fabrication was used and the specimens were polymerized at $250{ }^{\circ} \mathrm{C}$ for $2 \mathrm{~min}$. It was confirmed that the microwave plasma treatment did not induce chemical changes in the CF fabric, and that the chemical adsorption ability of the plasma-treated fabric was not altered. However, an increase in the surface roughness was induced by the micro-cavities, indicating that the mechanical interlocking ability between the plasma-treated CF fabrics and matrix was enhanced. The tensile strength of the as-received and plasma-treated pCBT/CF composites was enhanced by approximately $363 \%$ and $436 \%$, respectively, compared with that of the pCBT matrix. The improvements were found to originate from an enhancement of the 
interfacial bonding between the resin and reinforcement due to the enhanced mechanical interlocking between the resin and plasma-treated CF.

\subsection{Composites with natural fibres}

In recent years, a great deal of attention has been focussed on the development of sustainable natural (i.e. animal, vegetable or mineral) fibre reinforced composites. In particular, among the natural fibres that can be used as reinforcement, basalt fibres appear to be the most interesting due to their properties. Basalt is a natural material that is found in volcanic rocks originated from frozen lava, with a melting temperature comprised between 1500 and $1700{ }^{\circ} \mathrm{C} .{ }^{212}$ Overall, the manufacturing process of this kind of fibre is similar to that of glass fibre, but with less energy consumed and no additives, which makes it cheaper than glass or carbon fibres. ${ }^{212}$ Nevertheless, only few basalt fibre-reinforced pCBT composites have been reported.

Hao et al. ${ }^{213}$ studied the effect of the $T_{P}$ on the mechanical properties of woven basalt fabric-reinforced pCBT composites. Compression moulding was used to produce the composites at various polymerization temperatures, namely $220{ }^{\circ} \mathrm{C}, 230$ ${ }^{\circ} \mathrm{C}$ and $240{ }^{\circ} \mathrm{C}$ and the effect of different thermal histories during processing on the composites properties was investigated. Stiffness and strength of samples processed at $220^{\circ} \mathrm{C}$ and $230{ }^{\circ} \mathrm{C}$ were quite similar, whereas the mechanical properties of the sample processed at $240{ }^{\circ} \mathrm{C}$ declined sharply due to depolymerisation (c.f. table 4).

Baets and associates ${ }^{89}$ prepared basalt fibre reinforced pCBT composites using RTM processing. The aim was to reduce the inherent brittleness of isothermally processed pCBT composites by applying a non-isothermal production process, as already pointed out in section 3.5. Three-point bending tests were performed and it 
was found that the flexural strength and failure strain of quench cooled composites increased by $33 \%$ and $44 \%$, respectively, as compared to slowly cooled samples. Moreover, fracture toughness mode II tests showed a twofold increase of the crack propagation energy for the quenched samples as compared to slowly cooled samples.

Many different types of vegetable fibres are available and examples are jute, flax, hemp, remi, sisal, coconut or banana fibre. All these fibres are grown as agricultural plants in various parts of the world and are commonly used for making ropes, carpet backing, bags, and so on. The components of natural fibres are cellulose microfibrils dispersed in an amorphous matrix of lignin and hemicellulose. Depending on the type of the natural fibres, the cellulose content is in the range of $60-80 \mathrm{wt} \%$ and the lignin content is in the range of $5-20 \mathrm{wt} \%$. In addition, the moisture content in natural fibres can be up to $20 \mathrm{wt} \% .{ }^{194}$ Romão and co-workers ${ }^{214-}$ ${ }^{215}$ used TP-RTM to produce woven flax fabric fibre reinforced pCBT composites with a fibre volume fraction of $32 \%$. Polymerization conditions of $190{ }^{\circ} \mathrm{C}$ and $30 \mathrm{~min}$ were chosen due to the relatively low thermal stability (about $200{ }^{\circ} \mathrm{C}$ ) of the cellulosic component of natural fibres. Moreover, the used flax fibres were not surface treated. Consequently, weak and brittle composites with low interfacial adhesion were obtained. The tensile strength of neat pCBT was found to be $15 \mathrm{MPa}$, which increased to $20 \mathrm{MPa}$ and $26 \mathrm{MPa}$ when $\mathrm{pCBT}$ was reinforced with undried and dried fabrics, respectively.

\subsection{Hybrid composites}


The term 'hybrid composite' generally refers to a matrix containing at least two types of reinforcements. More specifically, fibre hybrid composites contain at least two types of reinforcing fibres. Fibre hybridisation is a promising strategy to toughen composite materials by combining two or more fibre types because hybrid composites typically offer better strength versus toughness than non-hybrid composites. The failure strain and toughness can be dramatically increased if brittle fibres are replaced by ductile fibres. In this respect, metal fibres have the potential of high stiffness and large failure strain, nevertheless they are limited by their high densities. $^{216}$

Aurrekoetxea et al. ${ }^{202}$ reinforced pCBT/CF composites with $2.3 \%$ of superelastic shape memory alloy (SMA) wires and investigated the impact behaviour. NiTi SMA wires can improve impact properties of composites due to their high damping capacity related to the hysteresis of stress-induced martensitic transformation. The hybrid $\mathrm{pCBT/CF/SMA}$ composites were subjected to instrumented Charpy impact tests at impact velocities ranging from 0.33 to $2.32 \mathrm{~m} / \mathrm{s}$. It was found that the stress-induced martensitic transformation mechanism was not activated at the subcritical impact. Nevertheless, at the supercritical regime, the dissipated energy increased from $2.22 \mathrm{~J}$ of the reference composite to $4.68 \mathrm{~J}$ of the hybrid one. The contribution of the SMA wires to the higher impact performance of the hybrid composite was not only related to their energy absorbing capability but also to the high reversible force that acted as a healing force and improved the load bearing of the composite.

Yang and co-workers ${ }^{217}$ prepared interply hybrid composites based on woven CF and GF fabrics and pCBT using a vacuum assisted prepregs process and subjected the composites to low-velocity impact. Finite element method simulation was also performed to investigate the hybridization effect on the composites under $68 / 107$ 
impact velocity of $3 \mathrm{~m} / \mathrm{s}, 5 \mathrm{~m} / \mathrm{s}$ and $7 \mathrm{~m} / \mathrm{s}$. Experimental results showed that hybrid composites with a carbon to glass mass ratio of $37: 63$ could enhance significantly both impact resistance and perforation thresholds as compared to $\mathrm{pCBT/CF}$ composites. The progressive failure model developed in the simulation can be used to predict the failure of interplay hybrid composites based on glass and carbon woven fabrics.

Wu et al. ${ }^{206}$ proposed a novel process for the manufacturing of fibre metal laminates with textile reinforced pCBT composites and aluminium alloy. To improve the adhesive bonding, prepregs were introduced as interlayer for a $2 / 1$ preform configuration, which was composed of two layers of dry CF fabrics and one layer of aluminium alloy in between. The preform was impregnated with CBT melt in an isothermal VARI process. After manufacturing, the FML was subjected to mechanical characterizations. First, the influence of various surface treatment methods was studied and the best results were obtained with an aluminium plate treated with a combination of mechanical abrasion with 180 grit and alkaline degreasing with 10 wt. $\% \mathrm{NaOH}$. Moreover, the optimal isothermal moulding temperature was found to be $190{ }^{\circ} \mathrm{C}$, which resulted in the highest ILSS and CIS of the fibre metal laminate samples.

\subsection{Recycling of pCBT composites}

Steenkamer and Sullivan ${ }^{218}$ investigated the recyclability of pCBT composites. The virgin composite was prepared by liquid moulding the CBT resin and a knitted glass fabric. The resultant high fibre content composite (58.7 wt.\%) was ground, compounded with two grades of commercial PBT, and then re-processed by injection 
moulding. A variety of physical and mechanical tests were then conducted on the blended pCBT composite and a baseline, short fibre reinforced PBT. In general, the recycled $\mathrm{pCBT}$ composite demonstrated comparable properties to the baseline material. The only exception was the ultimate tensile strain of the recyclate, which was almost $25 \%$ lower than that of the short fibre reinforced PBT.

\subsection{Applications of $\mathrm{pCBT}$ composites}

Several industrial applications of fibre-reinforced pCBT composites have been reported. A team comprised of Cyclics Corporation and various partners from university as well as from industry developed a program called "Cleanmould" which was partially funded by the European Commission ${ }^{219-222}$. The aim of the program was the development of novel GF-reinforced pCBT composites in order to produce thicksection parts with large surface areas using VI and VARTM processes as well as modified versions of a vacuum bag consolidation process using CBT prepregs. Within the framework of this project, a $13.6 \mathrm{~m}$ flat bed semi-trailer (c.f. figure 26) as well as $5 \mathrm{~m}$ flat bottom boat hull (c.f. figure 27) with multi- and unidirectional fibre layers were successfully manufactured in CBT. To date, the semi-trailer is the largest single, high performance TPC moulding in the world. The base of the trailer has a wall thickness between 8 and $15 \mathrm{~mm}$, weights over $600 \mathrm{~kg}$ and covers roughly $50 \mathrm{~m}^{2}$ in area. The trailer is currently producing weight savings of approximately $1500 \mathrm{~kg}$, generating over 700 litres of fuel savings per year as compared to the steel trailer that it has replaced. Regarding the $5 \mathrm{~m}$ flat bottom boat hull, this case study is the first reported application of a structural thermoplastic composite in a balsa-cored sandwich panel.

Wind turbine blades are another important application of pCBT composites. A R\&D program called "GreenBlade" was developed by Cyclics Corporation, ÉireComposites, Mitsubishi Heavy Industries and Ahlstrom Glassfibre to produce blades made of pCBT/GF composites. ${ }^{223-226}$ A $12.6 \mathrm{~m}$ long wind blade was manufactured in one shot with no adhesives in six hours (c.f. figure 28). CBT was applied as a film onto the surface of a glass fabric and unidirectional tapes were used 
for the spar cap and webs and biaxial 0/90 fabrics for the skins. These semi-prepregs were layed up into moulds and enveloped in a sacrificial vacuum bag. The assembly was heated to $200{ }^{\circ} \mathrm{C}$ for polymerization. The sacrificial vacuum bags melted into the layup and the component parts joined to create a one-shot $500 \mathrm{~kg}$ blade with a fibre volume fraction of $50 \%$.

\section{Conductive composites}

Conductive polymer composites (CPCs) have generated significant academic and industrial interest for many years since most polymers are not conductive. Conductive fillers have been incorporated into various polymers to fabricate CPCs. With increasing conductive filler content, a jump in conductivity can be observed when a critical filler content is reached in the polymer matrix and this phenomenon is often termed the electrical percolation threshold, $p_{c}$. As shown by both theoretical and experimental studies, $p_{c}$ generally decreases with increasing filler aspect ratio. Therefore, efforts have been made to build conductive networks in a polymer matrix using large aspect ratio conductive fillers. Recently, since the advent of large aspect ratio and multifunctional conductive fillers, such as CNTs and graphene, this area has attracted increasing amounts of attention. Three different methods for the production of CPCs are available: melt blending, solvent blending and in situ polymerization. ${ }^{227}$ Hence an increasing number of conductive pCBT composites can be found in literature because the very low melt viscosity of CBT is considered favourable for the dispersion of conductive fillers.

$\mathrm{Li}$ et al. $^{73}$ prepared $\mathrm{pCBT/CNT}$ mat composites by dissolving CBT in chloroform and then impregnating a pre-stretched CNT mat with the solution. After 
drying the impregnated CNT mat was compression moulded at $250{ }^{\circ} \mathrm{C}$ for $15 \mathrm{~min}$. The thermal conductivity of pCBT containing 64 wt. $\%$ of pre-stretched CNT mat was around $90 \mathrm{~W} / \mathrm{m} \cdot \mathrm{K}$ at room temperature and decreased as the CNT mat content decreased. When the CNT mat content was 15 wt. $\%$, the thermal conductivity at room temperature of the composite dropped to $15 \mathrm{~W} / \mathrm{m} \cdot \mathrm{K}$. This is due to the fact that pCBT resin is a poor thermal conductor (thermal conductivity of pCBT is $0.15 \mathrm{~W} / \mathrm{m} \cdot \mathrm{K}$ according to Ref. ${ }^{191}$ ), and phonon modes within CNTs can be damped and scattered by the polymer matrix, reducing the thermal conductivity of the CNTs themselves. While pCBT has a high electrical resistivity of approximately $1015 \Omega \cdot m$, the electrical resistivity of the composite was dramatically enhanced to $1.9 \times 10^{-5} \Omega \cdot \mathrm{m}$ by introducing an aligned CNT mat.

Noh and associates published various papers ${ }^{155-159,191-193}$ on the thermal and electrical conductivity of pCBT. Carbon black (CB), CNT, CNT mat and G were used as conductive fillers and the $\mathrm{pCBT}$ nanocomposites were prepared using solvent-free powder mixing and subsequent in situ polymerization during compression moulding at $250{ }^{\circ} \mathrm{C} .^{157}$ The electrical conductivity of the nanocomposites was measured with respect to the MWCNT content and to three types of surface treatment of the MWCNTs, including acid, hydrogen peroxide and heat treatments. Results indicated that a lower resistivity and a higher electrical conductivity of MWCNTs were obtained for MWCNTs with structures that more closely resembled that of complete graphite. However, the electrical conductivity of the MWCNT/pCBT nanocomposites was not consistent with those results, which indicated that a correlation between the electrical conductivity of MWCNT fillers and MWCNT/PCBT nanocomposites was a minor factor. The acid treatment generated primarily carboxylic acid groups on the surface of the MWCNTs, and the hydrogen peroxide treatment generated primarily alcohol groups on the MWCNTs. The degree of functionalization of the heat treated 72 / 107 
MWCNTs was limited because the surface was slightly altered by the treatments. The different functionalities of the MWCNTs with different surface treatments altered the dispersion state of the incorporated MWCNTs in the MWCNT/pCBT nanocomposites, and the dispersion state was found to be the dominant physical factor that determined the electrical percolation behaviour of the nanocomposites. For the nanocomposites that contained pristine MWCNTs the percolation threshold was observed at a MWCNT loading of $3 \mathrm{wt} \%$. The percolation threshold of the hydrogen peroxide treated MWCNT/pCBT nanocomposites was lower than $1 \mathrm{wt} \%$, whereas the one of the heat treated MWCNT/pCBT nanocomposites was observed at the lowest MWCNT loading. In a follow-up work, ${ }^{155-156,}$ 191-192 the thermal conductivities of pCBT composites containing nanofillers such as $\mathrm{G}, \mathrm{CNT}$ and $\mathrm{CB}$ were experimentally and theoretically investigated. The experimentally measured thermal conductivity of those composites was compared with the predicted values obtained from micromechanics models, accounting for the effect of both wavy nanofillers and multiple heterogeneities. The theoretical results obtained from a modified Mori-Tanaka method micromechanics model corresponded well with the results obtained through experimentation. The low bulk thermal conductivity of pCBT nanocomposites was found to be due to the waviness of the incorporated MWCNTs and the weak interface between the MWCNTs and the matrix. Consequently, the thermal conductivity of polymeric composites is profoundly determined by the shapes of the conductive fillers. ${ }^{155}$ In case of $\mathrm{pCBT/G}$ nanocomposites, the in-plane thermal conductivity of composites containing 20 wt. \% of $\mathrm{G}$ was found to reach a maximum value of $1.98 \mathrm{~W} / \mathrm{m} \cdot \mathrm{K} .{ }^{191}$ Moreover, the same authors ${ }^{193}$ found that the thermal conductivity of composite materials can be synergistically enhanced by the simultaneous incorporation of well-dispersed pitch-based CF and G nanoplatelets into the matrix. The isotropic and in-plane thermal conductivity of the composite 
containing both uniformly dispersed 5 wt. $\%$ of CF and 15 wt. $\%$ of $\mathrm{G}$ achieved improvements of $82 \%$ and $183 \%$ when compared to those containing $20 \mathrm{wt} \%$ of $\mathrm{G}$, and improvements of $65 \%$ and $74 \%$ when compared to those containing $20 \mathrm{wt} \%$ of $\mathrm{CF}$, respectively. The synergistic improvement of the thermal conductivity was maximized at the optimized composition due to the most efficient formation of thermally-conductive pathways and internal structures favourable for phonon transport.

Song et al. ${ }^{228}$ studied the rheological properties, morphology, mechanical properties, electrical resistivity and electromagnetic interference shielding effectiveness of CBT/graphite/CB composites. After the addition of $50 \%$ of graphite, the electrical resistivity of the $\mathrm{pCBT/graphite} \mathrm{composite} \mathrm{was} \mathrm{found} \mathrm{to} \mathrm{be} \mathrm{reduced} \mathrm{to}$ $1.85 \Omega \cdot \mathrm{m}$. As the graphite content increased to $60 \%$, the electrical resistivity of PBT/graphite composite was further dropped to $0.33 \Omega \cdot \mathrm{m}$. This was related to the formation of more conductive paths in PBT composites. A large decrease in electrical resistivity appeared when some graphite was replaced by carbon black. For $50 \%$ of filler composites, the electrical resistivity of the pCBT composites decreased to 0.19 $\Omega \cdot \mathrm{m}$ when $5 \%$ of graphite was replaced by the $5 \%$ of $\mathrm{CB}$, which indicated that the $\mathrm{CB}$ has major effect on the conductivity properties of the $\mathrm{pCBT}$ composite. The minimum electrical resistivity appeared at the composite with $35 \%$ of graphite and 15 $\%$ of carbon black with $0.04 \Omega \cdot \mathrm{m}$.

Chen et al. ${ }^{188}$ prepared pCBT nanocomposites with TRGO by solvent blending in THF and subsequent polymerization at $200{ }^{\circ} \mathrm{C}$. The pCBT grafted onto TRGO was confirmed by various characterization techniques and the grafting content was found to be up to $53 \%$. The percolation threshold was found to be $1.6 \mathrm{wt} . \%$ of TRGO and the electrical conductivity was around $10^{-7} \mathrm{~S} / \mathrm{m}$ when the TRGO content was $3 \mathrm{wt} . \%$. 


\section{$7 \quad$ Miscellaneous use of CBT}

\subsection{Impact modifier}

Due to its low melt viscosity and thermoplastic nature, CBT can be used as additive for various thermoset resins, thermoplastics as well as for rubbers. Wang et al. ${ }^{229}$ synthesized a novel organotin initiator with amino-terminated hyperbranched polysiloxane (HSiSn) for the ROP of CBT. Compared with a traditional initiator, butyltin chloride dihydroxide (BCD, structure (II) in fig. 3), HSiSn had a moderate initiate speed, lower toxicity and good reactivity. Moreover, the pCBT initiated by HSiSn had better thermal stability than that by BCD. A series of CBT-toughened bismaleimide $(\mathrm{BD})$ resins $(\mathrm{HSiSn} / \mathrm{CBT}-\mathrm{BD})$ were prepared through the in situ formation of $\mathrm{pCBT}$ during the prepolymerization of BD resin with HSiSn. Compared with $\mathrm{BCD} / \mathrm{CBT}-\mathrm{BD}$ and $\mathrm{BD}$ resins, $\mathrm{HSiSn} / \mathrm{CBT}-\mathrm{BD}$ resins with small loadings of $\mathrm{CBT}$ ( $\leq 5$ wt $\%$ ) had remarkably improved integrated performances, including higher impact strengths, improved flexural, and tensile properties, better dielectric properties, and excellent heat resistance. These attractive performances were attributed to the unique cross-linked structure induced by HSiSn.

Davoodi and co-workers ${ }^{230}$ studied the effect of CBT on the impact properties of hybrid kenaf/glass epoxy composites. The epoxy resin was mixed with 5 wt.\% of CBT at a temperature of $220^{\circ} \mathrm{C}$. Then a hardener was added, the blend was sprayed on the fibre reinforcements and the composite was cured at $85^{\circ} \mathrm{C}$ in a hot plate press. It was found for the CBT-toughened composite that the Izod impact resistance improved by $54 \%$ while tensile and flexural properties decreased. 
A hydrogenated nitrile rubber (HNBR) was modified with CBT and the HNBR/CBT hybrids exhibited improved mechanical and triblogical properties compared to pristine HNBR. ${ }^{79-80,231}$ It was found that the CBT in the blends only partly polymerized at $190{ }^{\circ} \mathrm{C}$ and the CBT was predominantly recrystallized from its molten state. The well developed prism- and platy-like, micron-scaled CBT crystals effectively reinforced the HNBR/CBT hybrid.

\subsection{Viscosity modifier}

Uncatalysed CBT can be also used as a viscosity modifier for various highly viscous thermoplastic resins due to its inherently low melt viscosity. Tzounis et al. ${ }^{232}$ studied the influence of CBT on the processability and thermoelectric properties of polycarbonate/MWCNT nanocomposites. Preliminary TGA analysis of the carboxylfunctionalised MWCNT (referred to MWCNT-COOH) revealed that melt blending was limited to low temperatures due to thermal decomposition of the MWCNT functional groups. Therefore, PC was mixed with 2.5 wt\% MWCNT-COOH (PC/MWCNT$\mathrm{COOH}$ ) at $240{ }^{\circ} \mathrm{C}$ and $270{ }^{\circ} \mathrm{C}$. In order to reduce the polymer melt viscosity, uncatalysed CBT was utilized as a low molecular weight additive, improving additionally the electrical conductivity of the nanocomposites. The melt rheological characterization of neat PC and PC/CBT blends demonstrated a significant decrease of the complex viscosity due to the addition of CBT (10 wt.\%). Optical microscopy and TEM showed an improved MWCNT dispersion in the PC/CBT blend. The electrical conductivity was remarkably higher for the PC/MWCNT-COOH/CBT composites as compared to the PC/MWCNT-COOH ones. 


\subsection{Blend compatibilizer}

The fast polymerization kinetics and high reactivity of CBT are advantageous for the compatibilization of partially miscible polymer blends. Tripathy and co-workers ${ }^{117}$ prepared $\mathrm{pCBT/poly(vinyl} \mathrm{butyral)} \mathrm{(PVB)} \mathrm{blends} \mathrm{with} \mathrm{varying} \mathrm{compositions} \mathrm{and}$ compared them with physical blends of conventional PBT and PVB. It was found that the in situ prepared blend of pCBT/PVB exhibited one glass transition temperature and showed evidence of miscibility. In contrast, the conventional blend of PBT/PVB showed incompatibility after blending. The cause of miscibility in the pCBT/PVB blends was thought to be the formation of a graft copolymer.

\section{Concluding remarks}

Cyclic butylene terephthalate oligomers are a promising alternative for thermoset matrices employed in fibre reinforced composites and also for conventional thermoplastic matrices in nanocomposites due to their remarkably low melt viscosity prior to polymerization. This unique property of CBT allows for facile impregnation of both fibrous and nano-reinforcements. Moreover, isothermal processing of CBT with simultaneous polymerization and crystallization is possible. Nevertheless, the brittleness of pCBT is considerably higher as compared to conventional PBT, especially when processed isothermally below the melting temperature of pCBT $\left(\sim 225^{\circ} \mathrm{C}\right)$. For this reason, the toughening of pCBT has become of great interest 
because brittleness is an undesired property for structural materials and various toughening methods for $\mathrm{pCBT}$ are available. Since the ring-opening polymerization is conducted in situ, CBT can be readily used as building blocks for copolymerization as well as for chemical modification. The excellent wetting characteristics of CBT allow the production of nanocomposites based on carbon nanotubes, carbon black, graphite or graphene with good electrical and thermal conductivity. Unpolymerized CBT can be used as impact modifier, viscosity modifier or blend compatibilizer for various thermoplastic and thermoset resins due to its ultra-low melt viscosity. Another important advantage of CBT used in long fibre reinforced composites is that composite parts can be milled at the end of their life cycle and used as feedstock for short fibre reinforced PBT. Recently the automated injection moulding of cyclic oligomers has been developed. This technique paves the way to the mass production of highly cost-effective thermoplastic fibre reinforced composite parts with integrated stiffening and functional elements. In this respect, CBT could cover a wide range of applications, especially in sectors where weight reduction may be achieved through fibre reinforced thermoplastic composites on CBT basis.

\section{Acknowledgement}

The authors gratefully acknowledge the financial support received from the Spanish Government through the projects PSS-370000-2008-13 and MAT2013-40730-P.

\section{Nomenclature}




\begin{tabular}{|c|c|}
\hline BCD & Butyltin chloride dihydroxide \\
\hline BD & Bismaleimide \\
\hline CB & Carbon black \\
\hline CBT & Cyclic butylene terephthalate (tradename, Cyclics Inc.) \\
\hline CDP & Cyclo-depolymerization \\
\hline CF & Carbon fibre \\
\hline $\mathrm{CIS}$ & Charpy Impact Strength \\
\hline $\mathrm{Cl} 30 \mathrm{~B}$ & Cloisite 30B (tradename, Southern Clay Products Inc.) \\
\hline $\mathrm{CM}$ & Compression moulding \\
\hline CNT & Carbon nanotube \\
\hline CPC & Conductive polymer composite \\
\hline c-pCBT & Macrocyclic polymerized CBT \\
\hline DMTA & Dynamic mechanical thermal analysis \\
\hline DSC & Differential scanning calorimetry \\
\hline EP & Epoxy resin \\
\hline EVA & Poly(ethylene-co-vinyl acetate) \\
\hline FBG & Fibre Bragg grating \\
\hline FRP & Fibre reinforced polymer \\
\hline G & Graphene \\
\hline GF & Glass fibre \\
\hline GO & Graphite oxide \\
\hline GPC & Gel permeation chromatography \\
\hline HDI & Hexamethylene diisocyanate \\
\hline HNBR & Hydrogenated nitrile rubber \\
\hline HPLC & High pressure liquid chromatography \\
\hline HSiSn & $\begin{array}{l}\text { Amino-terminated hyperbranched polysiloxane } \\
\qquad 79 / 107\end{array}$ \\
\hline
\end{tabular}




\begin{tabular}{|c|c|}
\hline ILSS & Interlaminar shear strength \\
\hline IM & Injection moulding \\
\hline IM-PBT & Injection moulded PBT \\
\hline ISP-PBT & In situ polymerized PBT \\
\hline LCM & Liquid composite moulding \\
\hline MCO & Macrocyclic oligomer \\
\hline MDI & 4,4"-methylenebis(phenyl isocyanate) \\
\hline MDSC & Modulated DSC \\
\hline MWCNT & Multiwalled carbon nanotubes \\
\hline MWCNT-COOH & Carboxyl-functionalised MWCNT \\
\hline NCO & Isocyanate \\
\hline NMR & Nuclear magnetic resonance spectroscopy \\
\hline PA & Polyamide \\
\hline PBT & Poly(butylene terephthalate) \\
\hline PC & Polycarbonate \\
\hline pCBT & polymerized cyclic butylene terephthalate \\
\hline PCL & Polycaprolactone \\
\hline PEGMA & Poly(ethylene-co-glycidyl methacrylate) \\
\hline PET & Poly(ethylene terephthalate) \\
\hline PLM & Polarized light microscopy \\
\hline PLS & Polymer/layered silicate nanocomposites \\
\hline PMDI & Polymeric methylenebis(phenyl isocyanate) \\
\hline polyTHF & Polytetrahydrofuran \\
\hline $\begin{array}{l}\text { POSS } \\
\text { HybridPlastics) }\end{array}$ & Polyhedral oligomeric \\
\hline PVB & $\begin{array}{l}\text { Poly(vinyl butyral) } \\
\qquad 80 / 107\end{array}$ \\
\hline
\end{tabular}


RFI

Resin film infusion

ROP

Ring-opening polymerization

RP-pCBT

Reprocessed pCBT

SALS

Small-angle light scattering

SC

Solution casting

SMA

Superelastic shape memory alloy

SRIM

Structural reaction injection moulding

SWCNT

Single-walled carbon nanotube

TEM

Transmission electron microscopy

TGA

Thermogravimetric analysis

THF

Tetrahydrofuran

$T_{P}$

Polymerization temperature

TPC

Thermoplastic composite

TPE

Thermoplastic elastomer

TP-RTM

Thermoplastic resin transfer moulding

TRGO

Thermally reduced graphite oxide

VARI

Vacuum-assisted resin infusion

VI

Vacuum infusion

VOC

Volatile organic compound

WAXS

Wide-angle X-ray scattering

\section{References}

1. D.J. Brunelle, Cyclic oligomer chemistry. J. Polym. Sci., Part A: Polym. Chem., 2008. 46(4): p. 1151-1164.

2. A.J. Hall and P. Hodge, Recent research on the synthesis and applications of cyclic oligomers. Reactive and Functional Polymers, 1999. 41(1-3): p. 133139. 
3. K. Pang, R. Kotek and A. Tonelli, Review of conventional and novel polymerization processes for polyesters. Prog. Polym. Sci., 2006. 31(11): p. 1009-1037.

4. D. Brunelle, Cyclic Oligomers of Polycarbonates and Polyesters, in Cyclic Polymers, J.A. Semlyen, Editor. 2002, Springer Netherlands. p. 185-228.

5. J.W. Hill and W.H. Carothers, Cyclic and Polymeric Formals. J. Am. Chem. Soc., 1935. 57(5): p. 925-928.

6. E.W. Spanagel and W.H. Carothers, Macrocyclic Esters. J. Am. Chem. Soc., 1935. 57(5): p. 929-934.

7. G.C. East and A.M. Girshab, Cyclic oligomers in poly(1,4-butylene terephthalate). Polymer, 1982, 23(3): p. 323-324.

8. D.J. Brunelle, Macrocyclic OTigomers of Engineering Thermoplastics, in Encyclopedia of Materials: Science and Technology (Second Edition), K.H.J.B. Editors-in-Chief: , W.C. Robert, C.F. Merton, I. Bernard, J.K. Edward, M. Subhash, and V. Patrick, Editors. 2001, Elsevier: Oxford. p. 4712-4720.

9. A. Tullo, BEST OF BOTH WORLDS. Chemical \& Engineering News Archive, 2002. 80(44): p. 22.

10. H.J. Radusch, Poly(Butylene Terephthalate), in Handbook of Thermoplastic Polyesters. 2005, Wiley-VCH Verlag GmbH \& Co. KGaA. p. 389-419.

11. K. van Rijswijk and H.E.N. Bersee, Reactive processing of textile fiberreinforced thermoplastic composites - An overview. Composites Part A: Applied Science and Manufacturing, 2007. 38(3): p. 666-681.

12. F.C. Campbell, Chapter 10 - Thermoplastic composites: An unfulfilled promise, in Manufacturing Processes for Advanced Composites, F.C. Campbell, Editor. 2003, Elsevier Science: Amsterdam. p. 357-397.

13. D.J. Brunelle, Synthesis and Polymerization of Cyclic Polyester Oligomers, in Modern Polyesters: Chemistry and Technology of Polyesters and Copolyesters. 2004, John Wiley \& Sons, Ltd. p. 117-142.

14. S.-S. Lee, Y.T. Ma, H.-W. Rhee and J. Kim, Exfoliation of layered silicate facilitated by ring-opening reaction of cyclic oligomers in PET-clay nanocomposites. Polymer, 2005. 46(7): p. 2201-2210.

15. S. Pavlidou and C.D. Papaspyrides, A review on polymer-layered silicate nanocomposites. Prog. Polym. Sci., 2008. 33(12): p. 1119-1198.

16. R.J. Young, I.A. Kinloch, L. Gong and K.S. Novoselov, The mechanics of graphene nanocomposites: A review. Compos. Sci. Technol., 2012. 72(12): p. 1459-1476.

17. P. Hodge, Some applications of reactions which interconvert monomers, polymers and/or macrocycles. React. Funct. Polym., 2001. 48(1-3): p. 15-23.

18. J.J.L. Bryant and J.A. Semlyen, Cyclic polyesters: 7. Preparation and characterization of cyclic oligomers from solution ring-chain reactions of poly(butylene terephthalate). Polymer, 1997. 38(17): p. 4531-4537.

19. A.J. Hall and P. Hodge, Recent research on the synthesis and applications of cyclic oligomers. React. Funct. Polym., 1999. 41(1-3): p. 133-139.

20. P. Hodge and H.M. Colquhoun, Recent work on entropically-driven ringopening polymerizations: some potential applications. Polym. Adv. Technol., 2005. 16(2-3): p. 84-94.

21. S.D. Kamau, P. Hodge and M. Helliwell, Cyclo-depolymerization of poly(propylene terephthalate): Some ring-opening polymerizations of the cyclic oligomers produced. Polym. Adv. Technol., 2003. 14(7): p. 492-501.

22. P. Hodge, Entropically Driven Ring-Opening Polymerization of Strainless Organic Macrocycles. Chem. Rev., 2014. 
23. P. Hodge, Cyclodepolymerization as a method for the synthesis of macrocyclic oligomers. React. Funct. Polym., 2014. 80(0): p. 21-32.

24. M. Rösch, PBT Oligomers: Always in Good Form. Kunststoffe international, 2005. 2005(1): p. 91-93.

25. D.J. Brunelle and T. Takekoshi, Process for preparing macrocyclic polyester oligomers. U.S. Patent 5,407,984. (1995). 1995.

26. G.R. Faler, Methods for converting linear polyesters to macrocyclic oligoester compositions and macrocyclic oligoesters. Patent application WO2002018476 A3. (2002). 2002.

27. M. Shaaban, R.P. Maskey, I. Wagner-Döbler and H. Laatsch, Pharacine, a Natural p-Cyclophane and Other Indole Derivatives from Cytophaga sp. Strain AM13.11. J. Nat. Prod., 2002. 65(11): p. 1660-1663.

28. D.J. Brunelle, J.E. Bradt, J. Serth-Guzzo, T. Takekoshi, T.L. Evans, E.J. Pearce and P.R. Wilson, Semicrystalline Polymers via Ring-Opening Polymerization: Preparation and Polymerization of Alkylene Phthalate Cyclic Oligomers. Macromolecules, 1998. 31(15): p. 4782-4790.

29. Z.A. Mohd Ishak, K.G. Gatos and J. Karger-Kocsis, On the in-situ polymerization of cyclic butylene terephthalate oligomers: DSC and rheological studies. Polymer Engineering \& Science, 2006. 46(6): p. 743-750.

30. M. Steeg, P. Mitschang, P. Chakraborty and T. Hartmann. Modeling the viscosity and conversion of in-situ polymerizing PBT using empirical data. in In: Proceedings of 17th international conference on composite materials (ICCM-17). 2009. Edinburgh, UK.

31. H. Chen, W. Yu and C. Zhou, Entropically-driven ring-opening polymerization of cyclic butylene terephthalate: Rheology and kinetics. Polymer Engineering \& Science, 2012. 52(1): p. 91-101.

32. C.-M. Wu and C.-W. Huang, Melting and crystallization behavior of copolymer from cyclic butylene terephthalate and polycaprolactone. Polymer Engineering \& Science, 2011. 51(5): p. 1004-1013.

33. A.R. Tripathy, A. Elmoumni, H.H. Winter and W.J. MacKnight, Effects of catalyst and polymerization temperature on the in-situ polymerization of cyclic poly(butylene terephthalate) oligomers for composite applications. Macromolecules, 2005. 38(3): p. 709-715.

34. Cyclics. CBT®160. Datasheet, available online: www.cyclics.com. [Accessed Sep. 28, 2009].

35. Arkema. Fascat $₫ 4105$. Datasheet, available online: www.arkemainc.us. [Accessed Sep. 28, 2009].

36. C. Hakmé, I. Stevenson, A. Maazouz, P. Cassagnau, G. Boiteux and G. Seytre, In situ monitoring of cyclic butylene terephtalate polymerization by dielectric sensing. J. Non-Cryst. Solids, 2007. 353(47-51): p. 4362-4365.

37. J.-q. Zhang, Z.-f. Li, Z. Zhang, H.-x. Feng, Z.-b. Wang, Y. Li, P. Chen and Q. $\mathrm{Gu}$, Correlation between polymerization of cyclic butylene terephthalate (CBT) and crystallization of polymerized CBT. Chin. J. Polym. Sci., 2015. 33(8): p. 1104-1113.

38. B. Wunderlich, Crystallization during Polymerization. Angewandte Chemie International Edition in English, 1968. 7(12): p. 912-919.

39. B. Wunderlich, Crystallization during polymerization, in Fortschritte der Hochpolymeren-Forschung. 1968, Springer Berlin Heidelberg. p. 568-619.

40. J. Zhang, Z. Wang, B. Wang, Q. Gou, J. Zhang, J. Zhou, Y. Li, P. Chen and Q. $\mathrm{Gu}$, Living lamellar crystal initiating polymerization and brittleness mechanism investigations based on crystallization during the ring-opening of cyclic $83 / 107$ 
butylene terephthalate oligomers. Polymer Chemistry, 2013. 4(5): p. 16481656.

41. H. Parton, Characterization of the in-situ polymerization production process for continuous fibre reinforced thermoplastics, in Department of Metallurgy and Materials Engineering. 2006, Katholieke Universiteit Leuven: Leuven, Belgium.

42. M. Harsch, J. Karger-Kocsis and A.A. Apostolov, Crystallization-induced shrinkage, crystalline, and thermomechanical properties of in situ polymerized cyclic butylene terephthalate. J. Appl. Polym. Sci., 2008. 108(3): p. 1455-1461.

43. B. Lehmann and J. Karger-Kocsis, Isothermal and non-isothermal crystallisation kinetics of pCBT and PBT. J. Therm. Anal. Calorim., 2009. 95(1): p. 221-227.

44. M. Avrami, Kinetics of Phase Change. I General Theory. The Journal of Chemical Physics, 1939. 7(12): p. 1103-1112.

45. M. Avrami, Kinetics of Phase Change. II Transformation-Time Relations for Random Distribution of Nuclei. The Journal of Chemical Physics, 1940. 8(2): p. 212-224.

46. N. Dangseeyun, P. Srimoaon, P. Supaphol and M. Nithitanakul, Isothermal melt-crystallization and melting behavior for three linear aromatic polyesters. Thermochim. Acta, 2004. 409(1): p. 63-77.

47. C.-M. Wu and C.-W. Jiang, Crystallization and morphology of polymerized cyclic butylene terephthalate. J. Polym. Sci., Part B: Polym. Phys., 2010. 48(11): p. 1127-1134.

48. M. Steeg, Prozesstechnologie für Cyclic Butylene Terephthalate im FaserKunststoff-Verbund, in Fachbereich Maschinenbau und Verfahrenstechnik. 2009, Technische Universität Kaiserslautern: Kaiserslautern, Germany.

49. S.M. Coll, A.M. Murtagh and C.M. Ó Brádaigh. Resin Film Infusion of Cyclic PBT Composites: A Fundamental Study. in Proceedings of the SAMPE Europe 25th International Jubilee Conference, Paris, France. 2004.

50. A. Doyle, P. Feerick, P. Mallon, C. O'bradaigh and D. Doyle, A heated mould for moulding polymeric composites, a method for making such mould and its use. European Patent EP 2344312B1. (2012).

51. A. Doyle, J. Lee, E. Archer, K. Doyle, P. Feerick, S. Coll, B.C. O, A. Murtagh, P. Mallon and W.U.L. Stanley, Composite articles comprising in-situpolymerisable thermoplastic material and processes for their construction. European Patent Appliction EP 1880833 A1. (2008).

52. G. Bäck, P. Egger and L.F. Berg, Continuous fiber reinforced structural components: Combining polymerization and molding within a single machine. Kunststoffe international, 2012. 102(10): p. 102-105.

53. A. Luisier, P.E. Bourban and J.A.E. Månson, Time-temperaturetransformation diagram for reactive processing of polyamide 12. J. Appl. Polym. Sci., 2001. 81(4): p. 963-972.

54. P. Ó Máirtín, P. McDonnell, M.T. Connor, R. Eder and C.M. Ó Brádaigh, Process investigation of a liquid PA-12/carbon fibre moulding system. Composites Part A: Applied Science and Manufacturing, 2001. 32(7): p. 915923.

55. D. Hull, Matrix-dominated properties of polymer matrix composite materials. Materials Science and Engineering: A, 1994. 184(2): p. 173-183.

56. X. Chen, J. Xu, H. Lu and Y. Yang, Isothermal crystallization kinetics of poly(butylene terephthalate)/attapulgite nanocomposites. J. Polym. Sci., Part B: Polym. Phys., 2006. 44(15): p. 2112-2121. 
57. X.Q. Shi, K. Aimi, H. Ito, S. Ando and T. Kikutani, Characterization on mixedcrystal structure of poly(butylene terephthalate/succinate/adipate) biodegradable copolymer fibers. Polymer, 2005. 46(3): p. 751-760.

58. M. Yasuniwa, S. Tsubakihara, K. Ohoshita and S.I. Tokudome, X-ray studies on the double melting behavior of poly(butylene terephthalate). J. Polym. Sci., Part B: Polym. Phys., 2001. 39(17): p. 2005-2015.

59. M. Yokouchi, Y. Sakakibara, Y. Chatani, H. Tadokoro, T. Tanaka and K. Yoda, Structures of Two Crystalline Forms of Poly(butylene terephthalate) and Reversible Transition between Them by Mechanical Deformation. Macromolecules, 1976. 9(2): p. 266-273.

60. M. Moneke, Die Kristallisation von verstärkten Thermoplasten während der schnellen Abkühlung und unter Druck. 2001, TU Darmstadt: Darmstadt.

61. P.H. Geil, Crystal Structure, Morphology, and Orientation of Polyesters: Section 2.2, in Handbook of Thermoplastic Polyesters. 2005, Wiley-VCH Verlag GmbH \& Co. KGaA. p. 154-167.

62. R.S. Stein and A. Misra, Morphological studies on polybutylene terephthalate. Journal of Polymer Science: Polymer Physics Edition, 1980. 18(2): p. 327-342.

63. H. Parton, J. Baets, P. Lipnik, B. Goderis, J. Devaux and I. Verpoest, Properties of poly(butylene terephthatlate) polymerized from cyclic oligomers and its composites. Polymer, 2005. 46(23): p. 9871-9880.

64. S. Miller, Macrocyclic polymers from cyclic oligomers of poly(butylene terephthalate). 1998, University of Massachusetts Amherst: Amherst, USA.

65. J. Karger-Kocsis, P.P. Shang, Z.A. Mohd Ishak and M. Rösch, Melting and crystallization of in-situ polymerized cyclic butylene terephthalates with and without organoclay: A modulated DSC study. eXPRESS Polymer Letters, 2007. 1(2): p. 60-68.

66. Z.A. Mohd Ishak, Y.W. Leong, M. Steeg and J. Karger-Kocsis, Mechanical properties of woven glass fabric reinforced in situ polymerized poly(butylene terephthalate) composites. Compos. Sci. Technol., 2007. 67(3-4): p. 390-398.

67. Z.A. Mohd Ishak, P.P. Shang and J. Karger-Kocsis, A modulated dsc study on the in situ polymerization of cyclic butylene terephthalate oligomers. J. Therm. Anal. Calorim., 2006. 84(3): p. 637-641.

68. A.R. Tripathy, W.J. MacKnight and S.N. Kukureka, In-Situ Copolymerization of Cyclic Poly(butylene terephthalate) Oligomers and $\varepsilon$-Caprolactone. Macromolecules, 2004. 37(18): p. 6793-6800.

69. H. Parton and I. Verpoest, In situ polymerization of thermoplastic composites based on cyclic oligomers. Polym. Compos., 2005. 26(1): p. 60-65.

70. J. Baets, Toughening of in-situ polymerized cyclic butyleneterephthalate for use in continuous fiber reinforced thermoplastic composites, in Department of Metallurgy and Materials Engineering. 2008, Katholieke Universiteit Leuven: Leuven, Belgium.

71. T. Abt, M. Sánchez-Soto and A. Martínez de Ilarduya, Toughening of in-situ polymerized cyclic butylene terephthalate by chain extension with a bifunctional epoxy resin. Eur. Polym. J., 2012. 48: p. 163-171.

72. G. Balogh, Development of cyclic butylene terephthalate matrix composites, in Department of Polymer Engineering. 2012, Budapest University of Technology and Economics: Budapest, Hungary.

73. Z. Li, R. Downes and Z. Liang, In Situ Polymerized pCBT Composites with Aligned Carbon Nanotube Buckypaper: Structure and Properties. Macromol. Chem. Phys., 2015. 216(3): p. 292-300. 
74. H.J. Ludwig and P. Eyerer, Influence of the processing conditions on morphology and deformation behavior of poly(butylene terephthalate) (PBT). Polymer Engineering \& Science, 1988. 28(3): p. 143-146.

75. J. Zhang, Study of poly(trimethylene terephthalate) as an engineering thermoplastics material. J. Appl. Polym. Sci., 2004. 91(3): p. 1657-1666.

76. T. Yu, C.M. Wu, C.Y. Chang, C.Y. Wang and S.P. Rwei, Effects of crystalline morphologies on the mechanical properties of carbon fiber reinforcing polymerized cyclic butylene terephthalate composites. eXPRESS Polymer Letters, 2012. 6(4): p. 318-328.

77. L. Mandelkern, The Relation between Structure and Properties of Crystalline Polymers. Polym. J., 1985. 17(1): p. 337-350.

78. L. Mandelkern, The structure of crystalline polymers. Acc. Chem. Res., 1990. 23(11): p. 380-386.

79. D. Xu and J. Karger-Kocsis, Rolling and sliding wear properties of hybrid systems composed of uncured/cured HNBR and partly polymerized cyclic butylene terephthalate (CBT). Tribology International. 43(1-2): p. 289-298.

80. D. Xu, J. Karger-Kocsis and A.A. Apostolov, Hybrids from HNBR and in situ polymerizable cyclic butylene terephthalate (CBT): Structure and rolling wear properties. Eur. Polym. J., 2009. 45(4): p. 1270-1281.

81. D.N. Bikiaris and G.P. Karayannidis, Effect of carboxylic end groups on thermooxidative stability of PET and PBT. Polym. Degrad. Stab., 1999. 63(2): p. 213-218.

82. L.E. Nielsen and R.F. Landel, Mechanical Properties of Polymers and Composites. 2nd ed. ed. 1994, New York: Marcel Dekker.

83. J. Baets, A. Godara, J. Devaux and I. Verpoest, Toughening of polymerized cyclic butylene terephthalate with carbon nanotubes for use in composites. Composites Part A: Applied Science and Manufacturing, 2008. 39(11): p. 1756-1761.

84. J. Baets, A. Godara, J. Devaux and I. Verpoest, Toughening of isothermally polymerized cyclic butylene terephthalate for use in composites. Polym. Degrad. Stab., 2010. 95(3): p. 346-352.

85. G. Broza, M. Kwiatkowska, Z. Rosłaniec and K. Schulte, Processing and assessment of poly(butylene terephthalate) nanocomposites reinforced with oxidized single wall carbon nanotubes. Polymer, 2005. 46(16): p. 5860-5867.

86. P.I. Vincent, The tough-brittle transition in thermoplastics. Polymer, 1960. 1(0): p. 425-444.

87. M. Xanthos, Reactive Modification/Compatibilization of Polyesters, in Handbook of Thermoplastic Polyesters. 2005, Wiley-VCH Verlag GmbH \& Co. KGaA. p. 815-833.

88. H.F. Mark, Supplemental Articles: Polymer Blends, in Encyclopedia of Polymer Science and Technology, Concise, 3rd Edition., H.F. Mark, Editor. 2005, Wiley-Interscience. p. $36 \mathrm{ff}$.

89. J. Baets, J. Devaux and I. Verpoest, Toughening of basalt fiber-reinforced composites with a cyclic butylene terephthalate matrix by a nonisothermal production method. Adv. Polym. Tech., 2010. 29(2): p. 70-79.

90. C. Dell'Olio, S. Leonard, B. Dao, R. Varley and K. Pingkarawat, Effect of modification of cyclic butylene terephthalate on crystallinity and properties after ring-opening polymerisation. J Mater Sci, 2015. 50(24): p. 8073-8088.

91. T. Abt, M. Sánchez-Soto, S. Illescas, J. Aurrekoetxea and M. Sarrionandia, Toughening of in situ polymerized cyclic butylene terephthalate by addition of tetrahydrofuran. Polym. Int., 2011. 60(4): p. 549-556.

$86 / 107$ 
92. A. Aróstegui and J. Nazábal, Compatibilization of a poly(butylene terephthalate)/poly(ethylene octene) copolymer blends with different amounts of an epoxy resin. J. Appl. Polym. Sci., 2004. 91(1): p. 260-269.

93. D.N. Bikiaris and G.P. Karayannidis, Chain extension of polyesters PET and PBT with two new diimidodiepoxides. II. J. Polym. Sci., Part A: Polym. Chem., 1996. 34(7): p. 1337-1342.

94. B. Guo and C.-M. Chan, Chain extension of poly(butylene terephthalate) by reactive extrusion. J. Appl. Polym. Sci., 1999. 71(11): p. 1827-1834.

95. X. Tang, W. Guo, G. Yin, B. Li and C. Wu, Reactive extrusion of recycled poly(ethylene terephthalate) with polycarbonate by addition of chain extender. J. Appl. Polym. Sci., 2007. 104(4): p. 2602-2607.

96. M. Xanthos, M.W. Young, G.P. Karayanndis and D.N. Bikiaris, Reactive modification of polyethylene terephthalate with polyepoxides. Polymer Engineering \& Science, 2001. 41(4): p. 643-655.

97. R.R. Dhavalikar, Reactive melt modification of polyethylene terephthalate, in Department of Chemical Engineering. 2003, New Jersey Institute of Technology: Newark, NJ, USA.

98. H. Inata and S. Matsumura, Chain extenders for polyesters. I. Addition-type chain extenders reactive with carboxyl end groups of polyesters. J. Appl. Polym. Sci., 1985. 30(8): p. 3325-3337.

99. H. Inata and S. Matsumura, Chain extenders for polyester. II. Reactivities of carboxyl-addition-type chain extenders; bis cyclic-imino-ethers. J. Appl. Polym. Sci., 1986. 32(5): p. 5193-5202.

100. H. Inata and S. Matsumura, Chain extenders for polyesters. III. Addition-type nitrogen-containing chain extenders reactive with hydroxyl end groups of polyesters. J. Appl. Polym. Sci., 1986. 32(4): p. 4581-4594.

101. H. Inata and S. Matsumura, Chain extenders for polyesters. IV. Properties of the polyesters chain-extended by 2,2'-bis(2-oxazoline). J. Appl. Polym. Sci., 1987. 33(8): p. 3069-3079.

102. H. Inata and S. Matsumura, Chain extenders for polyesters. V. Reactivities of hydroxyl-addition-type chain extender; 2,2'-bis(4h-3,1-benzoxazin-4-one). J. Appl. Polym. Sci., 1987. 34(7): p. 2609-2617.

103. H. Inata and S. Matsumura, Chain extenders for polyesters. VI. Properties of the polyesters chain-extended by 2,2'-bis(4H-3,1-benzoxazin-4-one). J. Appl. Polym. Sci., 1987. 34(8): p. 2769-2776.

104. S. Maier, Carbonylbiscaprolactam (CBC): Isocyanat-freier Zugang zu blockierten Isocyanaten, Blockcopolymeren und reaktiven Dispersionen, in Institut für Makromolekulare Chemie 2003, Albert-Ludwigs-Universität Freiburg im Breisgau: Freiburg im Breisgau, Germany.

105. D.J. Brunelle, Method for polymerizing macrocyclic polyester oligomers. U.S. Patent 5,498,651. (1996).

106. R.P. Dion, D.H. Bank, M.C. Beebe, P. Walia, C. LeBaron, J.D. Oelberg, M.A. Barger, M.S. Paquette and M.D. Read, Polymerized macrocyclic oligomer nanocomposite compositions. U.S. Patent Application US 2005/0059768 A1. (2005).

107. T. Takekoshi, P.D. Phelps, Y. Wang and S.J. Winckler, Methods for polymerizing macrocyclic polyester oligomers using catalyst promoters. U.S. Patent Application Publication US 2006/0115666 A1. (2006).

108. T. Abt, A.M. de Ilarduya, J.J. Bou and M. Sanchez-Soto, Isocyanate toughened pCBT: Reactive blending and tensile properties. eXPRESS Polymer Letters, 2013. 7(2): p. 172-185. 
109. T. Abt, Study of the properties of modified cyclic butylene terephthalate and its composites, in Departament de Ciència dels Materials i Enginyeria Metal·lúrgica. 2014, Universitat Politècnica de Catalunya: Barcelona, Spain.

110. Y.M. Mozheiko, Properties of Block Copolymers of Poly(Butylene Terephthalate) and Polyoxytetramethylene Glycol. Fibre Chemistry, 2002. 34(4): p. 254-259.

111. J. Devroede, Study of the THF formation during the TPA-based synthesis of PBT, in Dutch Polymer Institute. 2007, Technische Universiteit Eindhoven: Eindhoven, Netherlands.

112. E. Maréchal, Creation and Development of Thermoplastic Elastomers, and Their Position among Organic Materials, in Handbook of Condensation Thermoplastic Elastomers. 2006, Wiley-VCH Verlag GmbH \& Co. KGaA. p. 131.

113. Y. Nagai, T. Ogawa, Y. Nishimoto and F. Ohishi, Analysis of weathering of a thermoplastic polyester elastomer II. Factors affecting weathering of a polyether-polyester elastomer. Polym. Degrad. Stab., 1999. 65(2): p. 217-224.

114. Y. Nagai, T. Ogawa, L. Yu Zhen, Y. Nishimoto and F. Ohishi, Analysis of weathering of thermoplastic polyester elastomers-l. Polyether-polyester elastomers. Polym. Degrad. Stab., 1997. 56(1): p. 115-121.

115. R.P. Quirk, G. Holden and H.R. Kricheldorf, Thermoplastic Elastomers. 2004: Hanser.

116. W. Bahloul, V. Bounor-Legare, F. Fenouillot and P. Cassagnau, EVA/PBT nanostructured blends synthesized by in situ polymerization of cyclic cBT (cyclic butylene terephthalate) in molten EVA. Polymer, 2009. 50(12): p. 25272534.

117. A.R. Tripathy, W.J. Chen, S.N. Kukureka and W.J. MacKnight, Novel poly(butylene terephthalate)/poly(vinyl butyral) blends prepared by in situ polymerization of cyclic poly(butylene terephthalate) oligomers. Polymer, 2003. 44(6): p. 1835-1842.

118. J. Baets, M. Dutoit, J. Devaux and I. Verpoest, Toughening of glass fiber reinforced composites with a cyclic butylene terephthalate matrix by addition of polycaprolactone. Composites Part A: Applied Science and Manufacturing, 2008. 39(1): p. 13-18.

119. A.R. Tripathy, R.J. Farris and W.J. MacKnight, Novel fire resistant matrixes for composites from cyclic poly(butylene terephthalate) oligomers. Polymer Engineering \& Science, 2007. 47(10): p. 1536-1543.

120. G.W. Ehrenstein, Polymeric Materials. Polymeric Materials. 2001: Carl Hanser Verlag GmbH \& Co. KG. 277.

121. S. Samsudin, S. Kukureka and M. Jenkins, The equilibrium melting temperature and isothermal crystallisation kinetics of cyclic poly(butylene terephthalate) and styrene maleimide (c-PBT/SMI) blends. J. Therm. Anal. Calorim., 2013. 114(3): p. 1307-1315.

122. S.A. Samsudin, The thermal behaviour and isothermal crystallisation of cyclic poly(butylene terephthalate) and its blends., in School of Metallurgy and Materials. 2010, University of Birmingham: Birmingham, England.

123. S.A. Samsudin, S.N. Kukureka and M.J. Jenkins, Miscibility in cyclic poly(butylene terephthalate) and styrene maleimide blends prepared by soliddispersion and in situ polymerization of cyclic butylene terephthalate oligomers within styrene maleimide. J. Appl. Polym. Sci., 2012. 126(S2): p. E290-E297. 
124. M. Alexandre and P. Dubois, Polymer-layered silicate nanocomposites: preparation, properties and uses of a new class of materials. Materials Science and Engineering: R: Reports, 2000. 28(1-2): p. 1-63.

125. P. Kiliaris and C.D. Papaspyrides, Polymer/layered silicate (clay) nanocomposites: An overview of flame retardancy. Prog. Polym. Sci., 2010. 35(7): p. 902-958.

126. S. Sinha Ray and M. Okamoto, Polymer/layered silicate nanocomposites: a review from preparation to processing. Prog. Polym. Sci., 2003. 28(11): p. 1539-1641.

127. J.R. Potts, D.R. Dreyer, C.W. Bielawski and R.S. Ruoff, Graphene-based polymer nanocomposites. Polymer, 2011. 52(1): p. 5-25.

128. V. Singh, D. Joung, L. Zhai, S. Das, S.I. Khondaker and S. Seal, Graphene based materials: Past, present and future. Prog. Mater Sci., 2011. 56(8): p. 1178-1271.

129. J.K.W. Sandler and M.S.P. Shaffer, Carbon Nanotube/Nanofibre Polymer Composites, in Processing and Properties of Nanocomposites. p. 1-59.

130. J.N. Coleman, U. Khan and Y.K. Gun'ko, Mechanical Reinforcement of Polymers Using Carbon Nanotubes. Adv. Mater., 2006. 18(6): p. 689-706.

131. M. Joshi and B.S. Butola, Polymeric Nanocomposites-Polyhedral Oligomeric Silsesquioxanes (POSS) as Hybrid Nanofiller. Journal of Macromolecular Science, Part C, 2004. 44(4): p. 389-410.

132. S.-W. Kuo and F.-C. Chang, POSS related polymer nanocomposites. Prog. Polym. Sci., 2011. 36(12): p. 1649-1696.

133. J. Wu and P.T. Mather, POSS Polymers: Physical Properties and Biomaterials Applications. Polymer Reviews, 2009. 49(1): p. 25-63.

134. C. Berti, M. Fiorini and L. Sisti, Synthesis of poly(butylene terephtahlate) nanocomposites using anionic clays. Eur. Polym. J., 2009. 45(1): p. 70-78.

135. Y.-W. Chang, S. Kim and Y. Kyung, Poly(butylene terephthalate)-clay nanocomposites prepared by melt intercalation: morphology and thermomechanical properties. Polym. Int., 2005. 54(2): p. 348-353.

136. S.-s. Hwang, S.-p. Liu, P.P. Hsu, J.-m. Yeh, K.-c. Chang and Y.-z. Lai, Effect of organoclay on the mechanical/thermal properties of microcellular injection molded PBT-clay nanocomposites. International Communications in Heat and Mass Transfer, 2010. 37(8): p. 1036-1043.

137. X. Li, T. Kang, W.-J. Cho, J.-K. Lee and C.-S. Ha, Preparation and Characterization of Poly(butyleneterephthalate)/Organoclay Nanocomposites. Macromol. Rapid Commun., 2001. 22(16): p. 1306-1312.

138. J. Xiao, Y. Hu, Z. Wang, Y. Tang, Z. Chen and W. Fan, Preparation and characterization of poly(butylene terephthalate) nanocomposites from thermally stable organic-modified montmorillonite. Eur. Polym. J., 2005. 41(5): p. 1030-1035.

139. C. Berti, E. Binassi, M. Colonna, M. Fiorini, T. Zuccheri, S. Karanam and D. J. Brunelle, Improved dispersion of clay platelets in poly(butylene terephthalate) nanocomposite by ring-opening polymerization of cyclic oligomers: Effect of the processing conditions and comparison with nanocomposites obtained by melt intercalation. J. Appl. Polym. Sci., 2009. 114(5): p. 3211-3217.

140. R.P. Dion, D.H. Bank, M.C. Beebe, P. Walia, C. LeBaron, J.D. Oelberg, M.A. Barger, M.S. Paquette and M.D. Read, Polymerized macrocyclic oligomer nanocomposite compositions. U.S. Patent Application US 2005/0059768 A1. 2005. 
141. Y. Hong, H. Yoon and S. Lim, Preparation of PBT/clay nanocomposites using supercritical process. Int. J. Precis. Eng. Manuf., 2009. 10(3): p. 115-118.

142. G. Lanciano, A. Greco, A. Maffezzoli and L. Mascia, Effects of thermal history in the ring opening polymerization of CBT and its mixtures with montmorillonite on the crystallization of the resulting poly(butylene terephthalate). Thermochim. Acta, 2009. 493(1-2): p. 61-67.

143. A. McLauchlin, X. Bao and F. Zhao, Organoclay polybutylene terephthalate nanocomposites using dual surfactant modified montmorillonite prepared by the masterbatch method. Applied Clay Science, 2011. 53(4): p. 749-753.

144. A.R. Tripathy, E. Burgaz, S.N. Kukureka and W.J. MacKnight, Poly(butylene terephthalate) nanocomposites prepared by in-situ polymerization. Macromolecules, 2003. 36(23): p. 3.

145. C. Wan, F. Zhao, X. Bao, B. Kandasubramanian and M. Duggan, Surface Characteristics of Polyhedral Oligomeric Silsesquioxane Modified Clay and Its Application in Polymerization of Macrocyclic Polyester Oligomers. The Journal of Physical Chemistry B, 2008. 112(38): p. 11915-11922.

146. F.M. Wu and G.S. Yang, Poly(butylene terephthalate)/organoclay nanocomposites prepared by in-situ bulk polymerization with cyclic poly(butylene terephthalate). Mater. Lett., 2009. 63(20): p. 1686-1688.

147. T. Abt, J.J. Bou and M. Sanchez-Soto, Isocyanate toughening of pCBT/organoclay nanocomposites with exfoliated structure and enhanced mechanical properties. eXPRESS Polymer Letters, 2014. 8(12): p. 953-966.

148. C. Soldano, A. Mahmood and E. Dujardin, Production, properties and potential of graphene. Carbon, 2010. 48(8): p. 2127-2150.

149. E.T. Thostenson, Z. Ren and T.-W. Chou, Advances in the science and technology of carbon nanotubes and their composites: a review. Compos. Sci. Technol., 2001. 61(13): p. 1899-1912.

150. D. Wu, L. Wu, G. Yu, B. Xu and M. Zhang, Crystallization and thermal behavior of multiwalled carbon nanotube/poly(butylenes terephthalate) composites. Polymer Engineering \& Science, 2008. 48(6): p. 1057-1067.

151. G. Romhány, J. Vígh, R. Thomann, J. Karger-Kocsis and I.E. Sajó, pCBT/MWCNT Nanocomposites Prepared by In situ Polymerization of CBT After Solid-Phase High-Energy Ball Milling of CBT with MWCNT. Macromolecular Materials and Engineering, 2011. 296(6): p. 544-550.

152. H. Fang and F. Wu, Nonisothermal crystallization kinetics of poly(butylene terephthalate)/multiwalled carbon nanotubes nanocomposites prepared by in situ polymerization. J. Appl. Polym. Sci., 2014. 131(19): p. n/a-n/a.

153. F. Wu and G. Yang, Synthesis and properties of poly(butylene terephthalate)/multiwalled carbon nanotube nanocomposites prepared by in situ polymerization and in situ compatibilization. J. Appl. Polym. Sci., 2010. 118(5): p. 2929-2938.

154. F. Wu and G. Yang, Poly(butylene terephthalate)-functionalized MWNTs by in situ ring-opening polymerization of cyclic butylene terephthalate oligomers. Polym. Adv. Technol., 2011. 22(10): p. 1466-1470.

155. S.Y. Kim, Y.J. Noh and J. Yu, Improved thermal conductivity of polymeric composites fabricated by solvent-free processing for the enhanced dispersion of nanofillers and a theoretical approach for composites containing multiple heterogeneities and geometrized nanofillers. Compos. Sci. Technol., 2014. 101(0): p. 79-85.

156. S.Y. Kim, Y.J. Noh and J. Yu, Prediction and experimental validation of electrical percolation by applying a modified micromechanics model $90 / 107$ 
considering multiple heterogeneous inclusions. Compos. Sci. Technol., 2015. 106(0): p. 156-162.

157. Y.J. Noh, S.Y. Pak, S.H. Hwang, J.Y. Hwang, S.Y. Kim and J.R. Youn, Enhanced dispersion for electrical percolation behavior of multi-walled carbon nanotubes in polymer nanocomposites using simple powder mixing and in situ polymerization with surface treatment of the fillers. Compos. Sci. Technol., 2013. 89(0): p. 29-37.

158. Y. Noh, H. Kim and S. Kim, Carbon nanotube mat reinforced thermoplastic composites with a polymerizable, low-viscosity cyclic butylene terephthalate matrix. Macromol. Res., 2014. 22(11): p. 1183-1189.

159. Y.J. Noh, H.S. Kim and S.Y. Kim, Improved Electrical Conductivity of a Carbon Nanotube Mat Composite Prepared by In-Situ Polymerization and Compression Molding with Compression Pressure. Carbon letters 2012. 13(4): p. 243-247.

160. M. Sánchez-Soto, D.A. Schiraldi and S. Illescas, Study of the morphology and properties of melt-mixed polycarbonate-POSS nanocomposites. Eur. Polym. J., 2009. 45(2): p. 341-352.

161. Y. Zhao and D.A. Schiraldi, Thermal and mechanical properties of polyhedral oligomeric silsesquioxane (POSS)/polycarbonate composites. Polymer, 2005. 46(25): p. 11640-11647.

162. A. Fina, D. Tabuani, T. Peijs and G. Camino, POSS grafting on PPgMA by one-step reactive blending. Polymer, 2009. 50(1): p. 218-226.

163. R. Misra, A.H. Alidedeoglu, W.L. Jarrett and S.E. Morgan, Molecular miscibility and chain dynamics in POSS/polystyrene blends: Control of POSS preferential dispersion states. Polymer, 2009. 50(13): p. 2906-2918.

164. A. Romo-Uribe, P.T. Mather, T.S. Haddad and J.D. Lichtenhan, Viscoelastic and morphological behavior of hybrid styryl-based polyhedral oligomeric silsesquioxane (POSS) copolymers. J. Polym. Sci., Part B: Polym. Phys., 1998. 36(11): p. 1857-1872.

165. W. Zhang, B.X. Fu, Y. Seo, E. Schrag, B. Hsiao, P.T. Mather, N.-L. Yang, D. $\mathrm{Xu}, \mathrm{H}$. Ade, M. Rafailovich and J. Sokolov, Effect of Methyl Methacrylate/Polyhedral Oligomeric Silsesquioxane Random Copolymers in Compatibilization of Polystyrene and Poly(methyl methacrylate) Blends. Macromolecules, 2002. 35(21): p. 8029-8038.

166. J.-H. Chen, B.-X. Yao, W.-B. Su and Y.-B. Yang, Isothermal crystallization behavior of isotactic polypropylene blended with small loading of polyhedral oligomeric silsesquioxane. Polymer, 2007. 48(6): p. 1756-1769.

167. K.-W. Huang, L.-W. Tsai and S.-W. Kuo, Influence of octakis-functionalized polyhedral oligomeric silsesquioxanes on the physical properties of their polymer nanocomposites. Polymer, 2009. 50(20): p. 4876-4887.

168. R. Verker, E. Grossman, I. Gouzman and N. Eliaz, TriSilanolPhenyl POSSpolyimide nanocomposites: Structure-properties relationship. Compos. Sci. Technol., 2009. 69(13): p. 2178-2184.

169. K. Zeng, Y. Liu and S. Zheng, Poly(ethylene imine) hybrids containing polyhedral oligomeric silsesquioxanes: Preparation, structure and properties. Eur. Polym. J., 2008. 44(12): p. 3946-3956.

170. L. Zheng, R.J. Farris and E.B. Coughlin, Novel Polyolefin Nanocomposites: Synthesis and Characterizations of Metallocene-Catalyzed Polyolefin Polyhedral Oligomeric Silsesquioxane Copolymers. Macromolecules, 2001. 34(23): p. 8034-8039. 
171. F.C.L. Ciolacu, N.R. Choudhury, N. Dutta and E. Kosior, Molecular Level Stabilization of Poly(ethylene terephthalate) with Nanostructured Open Cage Trisilanolisobutyl-POSS. Macromolecules, 2006. 40(2): p. 265-272.

172. J.K. Kim, K.H. Yoon, D.S. Bang, Y.-B. Park, H.-U. Kim and Y.-H. Bang, Morphology and rheological behaviors of poly(ethylene terephthalate) nanocomposites containing polyhedral oligomeric silsesquioxanes. J. Appl. Polym. Sci., 2008. 107(1): p. 272-279.

173. H. Sirin, D. Turan, G. Ozkoc and S. Gurdag, POSS reinforced PET based composite fibers: "Effect of POSS type and loading level". Composites Part B: Engineering, 2013. 53(0): p. 395-403.

174. A. Vannier, S. Duquesne, S. Bourbigot, A. Castrovinci, G. Camino and R. Delobel, The use of POSS as synergist in intumescent recycled poly(ethylene terephthalate). Polym. Degrad. Stab., 2008. 93(4): p. 818-826.

175. K.H. Yoon, M.B. Polk, J.H. Park, B.G. Min and D.A. Schiraldi, Properties of poly(ethylene terephthalate) containing epoxy-functionalized polyhedral oligomeric silsesquioxane. Polym. Int., 2005. 54(1): p. 47-53.

176. J. Zeng, S. Kumar, S. Iyer, D.A. Schiraldi and R.I. Gonzalez, Reinforcement of Poly(ethylene terephthalate) Fibers with Polyhedral Oligomeric Silsesquioxanes (POSS). High Perform. Polym., 2005. 17(3): p. 403-424.

177. N. Hao, M. Böhning, H. Goering and A. Schönhals, Nanocomposites of Polyhedral Oligomeric Phenethylsilsesquioxanes and Poly(bisphenol A carbonate) as Investigated by Dielectric Spectroscopy. Macromolecules, 2007. 40(8): p. 2955-2964.

178. E.S. Cozza, Q. Ma, O. Monticelli and P. Cebe, Nanostructured nanofibers based on PBT and POSS: Effect of POSS on the alignment and macromolecular orientation of the nanofibers. Eur. Polym. J., 2013. 49(1): p. 33-40.

179. Z. Zhou, N. Yin, Y. Zhang and Y. Zhang, Properties of poly(butylene terephthalate) chain-extended by epoxycyclohexyl polyhedral oligomeric silsesquioxane. J. Appl. Polym. Sci., 2008. 107(2): p. 825-830.

180. T. Abt, M. Sánchez-Soto, S. Illescas and A. Arostegui, Properties of POSS blends with pCBT, PMMA, PC and POM thermoplastics. International Journal of Materials and Structural Integrity, 2013. 7(Nos. 1/2/3): p. 48-78.

181. F. Wu, T. Xie and G. Yang, Characterization of PBT/POSS nanocomposites prepared by in situ polymerization of cyclic poly(butylene terephthalate) initiated by functionalized POSS. J. Polym. Sci., Part B: Polym. Phys., 2010. 48(16): p. 1853-1859.

182. T. Kuila, S. Bose, A.K. Mishra, P. Khanra, N.H. Kim and J.H. Lee, Chemical functionalization of graphene and its applications. Prog. Mater Sci., 2012. 57(7): p. 1061-1105.

183. T. Kuilla, S. Bhadra, D. Yao, N.H. Kim, S. Bose and J.H. Lee, Recent advances in graphene based polymer composites. Prog. Polym. Sci., 2010. 35(11): p. 1350-1375.

184. W.S. Hummers and R.E. Offeman, Preparation of Graphitic Oxide. J. Am. Chem. Soc., 1958. 80(6): p. 1339-1339.

185. S. Stankovich, R.D. Piner, S.T. Nguyen and R.S. Ruoff, Synthesis and exfoliation of isocyanate-treated graphene oxide nanoplatelets. Carbon, 2006. 44(15): p. 3342-3347.

186. S. Stankovich, D.A. Dikin, R.D. Piner, K.A. Kohlhaas, A. Kleinhammes, Y. Jia, Y. Wu, S.T. Nguyen and R.S. Ruoff, Synthesis of graphene-based nanosheets 
via chemical reduction of exfoliated graphite oxide. Carbon, 2007. 45(7): p. 1558-1565.

187. S. Stankovich, D.A. Dikin, G.H.B. Dommett, K.M. Kohlhaas, E.J. Zimney, E.A. Stach, R.D. Piner, S.T. Nguyen and R.S. Ruoff, Graphene-based composite materials. Nature, 2006. 442(7100): p. 282-286.

188. H. Chen, C. Huang, W. Yu and C. Zhou, Effect of thermally reduced graphite oxide ( $\operatorname{TrGO}$ ) on the polymerization kinetics of poly(butylene terephthalate) (pCBT)/TrGO nanocomposites prepared by in situ ring-opening polymerization of cyclic butylene terephthalate. Polymer, 2013. 54(6): p. 1603-1611.

189. P. Fabbri, E. Bassoli, S.B. Bon and L. Valentini, Preparation and characterization of poly (butylene terephthalate)/graphene composites by insitu polymerization of cyclic butylene terephthalate. Polymer, 2012. 53(4): p. 897-902.

190. G. Balogh, S. Hajba, J. Karger-Kocsis and T. Czigány, Preparation and characterization of in situ polymerized cyclic butylene terephthalate/graphene nanocomposites. J Mater Sci, 2013. 48(6): p. 2530-2535.

191. S.Y. Kim, Y.J. Noh and J. Yu, Thermal conductivity of graphene nanoplatelets filled composites fabricated by solvent-free processing for the excellent filler dispersion and a theoretical approach for the composites containing the geometrized fillers. Composites Part A: Applied Science and Manufacturing, 2015. 69(0): p. 219-225.

192. Y.J. Noh, H.-I. Joh, J. Yu, S.H. Hwang, S. Lee, C.H. Lee, S.Y. Kim and J.R. Youn, Ultra-high dispersion of graphene in polymer composite via solvent free fabrication and functionalization. Scientific Reports, 2015. 5: p. 9141.

193. Y.J. Noh and S.Y. Kim, Synergistic improvement of thermal conductivity in polymer composites filled with pitch based carbon fiber and graphene nanoplatelets. Polym. Test., 2015. 45(0): p. 132-138.

194. P.K. Mallick, Fiber-reinforced composites: materials, manufacturing, and design. 1988: M. Dekker.

195. P. Mallon, VARTM \& RTM Processing of PBT \& PA Thermoplastic Composites. 2002: Limerick University (Ireland).

196. E. Mäder, S.-L. Gao, R. Plonka and J. Wang, Investigation on adhesion, interphases, and failure behaviour of cyclic butylene terephthalate (CBT®)/glass fiber composites. Compos. Sci. Technol., 2007. 67(15-16): p. 3140-3150.

197. R.T. Durai Prabhakaran, S. Pillai, S. Charca, S. Oshkovr, H. Knudsen, T. Andersen, J. Bech, O. Thomsen and H. Lilholt, Effect of Polymer Form and its Consolidation on Mechanical Properties and Quality of Glass/PBT Composites. Appl. Compos. Mater., 2014. 21(2): p. 301-324.

198. A. Agirregomezkorta, Fabricación de materiales compuesto de polibutilén tereftalato cíclico reforzados con tejido de fibra de carbono mediante VARTM, y su posterior caracterización a impacto, in Departamento de Mecánica y Producción Industrial. 2012, Mondragon Unibertsitatea: Mondragón, Spain.

199. A. Agirregomezkorta, A.B. Martínez, M. Sánchez-Soto, G. Aretxaga, M. Sarrionandia and J. Aurrekoetxea, Impact behaviour of carbon fibre reinforced epoxy and non-isothermal cyclic butylene terephthalate composites manufactured by vacuum infusion. Composites Part B: Engineering, 2012. 43(5): p. 2249-2256.

200. A. Agirregomezkorta, M. Sánchez-Soto, G. Aretxaga, M. Sarrionandia and J. Aurrekoetxea, Effects of vacuum infusion processing parameters on the 
impact behavior of carbon fiber reinforced cyclic butylene terephthalate composites. J. Compos. Mater., 2014. 48(3): p. 333-344.

201. A. Agirregomezkorta, J. Zurbitu, G. Aretxaga, M. Sarrionandia and J. Aurrekoetxea. Strain rate effect on interlaminar shear strength of carbon fibre reinforced pCBT and epoxy composites. in Seventeenth international conference of composites materials (ICCM-17). 2009.

202. J. Aurrekoetxea, J. Zurbitu, I. Ortiz de Mendibil, A. Agirregomezkorta, M. Sánchez-Soto and M. Sarrionandia, Effect of superelastic shape memory alloy wires on the impact behavior of carbon fiber reinforced in situ polymerized poly(butylene terephthalate) composites. Mater. Lett., 2011. 65(5): p. 863-865.

203. E. Archer, R. Mulligan, D. Dixon, S. Buchanan, G. Stewart and A. Mcllhagger, An investigation into thermoplastic matrix 3D woven carbon fibre composites. J. Reinf. Plast. Compos., 2012. 31(13): p. 863-873.

204. S.H. Kim, Y.J. Noh, Y.W. Ko, S.Y. Kim and J.R. Youn, Improved tensile strength and thermal stability of thermoplastic carbon fiber fabric composites by heat induced crystallization of in situ polymerizable cyclic butylene terephthalate oligomers. Polymer Engineering \& Science, 2014. 54(9): p. 2161-2169.

205. W. Wu, Simultaneous Binding and Toughening Concept for an Efficient and Qualified Manufacturing of Textile Reinforced pCBT Composites., in Faculty of Natural and Materials Science. 2013, Clausthal University of Technology: Clausthal, Germany.

206. W. Wu, D. Abliz, B. Jiang, G. Ziegmann and D. Meiners, A novel process for cost effective manufacturing of fiber metal laminate with textile reinforced pCBT composites and aluminum alloy. Compos. Struct., 2014. 108(0): p. 172180.

207. W. Wu, F. Klunker, L. Xie, B. Jiang and G. Ziegmann, Simultaneous binding and ex situ toughening concept for textile reinforced pCBT composites: Influence of preforming binders on interlaminar fracture properties. Composites Part A: Applied Science and Manufacturing, 2013. 53(0): p. $190-$ 203.

208. W. Wu, L. Xie, B. Jiang and G. Ziegmann, Simultaneous binding and toughening concept for textile reinforced pCBT composites: Manufacturing and flexural properties. Compos. Struct., 2013. 105(0): p. 279-287.

209. W. Wu, L. Xie, B. Jiang and G. Ziegmann, Influence of textile preforming binder on the thermal and rheological properties of the catalyzed cyclic butylene terephthalate oligomers. Composites Part B: Engineering, 2013. 55(0): p. 453-462.

210. T. Abt, J. Karger-Kocsis and M. Sánchez-Soto, Toughened carbon fiber fabricreinforced pCBT composites. Polym. Compos., 2014: p. n/a-n/a.

211. H.S. Lee, S.-y. Kim, Y.J. Noh and S.Y. Kim, Design of microwave plasma and enhanced mechanical properties of thermoplastic composites reinforced with microwave plasma-treated carbon fiber fabric. Composites Part B: Engineering, 2014. 60: p. 621-626.

212. V. Fiore, T. Scalici, G. Di Bella and A. Valenza, A review on basalt fibre and its composites. Composites Part B: Engineering, 2015. 74: p. 74-94.

213. K.A. Hao, H.L. Cao, Z. Fan, J.G. Teng and L.M. Zhou, The effect of thermal history on mechanical properties of woven basalt fabric reinforced poly(butylene terephthalate) composites, in Eightteenth international conference on composite materials (ICCM-18). 2011. 
214. C. Romão, C.M.C. Pereira and J.L. Esteves, A Mechanical Analysis of In Situ Polymerized Poly(butylene terephthalate) Flax Fiber Reinforced Composites Produced by RTM. Conference Papers in Materials Science, 2013. 2013: p. 5.

215. C.M. Romão, J.L. Esteves and C.M. Pereira. Woven flax fabric fiber reinforced in-situ polymerized poly(butylene terephthalate) composites produced by RTM. in ECCM 2012 - Composites at Venice, Proceedings of the 15th European Conference on Composite Materials. 2012.

216. Y. Swolfs, L. Gorbatikh and I. Verpoest, Fibre hybridisation in polymer composites: A review. Composites Part A: Applied Science and Manufacturing, 2014. 67: p. 181-200.

217. B. Yang, Z. Wang, L. Zhou, J. Zhang and W. Liang, Experimental and numerical investigation of interply hybrid composites based on woven fabrics and PCBT resin subjected to low-velocity impact. Compos. Struct., 2015. 132: p. 464-476.

218. D.A. Steenkamer and J.L. Sullivan, On the recyclability of a cyclic thermoplastic composite material. Composites Part B: Engineering, 1998. 29(6): p. 745-752.

219. EPL Composite Solutions Ltd. European project TST5-CT-2006-031528 Cleanmould. Development of Lightweight, Recyclable Thermoplastic Composite Semi-trailer and Boat Hulls with Enhanced Performance. D27 Final Project Report. Available at: http://www.transportresearch.info/project/boat-hulls-enhanced-performance. 2010.

220. E. Bittmann, Resins and reactive systems. Kunststoffe International, 2011. 10: p. 67-70.

221. J. Mihalich. Production of class-8 truck trailer bed using CPBT thermoplastic prepreg \& vacuum-bag processing. in 10th-Annual SPE Automotive Composites Conference \& Exhibition (ACCE), Troy, Michigan, USA. 2010.

222. J. Mihalich. In-situ polymerization of reinforced thermoplastics. in 12th-Annual SPE Automotive Composites Conference \& Exhibition (ACCE), Troy, Michigan, USA. 2012.

223. C.M. O'Brádaigh, A. Doyle, D. Doyle and P.J. Feerick, Electrically-Heated Ceramic Composites Tooling for Out-of-Autoclave Manufacturing of Large Composite Structures. SAMPE J., 2011. 47(4): p. 6-14.

224. G. Gardiner (April 2012) Thermoplastic Wind Blades: To be or not? Composites Technogy 18, 30.

225. G. Gardiner (November 2008) Wind Blade Manufacturing, Part II: Are thermoplastic composites the future? High-Performance Composites 16, 3648.

226. C. Ó'Brádaigh (October 2013) Reactive Thermoplastic Composites - A Potential Game Changer? SAMPE Masterclass, NCC, Bristol.

227. H. Deng, L. Lin, M. Ji, S. Zhang, M. Yang and Q. Fu, Progress on the morphological control of conductive network in conductive polymer composites and the use as electroactive multifunctional materials. Prog. Polym. Sci., 2014. 39(4): p. 627-655.

228. J. Song, W. Zhang, W. Yang, J. Xu and J. Lai, Rheological properties, morphology, mechanical properties, electrical resistivity and EMI SE of cyclic butylene terephthalate/graphite/carbon black composites. J Polym Res, 2014. 21(9): p. 1-8.

229. Y. Wang, L. Yuan, G. Liang and A. Gu, New Bismaleimide Resin Toughened by In Situ Ring-Opening Polymer of Cyclic Butylene Terephthalate Oligomer 
with Unique Organotin Initiator. Industrial \& Engineering Chemistry Research, 2015.

230. M.M. Davoodi, S.M. Sapuan, D. Ahmad, A. Aidy, A. Khalina and M. Jonoobi, Effect of polybutylene terephthalate (PBT) on impact property improvement of hybrid kenaf/glass epoxy composite. Mater. Lett., 2012. 67(1): p. 5-7.

231. J. Karger-Kocsis, D. Felhos, T. Bárány and T. Czigány, Hybrids of HNBR and in situ polymerizable cyclic butylene terephthalate (CBT) oligomers: Properties and dry sliding behavior. eXPRESS Polymer Letters, 2008. 2(7): p. 520-527.

232. L. Tzounis, T. Gärtner, M. Liebscher, P. Pötschke, M. Stamm, B. Voit and G. Heinrich, Influence of a cyclic butylene terephthalate oligomer on the processability and thermoelectric properties of polycarbonate/MWCNT nanocomposites. Polymer, 2014. 55(21): p. 5381-5388. 


\section{Figure Captions}

Fig. 1: Chemical structure of CBT oligomers. Adapted with permission from Ref. 28. Copyright 1998 American Chemical Society.

Fig. 2: Initiation and propagation steps during the ring-opening polymerization of CBT using a tin-based catalyst. Adapted with permission from Ref. 31. Copyright 2012 John Wiley and Sons.

Fig. 3: CBT catalyst systems stannoxane (I), butyltin chloride dihydroxide (II) and tetrakis-(2-ethylhexyl) titanate (III). Reprinted with permission from Ref. 33. Copyright 2005 American Chemical Society.

Fig. 4: Incorporation of cyclic stannoxane initiator into CBT and ring-expansion mechanism of macrocyclic c-pCBT. Reprinted with permission from Ref. 28. Copyright 1998 American Chemical Society.

Fig. 5: In situ monitoring of the electrical conductivity by dielectric sensing at $10 \mathrm{~Hz}$ for several polymerization temperatures. Reprinted from Ref. 36 with permission from Elsevier.

Fig. 6: Conversion data for isothermal polymerization of CBT based on GPC data. Reprinted from Ref. 30.

Fig. 7: Variation of complex viscosity of CBT with time (a) and variations of the relative molecular weight $M w(t) / M w(\infty)$ with time at different temperatures. Reprinted with permission from Ref. 31. Copyright 2012 John Wiley and Sons.

Fig. 8: Polymerization kinetics modelled with first order ordinary differential equation model from isothermal GPC data. Reprinted from Ref. 30.

Fig. 9: Possible chain conformations in polymers. Reprinted with permission from Ref. 39. Copyright 1968 Springer. 
Fig. 10: Schematic representation of the evolution of living lamellar pCBT crystals. Reprinted from Ref. 40 with kind permission from Springer Science and Business Media.

Fig. 11: Avrami plot of CBT160, CBT XB3-CA4, PBT B4520 and PBT B6550 as obtained at $195{ }^{\circ} \mathrm{C}$. Reprinted from Ref. 43 with kind permission from Springer Science and Business Media.

Fig. 12: Conditioning of CBT160 powder $(\bullet)$ and pellets $(\mathbf{a})$ at 80 and $100^{\circ} \mathrm{C}$. CBT water content over drying time (a) and water uptake of dry CBT in ambient atmosphere at $60 \%$ relative humidity over time. Reprinted from Ref. 48.

Fig. 13: Effect of testing temperatures on the variation of melt viscosity with time (a) and impregnation time and apparent polymerization time as a function of temperature (b). Reprinted with permission from Ref. 29. Copyright 2006 John Wiley and Sons.

Fig. 14: Elementary cells of PBT: (a) $\alpha$-form and (b) $\beta$-form. Reprinted with permission from Ref. 58. Copyright 1976 American Chemical Society.

Fig. 15: PLM morphologies of pCBT corresponding to the crystallization temperature range of $190-215^{\circ} \mathrm{C}$. Reprinted with permission from Ref. 47. Copyright 2010 John Wiley and Sons.

Fig. 16: TEM micrographs of PBT (a), pCBT (b) and reprocessed RP-pCBT (c). Reprinted from Ref. 63 with permission from Elsevier.

Fig. 17: DSC thermograms of CBT, injection moulded PBT (denoted as IM-PBT) and isothermally polymerized pCBT (denoted as ISP-PBT). First heating scan (a), second heating scan (b). Heating and cooling rates: $5^{\circ} \mathrm{C} / \mathrm{min}$. Reprinted from Ref. 66 with permission from Elsevier.

Fig. 18: Typical 3 point bending stress-strain curves for pCBT and PBT. Reprinted from Ref. 63 with permission from Elsevier. 
Fig. 19: Remaining cyclic oligomer crystals after polymerization at $190{ }^{\circ} \mathrm{C}$ for $30 \mathrm{~min}$; PLM image (a) and SEM image (b). Reprinted from Ref. 40 with kind permission from Springer Science and Business Media.

Fig. 20: Brittleness mechanism of remaining cyclic oligomer crystals in pCBT. Reprinted from Ref. 40 with kind permission from Springer Science and Business Media.

Fig. 21: Reactions of carboxylic groups with various electrophilic groups. Reprinted with permission from Ref. 87. Copyright 2005 John Wiley and Sons.

Fig. 22: Schematic representation of nanocomposite formation by ROP of cyclic ethylene terephthalate oligomers in between silicate layers. Reproduced from ref. 14 with permission of Elsevier Science Ltd., UK.

Fig. 23: Synthesis route of MWCNT-grafted pCBT. Reproduced from ref. 153 with permission of John Wiley and Sons.

Fig. 24: Chemical structures of POSS; cage structure (a) and partial cage structure (b). Reproduced from ref. 133 with permission of Elsevier.

Fig. 25: Polymerization mechanism of TRGO and CBT. Reproduced from ref. 188 with permission of Elsevier.

Fig. 26: World's first lightweight and aerodynamic thermoplastic composite trailer. Reproduced from ref. 219.

Fig. 27: Flat bottom boat case study manufactured from pCBT/GF composite and a balsa-cored sandwich panel. Reproduced from ref. 219.

Fig. 28: $12.6 \mathrm{~m}$ long pCBT/GF wind turbine blade manufactured at $200{ }^{\circ} \mathrm{C}$, (a) removing moulded blade from tool; and (b) a $4.0 \mathrm{~m}$ moulded section of the blade, showing the spar-cap and shear-webs moulded in a "one-shot" process. Reproduced from ref. 223 


\section{Tables}

Table 1: Molecular weights and polydispersities of pCBT polymerized at different temperatures and with different catalysts. Reprinted with permission from Ref. 32. Copyright 2005 American Chemical Society.

\begin{tabular}{|c|c|c|c|c|c|}
\hline catalytic & amount & $T_{p}$ & conversion $\alpha$ & $M_{n}$ & PDI \\
\hline system & [wt.\%] & $\left({ }^{\circ} \mathrm{C}\right)$ & [\%] & {$[\mathrm{kg} / \mathrm{mol}]$} & {$\left[M_{w} / M_{n}\right]$} \\
\hline \multirow{5}{*}{ stannoxane (I) } & 0.25 & 175 & 83 & 45.0 & 2.7 \\
\hline & 0.25 & 180 & 84 & 41.6 & 2.9 \\
\hline & 0.25 & 185 & 84 & 41.0 & 2.9 \\
\hline & 0.25 & 190 & 92 & 41.8 & 2.7 \\
\hline & 0.25 & 195 & 94 & 42.2 & 2.8 \\
\hline \multirow{5}{*}{ butyltin chloride dihydroxide (II) } & 0.3 & 185 & 65 & 31.6 & 2.6 \\
\hline & 0.3 & 190 & 77 & 34.8 & 2.6 \\
\hline & 0.3 & 195 & 93 & 46.6 & 2.6 \\
\hline & 0.3 & 200 & 94 & 46.2 & 2.6 \\
\hline & 0.3 & 205 & 97 & 50.1 & 2.6 \\
\hline \multirow{5}{*}{ tetrakis-(2-ethylhexyl) titanate (III) } & 0.3 & 185 & 84 & 54.8 & 2.5 \\
\hline & 0.3 & 190 & 87 & 55.1 & 2.4 \\
\hline & 0.3 & 195 & 94 & 57.7 & 2.5 \\
\hline & 0.3 & 200 & 95 & 54.7 & 2.5 \\
\hline & 0.3 & 205 & 92 & 52.0 & 2.6 \\
\hline
\end{tabular}


Table 2: Physical properties of PBT, pCBT and macrocyclic c-pCBT.

\begin{tabular}{|c|c|c|c|c|c|c|c|c|c|c|c|c|}
\hline Sample & $\begin{array}{c}\text { Processing } \\
\text { method }\end{array}$ & $\begin{array}{l}T_{R O P} \\
{\left[{ }^{\circ} \mathrm{C}\right]}\end{array}$ & $\begin{array}{l}T_{\text {cool }} \\
{\left[{ }^{\circ} \mathrm{C}\right]}\end{array}$ & Testing & $\begin{array}{c}E \\
{[\mathrm{GPa}]}\end{array}$ & $\begin{array}{c}\sigma \\
{[\mathrm{MPa}]}\end{array}$ & $\begin{array}{c}\varepsilon \\
{[\%]}\end{array}$ & $\begin{array}{c}X_{C, D S C^{* *}} \\
{[\%]}\end{array}$ & $\begin{array}{c}M_{n} \\
{[\mathrm{~kg} / \mathrm{mol}]}\end{array}$ & $\begin{array}{c}M_{w} \\
{[\mathrm{~kg} / \mathrm{mol}]}\end{array}$ & $\begin{array}{c}\alpha \\
{[\%]}\end{array}$ & Ref. \\
\hline PBT & IM & 250 & non-iso & flexural & $2.2 \pm 0.1$ & $73 \pm 11$ & $\star 3.3 \pm 0.3$ & 35 & 33.8 & 69.3 & 98.8 & [58] \\
\hline RP-PBT & IM & 250 & non-iso & tensile & $2.5 \pm 0.2$ & $50 \pm 1$ & $16-225$ & 34 & 32.3 & 66.3 & 98.7 & [58] \\
\hline pCBT190 & TP-RTM & 190 & 190-iso & flexural & $3.2 \pm 0.1$ & $54 \pm 5$ & $1.6 \pm 0.2$ & 47 & 29.3 & 61.4 & 98.2 & [58] \\
\hline pCBT230 & TP-RTM & 230 & 190 -iso & flexural & $3.1 \pm 0.2$ & $73 \pm 14$ & $2.3 \pm 0.7$ & 42 & 35.0 & 73.3 & 98.7 & [58] \\
\hline RP-pCBT & IM & - & - & tensile & $2.3 \pm 0.2$ & $46 \pm 7$ & $3-70$ & 35 & 20.5 & 40.6 & 97.9 & [58] \\
\hline pCBT & TP-RTM & 190 & 190-iso & flexural & $3.5 \pm 0.1$ & $61 \pm 3$ & $1.9 \pm 0.1$ & 44 & 36 & 78 & 99 & [65] \\
\hline pCBT & CM & 240 & non-iso & tensile & $2.1 \pm 0.3$ & $57 \pm 13$ & $3.2 \pm 1.1$ & 33 & - & 67.6 & 98.5 & [67] \\
\hline pCBT & $\mathrm{CM}$ & 240 & non-iso & tensile & $2.8 \pm 0.4$ & $57 \pm 5$ & $7 \pm 3$ & 32 & 10.0 & 22.0 & 96.6 & [66] \\
\hline c-pCBT & $\mathrm{CM}$ & 190 & 190-iso & tensile & 3.0 & 46 & 2 & 50 & $\sim 100$ & 300 & - & [59] \\
\hline pCBT & $\mathrm{CM}$ & 250 & non-iso & tensile & $2.4 \pm 0.4$ & $67 \pm 10$ & $3.8 \pm 0.8$ & - & - & - & - & [68] \\
\hline pCBT & SC & 190 & quenched & tensile & $1.3 \pm 0.1$ & $17.3 \pm 0.7$ & $5.3 \pm 0.1$ & - & - & - & - & [38] \\
\hline
\end{tabular}

* strain at yield; no break.

** calculated from first heating

IM: Injection moulding 
TP-RTM: Thermoplastic resin transfer moulding

CM: Compression moulding

SC: Solution casting 
Table 3: Physical properties of modified pCBT.

\begin{tabular}{|c|c|c|c|c|c|c|c|c|c|c|}
\hline Modifier & $\begin{array}{c}\text { Modifier content } \\
\text { [wt. \%] }\end{array}$ & Testing & $\begin{array}{c}E \\
{[\mathrm{GPa}]}\end{array}$ & $\begin{array}{c}\sigma \\
{[\mathrm{MPa}]}\end{array}$ & $\begin{array}{c}\varepsilon_{\text {break }} \\
{[\%]}\end{array}$ & $\begin{array}{c}X_{C, D S C^{*}} \\
{[\%]}\end{array}$ & $\begin{array}{c}M_{n} \\
{[\mathrm{~kg} / \mathrm{mol}]}\end{array}$ & $\begin{array}{c}M_{w} \\
{[\mathrm{~kg} / \mathrm{mol}]}\end{array}$ & $\begin{array}{c}\alpha \\
{[\%]}\end{array}$ & Ref. \\
\hline pTHF & 10 & flexural & $2.1 \pm 0.1$ & $27 \pm 4$ & $1.3 \pm 0.4$ & 48 & 22 & 44 & 99 & [79] \\
\hline EVA & 75 & tensile & 0,003 & 4 & 1030 & - & - & - & 96 & [111] \\
\hline EP & 2 & tensile & $2.8 \pm 0.1$ & $62 \pm 1$ & $49 \pm 25$ & 24 & 9,4 & 65 & 92 & [66] \\
\hline PMDI & 1 & tensile & $2.6 \pm 0.2$ & $51 \pm 1$ & $215 \pm 28$ & 30 & 41,1 & 137,6 & - & [103] \\
\hline MDI & 1 & tensile & $2.7 \pm 0.2$ & $55 \pm 1$ & $79 \pm 11$ & 32 & - & - & - & [103] \\
\hline HDI & 1 & tensile & $2.8 \pm 0.2$ & $54 \pm 1$ & $109 \pm 21$ & 33 & - & - & - & [103] \\
\hline $\mathrm{CL}$ & 20 & tensile & 0,06 & 13,9 & 368 & 36 & 29 & 72 & - & [63] \\
\hline $\mathrm{CL}$ & 30 & tensile & 0,17 & 18,9 & 704 & 32 & - & - & - & [63] \\
\hline $\mathrm{CL}$ & 40 & tensile & 0,05 & 8,2 & 397 & 19 & 31 & 68 & - & [63] \\
\hline $\mathrm{CL}$ & 50 & tensile & 0,02 & 5,3 & 690 & 16 & 48 & 110 & - & [63] \\
\hline $\mathrm{CL}$ & 70 & tensile & 0,0004 & 3,6 & 820 & - & - & - & - & [63] \\
\hline PCL & 7 & flexural & $2.7 \pm 0.1$ & $95 \pm 7$ & $5 \pm 0.8$ & 32 & 34 & 77 & 99 & [113] \\
\hline PCL & 7,5 & tensile & 1,25 & 27 & 6 & 32 & - & - & - & [67] \\
\hline
\end{tabular}


* calculated from second heating. polyTHF: Polytetrahydrofuran; EVA: Poly(ethylene-co-vinyl acetate); CL: $\varepsilon$-caprolactone; PCL: Polycaprolactone; EP: Diepoxide; HDI: Hexamethylene diisocyanate; MDI: 4,4'-methylenebis(phenyl isocyanate); PMDI: Polymeric methylene diphenyl diisocyanate. 
Table 4: Flexural properties and interlaminar shear strength (ILSS) of continuous fibre reinforced pCBT composites.

\begin{tabular}{|c|c|c|c|c|c|c|c|c|c|c|c|c|c|c|c|}
\hline & & Modifier & & & & & & Fibre & raction & & & & & & \\
\hline $\begin{array}{l}\text { Processing } \\
\text { method }\end{array}$ & Modifier & $\begin{array}{l}\text { content } \\
\text { [wt.\%] }\end{array}$ & $\begin{array}{l}T_{R O P} \\
{\left[{ }^{\circ} \mathrm{C}\right]}\end{array}$ & $\begin{array}{l}T_{\text {cool }} \\
{\left[{ }^{\circ} \mathrm{C}\right]}\end{array}$ & $\begin{array}{l}\text { Fiber } \\
\text { type }\end{array}$ & $\begin{array}{c}\text { Fiber } \\
\text { architecture }\end{array}$ & $\begin{array}{l}\text { Composite } \\
\text { lay-up }\end{array}$ & $\begin{array}{c}w_{f} \\
\text { [wt.\%] }\end{array}$ & $\begin{array}{c}v_{f} \\
\text { [vol.\%] }\end{array}$ & $\begin{array}{c}\text { Void content } \\
\text { [\%] }\end{array}$ & $\begin{array}{c}E_{f} \\
{[\mathrm{GPa}]}\end{array}$ & $\begin{array}{c}\sigma_{F M} \\
{[\mathrm{MPa}]}\end{array}$ & $\begin{array}{c}\mathcal{E}_{\mathrm{FB}} \\
{[\%]}\end{array}$ & $\begin{array}{l}\text { ILSS } \\
\text { [MPa] }\end{array}$ & Ref. \\
\hline RTM & $\overline{-}$ & - & 190 & 190 & glass & unidirectional & $0^{\circ}$ & - & 54 & $\overline{-}$ & $38.3 \pm 1.2$ & $766 \pm 113$ & $\overline{-}$ & $\overline{-}$ & [58] \\
\hline RTM & - & - & 190 & 190 & glass & multidirectional & $0^{\circ} / 90^{\circ} /$ random & - & 52 & - & $37.8 \pm 1.3$ & $901 \pm 64$ & - & - & [58] \\
\hline RTM & - & - & 190 & 190 & glass & unidirectional & $0^{\circ}$ & - & 54 & $4.2 \pm 1.7$ & $37.6 \pm 1.3$ & $775 \pm 118$ & $2.3 \pm 0.3$ & - & [64] \\
\hline RTM & - & - & 190 & 190 & glass & unidirectional & $0^{\circ}$ & - & 48 & - & $32 \pm 2$ & $680 \pm 62$ & $2.9 \pm 0.3$ & - & [113] \\
\hline RTM & PCL & 7 & 190 & 190 & glass & unidirectional & $0^{\circ}$ & - & 48 & - & $31 \pm 4$ & $613 \pm 57$ & $2.5 \pm 0.3$ & - & [113] \\
\hline $\mathrm{CM}(\mathrm{DC})$ & - & - & 190 & non-iso & glass & bidirectional & $0^{\circ} / 90^{\circ}$ & - & 54.4 & 4.7 & $22.3 \pm 0.1$ & $482 \pm 13$ & - & $28.2 \pm 1.5$ & [61] \\
\hline $\mathrm{CM}(\mathrm{PC})$ & - & - & 190 & non-iso & glass & bidirectional & $0^{\circ} / 90^{\circ}$ & - & 53.6 & $<1$ & $24.5 \pm 0.3$ & $578 \pm 8$ & - & $34.3 \pm 1.1$ & [61] \\
\hline VI & - & - & 230 & non-iso & glass & unidirectional & $0^{\circ}$ & - & 50.8 & - & - & - & $6.1 \pm 0.5$ & 48 & [191] \\
\hline $\mathrm{CM}$ & - & - & 230 & 185 & carbon & bidirectional & $0^{\circ} / 90^{\circ}$ & - & 51 & 0.4 & $43.6 \pm 2.4$ & $403 \pm 8$ & - & $54.1 \pm 1.2$ & [71] \\
\hline $\mathrm{CM}$ & - & - & 230 & 195 & carbon & bidirectional & $0^{\circ} / 90^{\circ}$ & - & 51 & 0.4 & $42.4 \pm 1.0$ & $407 \pm 9$ & - & $55.2 \pm 1.0$ & [71] \\
\hline $\mathrm{CM}$ & - & - & 230 & 210 & carbon & bidirectional & $0^{\circ} / 90^{\circ}$ & - & 51 & 0.4 & $45.1 \pm 3.3$ & $508 \pm 13$ & - & $59.7 \pm 0.4$ & [71] \\
\hline VI & - & - & 205 & 205 & carbon & bidirectional & $0^{\circ} / 90^{\circ}$ & 61 & - & - & $26.5 \pm 2.5$ & $421 \pm 21$ & $1.6 \pm 0.1$ & - & [202] \\
\hline VI & EP & 2 & 205 & 205 & carbon & bidirectional & $0^{\circ} / 90^{\circ}$ & 61 & - & - & $28.7 \pm 0.9$ & $712 \pm 31$ & $2.8 \pm 0.2$ & - & [202] \\
\hline VI & EP & 4 & 205 & 205 & carbon & bidirectional & $0^{\circ} / 90^{\circ}$ & 61 & - & - & $21.5 \pm 1.7$ & $347 \pm 11$ & $1.7 \pm 0.3$ & - & [202] \\
\hline $\mathrm{CM}$ & - & - & 230 & non-iso & carbon & bidirectional & $0^{\circ} / 90^{\circ}$ & 67 & - & 0.8 & $35.3 \pm 7.0$ & $453 \pm 31$ & $1.1 \pm 0.1$ & $29.6 \pm 2.0$ & [204] \\
\hline $\mathrm{CM}$ & EP & 3 & 230 & non-iso & carbon & bidirectional & $0^{\circ} / 90^{\circ}$ & 67 & - & 0.6 & $37.7 \pm 5.5$ & $736 \pm 86$ & $1.5 \pm 0.2$ & $40.8 \pm 3.3$ & [204] \\
\hline $\mathrm{CM}$ & PMDI & 1 & 230 & non-iso & carbon & bidirectional & $0^{\circ} / 90^{\circ}$ & 71 & - & 1.5 & $34.7 \pm 6.8$ & $668 \pm 79$ & $1.4 \pm 0.2$ & $42.2 \pm 3.2$ & [204] \\
\hline $\mathrm{CM}$ & $\mathrm{HDI}$ & 1 & 230 & non-iso & carbon & bidirectional & $0^{\circ} / 90^{\circ}$ & 68 & - & 1 & $34.1 \pm 5.9$ & $680 \pm 152$ & $1.3 \pm 0.3$ & $42.5 \pm 2.0$ & [204] \\
\hline RTM & - & - & 190 & non-iso & carbon & 3D woven fabric & $0^{\circ} / 90^{\circ}$ & - & 48 & - & $49.0 \pm 2.2$ & $560 \pm 59$ & $1.5 \pm 0.01$ & $40.5 \pm 1.7$ & [197] \\
\hline $\mathrm{CM}$ & - & - & 220 & non-iso & basalt & bidirectional & $0^{\circ} / 90^{\circ}$ & - & - & - & 16.7 & 446 & - & 38.5 & [207] \\
\hline
\end{tabular}




\begin{tabular}{cccccccccccccccc}
$\mathrm{CM}$ & - & - & 230 & non-iso & basalt & bidirectional & $0^{\circ} / 90^{\circ}$ & - & - & - & 17.3 & 467 & - & 44 & {$[207]$} \\
$\mathrm{CM}$ & - & - & 240 & non-iso & basalt & bidirectional & $0^{\circ} / 90^{\circ}$ & - & - & - & 15.4 & 305 & - & 21.1 & {$[207]$} \\
RTM & - & - & 240 & non-iso & basalt & bidirectional & $0^{\circ} / 90^{\circ}$ & - & 43 & - & $28 \pm 1$ & $593 \pm 32$ & $2.6 \pm 0.4$ & - & {$[84]$} \\
\hline
\end{tabular}

CM: Compression moulding

CM(DC): Displacement-controlled compression moulding

$\mathrm{CM}(\mathrm{PC})$ : Pressure-controlled compression moulding

RTM: Resin transfer moulding

VI: Vacuum infusion

$v_{f}$. Fibre volume fraction

$w_{f}$ : Fibre weight fraction 


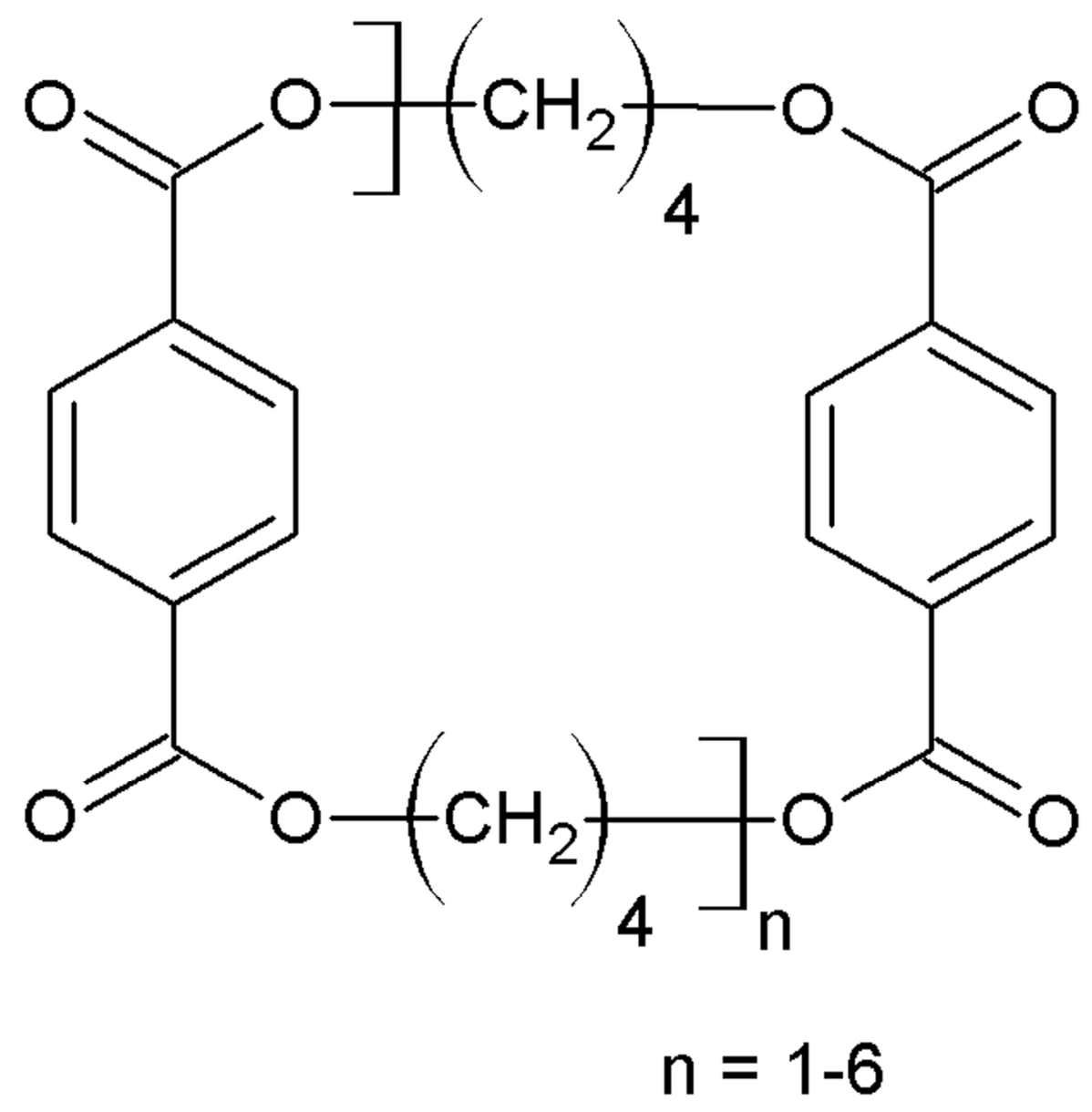

Fig. 1: Chemical structure of CBT oligomers. Adapted with permission from Ref. 28. Copyright 1998 American Chemical Society.

$67 \times 65 \mathrm{~mm}(600 \times 600 \mathrm{DPI})$ 


\section{Initiation:}

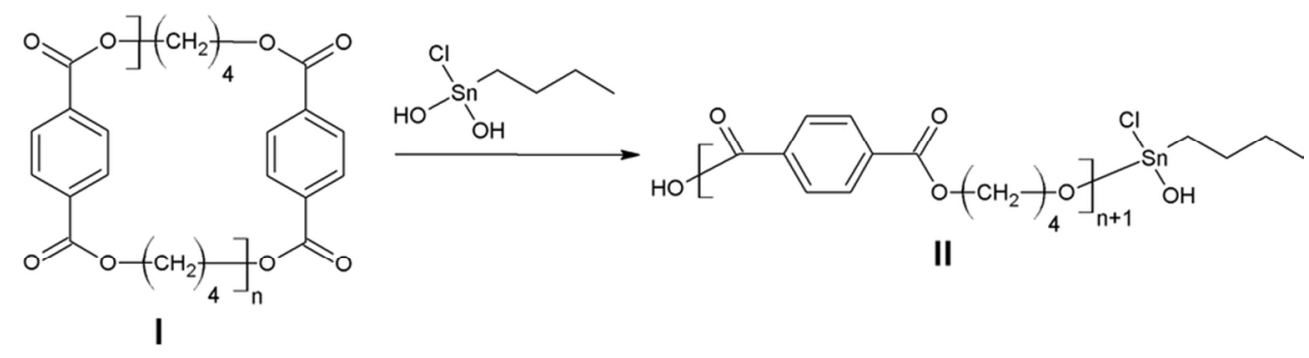

Propagation:

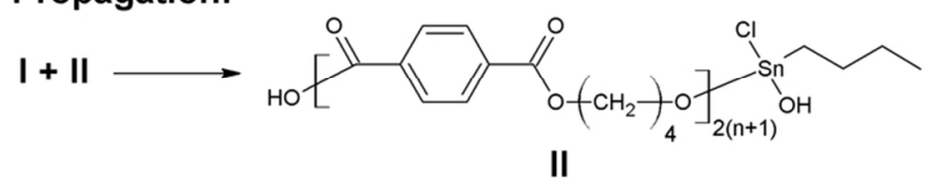

Fig. 2: Initiation and propagation steps during the ring-opening polymerization of CBT using a tin-based catalyst. Adapted with permission from Ref. 31. Copyright 2012 John Wiley and Sons. $81 \times 44 \mathrm{~mm}(300 \times 300$ DPI $)$ 


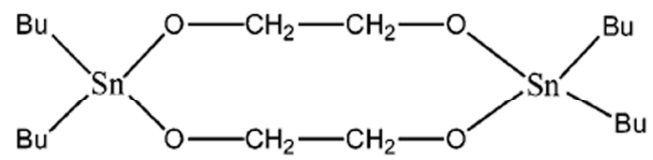

(I)

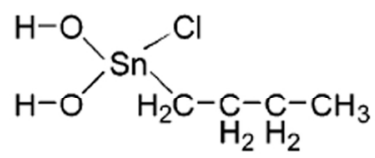

(II)
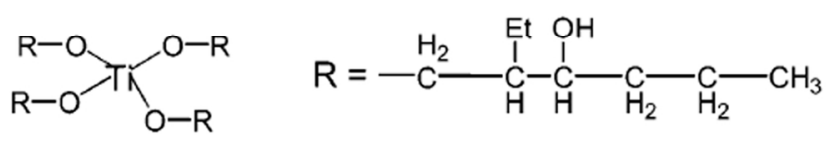

(III)

Fig. 3: CBT catalyst systems stannoxane (I), butyltin chloride dihydroxide (II) and tetrakis-(2-ethylhexyl) titanate (III). Reprinted with permission from Ref. 33. Copyright 2005 American Chemical Society. $64 \times 28 \mathrm{~mm}(600 \times 600 \mathrm{DPI})$ 


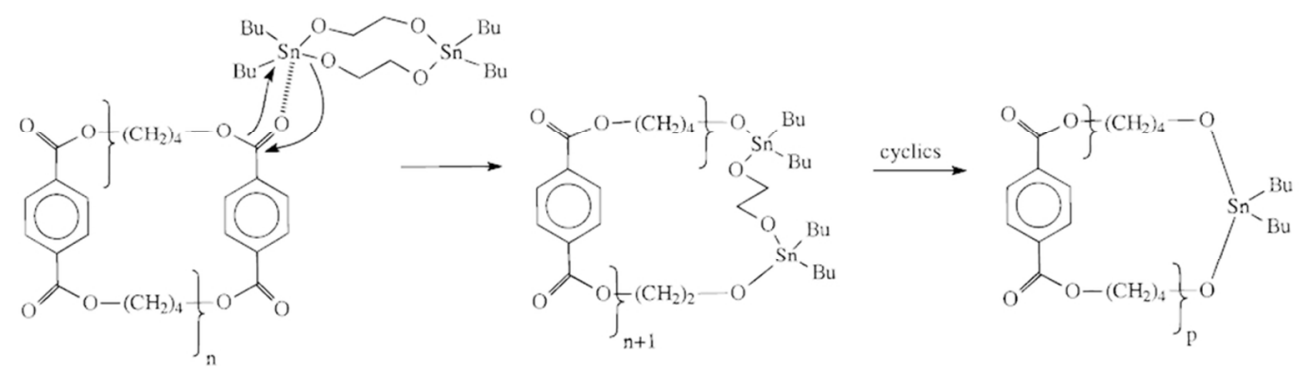

Fig. 4: Incorporation of cyclic stannoxane initiator into CBT and ring-expansion mechanism of macrocyclic cpCBT. Reprinted with permission from Ref. 28. Copyright 1998 American Chemical Society. $49 \times 14 \mathrm{~mm}(600 \times 600 \mathrm{DPI})$ 


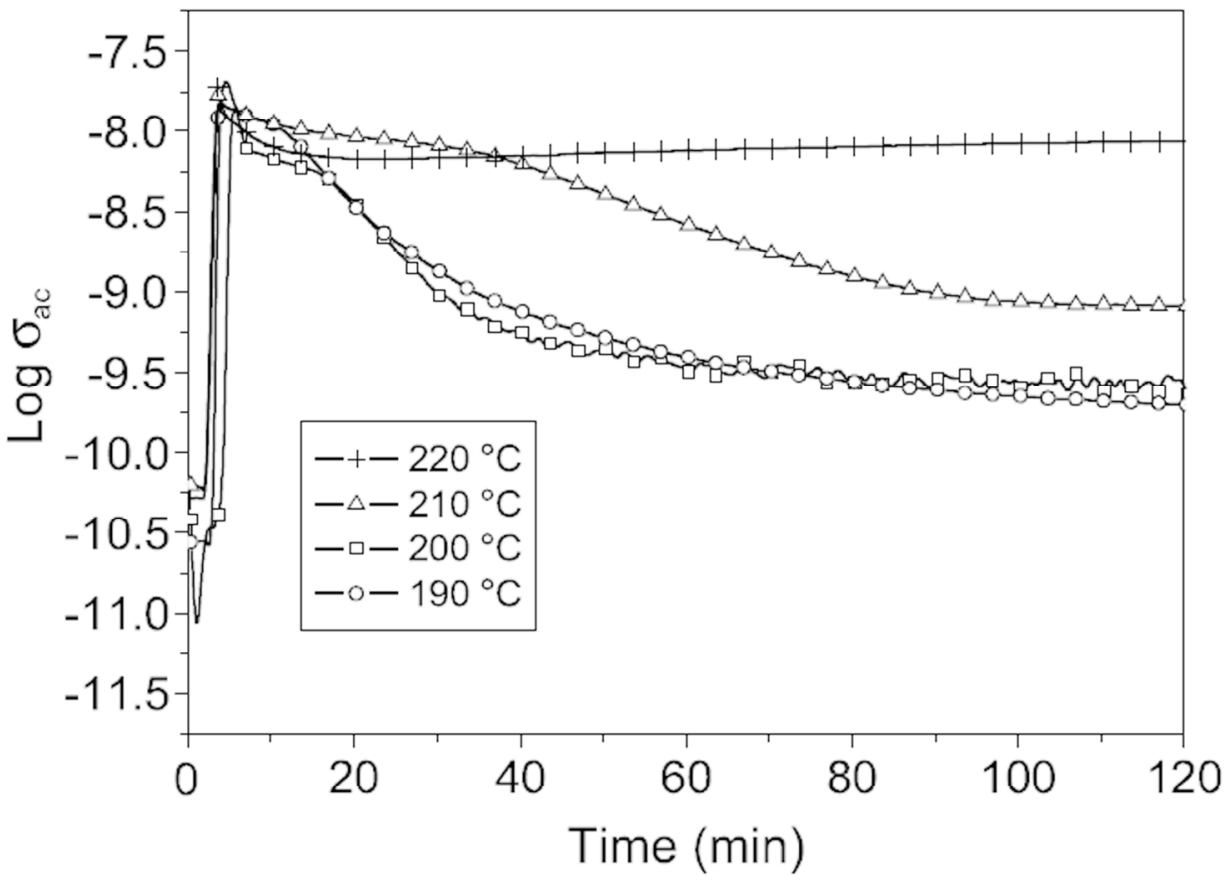

Fig. 5: In situ monitoring of the electrical conductivity by dielectric sensing at $10 \mathrm{~Hz}$ for several polymerization temperatures. Reprinted from Ref. 36 with permission from Elsevier. $71 \times 51 \mathrm{~mm}(600 \times 600 \mathrm{DPI})$ 


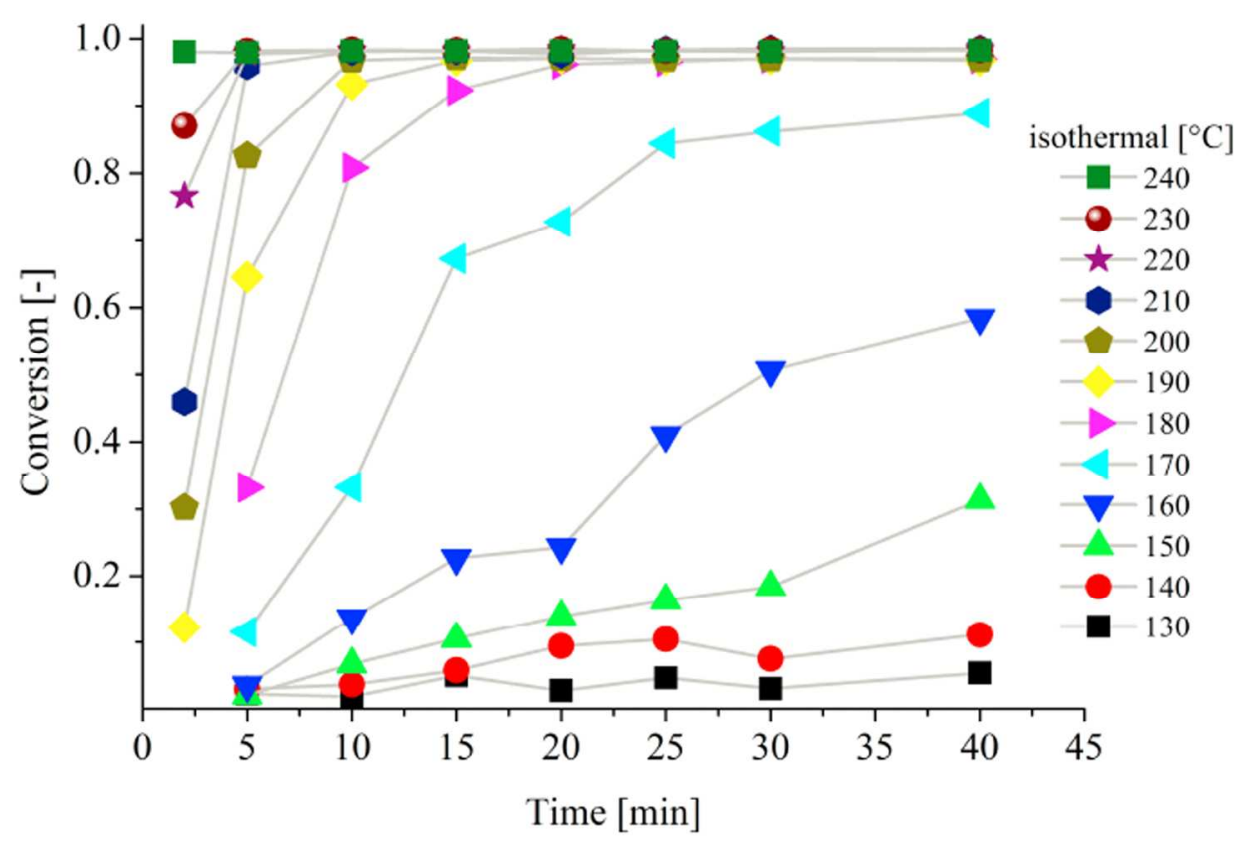

Fig. 6: Conversion data for isothermal polymerization of CBT based on GPC data. Reprinted from Ref. 30. $98 \times 64 \mathrm{~mm}(600 \times 600 \mathrm{DPI})$ 

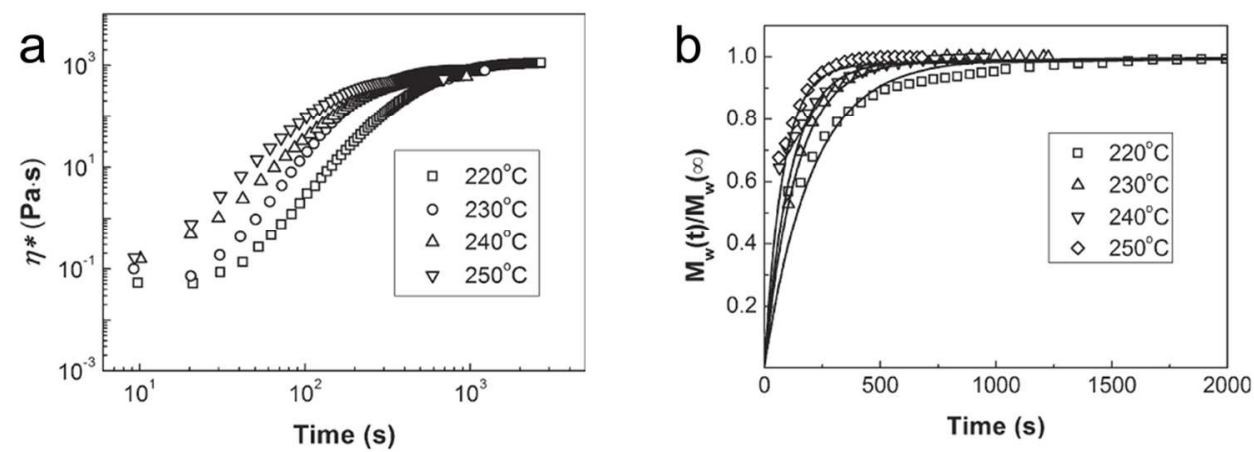

Fig. 7: Variation of complex viscosity of CBT with time (a) and variations of the relative molecular weight Mw $(\mathrm{t}) / \mathrm{Mw}(\infty)$ with time at different temperatures. Reprinted with permission from Ref. 31. Copyright 2012 John Wiley and Sons.

$56 \times 19 \mathrm{~mm}(600 \times 600$ DPI $)$ 


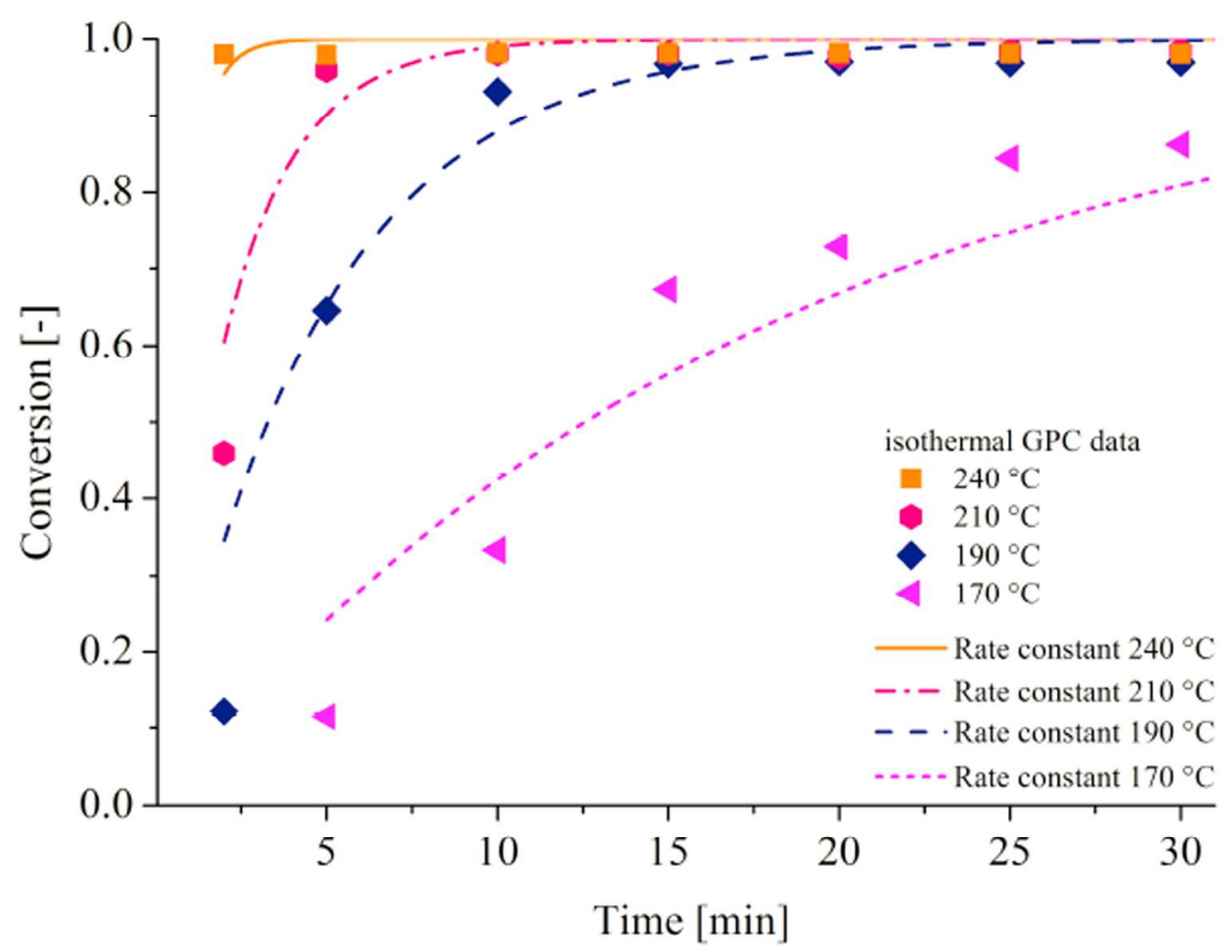

Fig. 8: Polymerization kinetics modelled with first order ordinary differential equation model from isothermal GPC data. Reprinted from Ref. 30.

$92 \times 70 \mathrm{~mm}(600 \times 600 \mathrm{DPI})$ 


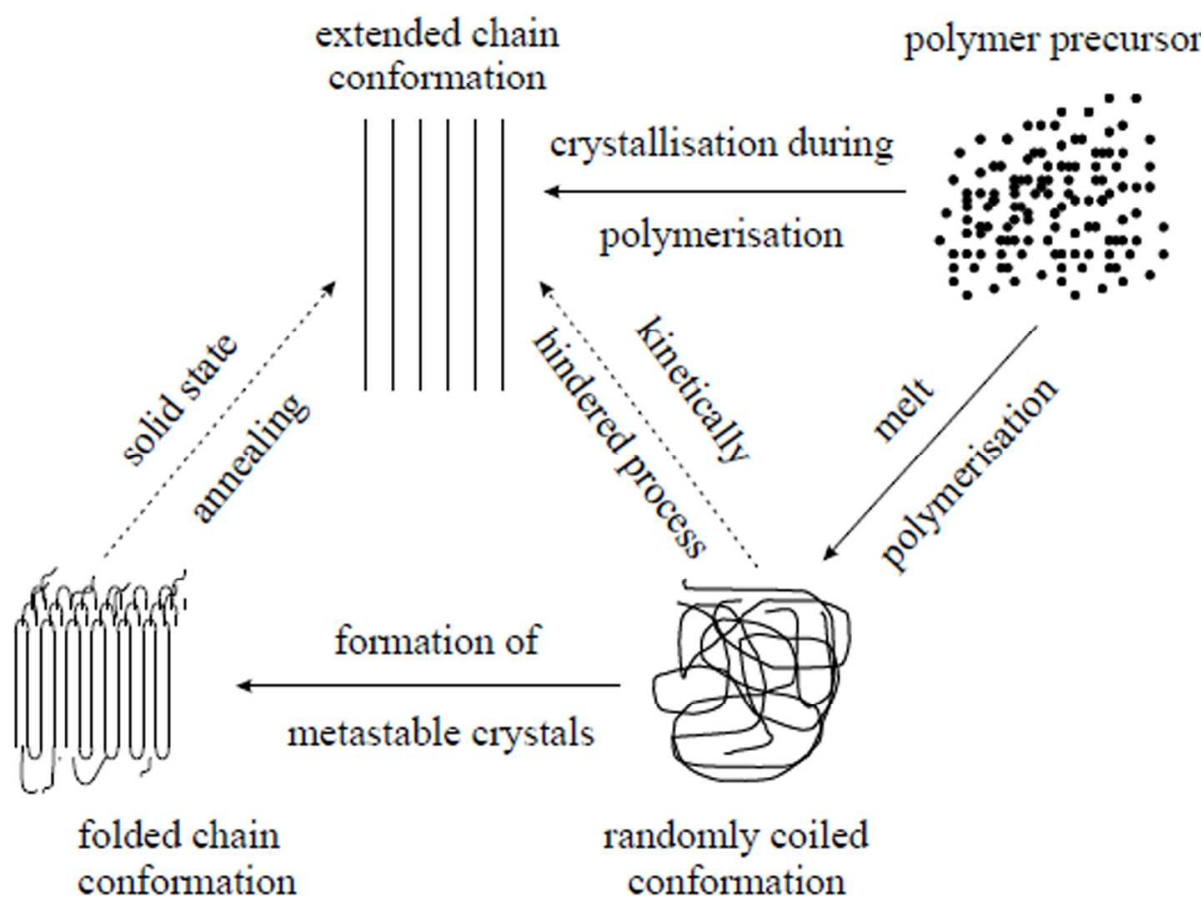

Fig. 9: Possible chain conformations in polymers. Reprinted with permission from Ref. 39. Copyright 1968 Springer.

$113 \times 86 \mathrm{~mm}(600 \times 600 \mathrm{DPI})$ 


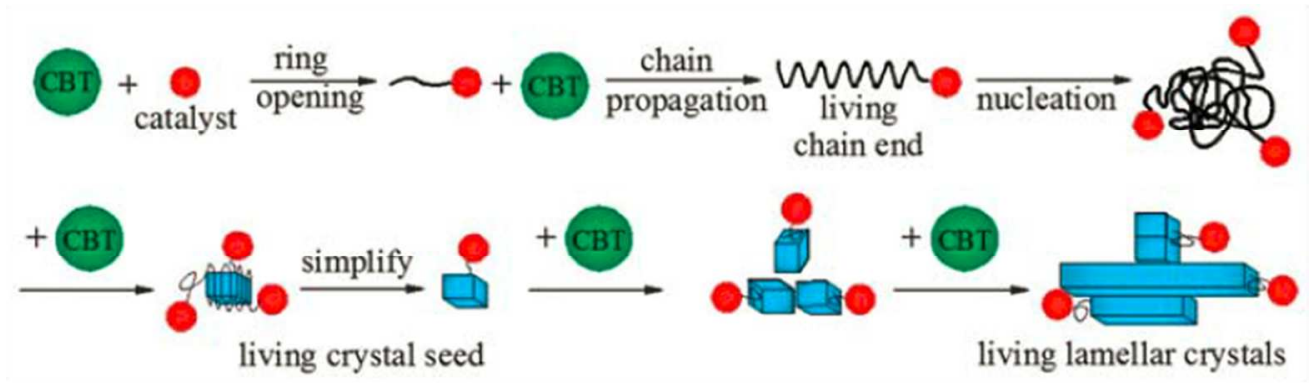

Fig. 10: Schematic representation of the evolution of living lamellar pCBT crystals. Reprinted from Ref. 40 with kind permission from Springer Science and Business Media. $49 \times 14 \mathrm{~mm}(600 \times 600 \mathrm{DPI})$ 


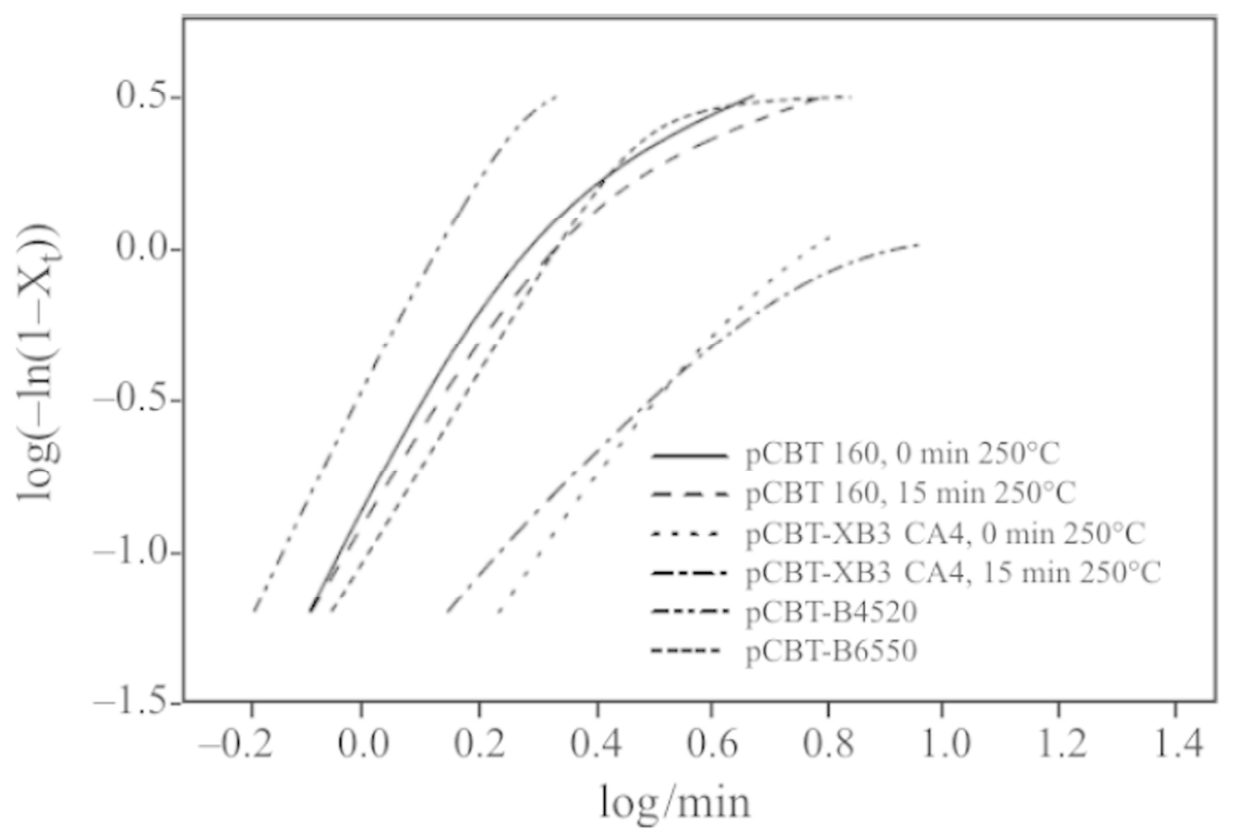

Fig. 11: Avrami plot of CBT160, CBT XB3-CA4, PBT B4520 and PBT B6550 as obtained at $195{ }^{\circ} \mathrm{C}$. Reprinted from Ref. 43 with kind permission from Springer Science and Business Media. $88 \times 59 \mathrm{~mm}(600 \times 600 \mathrm{DPI})$ 

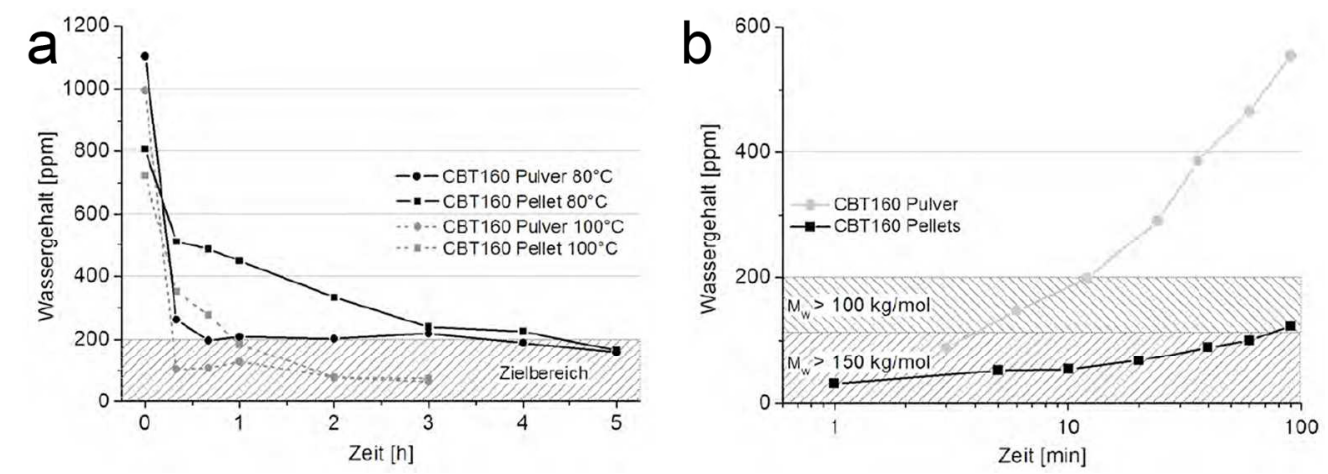

Fig. 12: Conditioning of CBT160 powder (•) and pellets ( $\bullet$ ) at 80 and $100^{\circ} \mathrm{C}$. CBT water content over drying time (a) and water uptake of dry CBT in ambient atmosphere at $60 \%$ relative humidity over time. Reprinted from Ref. 48.

$170 \times 60 \mathrm{~mm}(300 \times 300 \mathrm{DPI})$ 

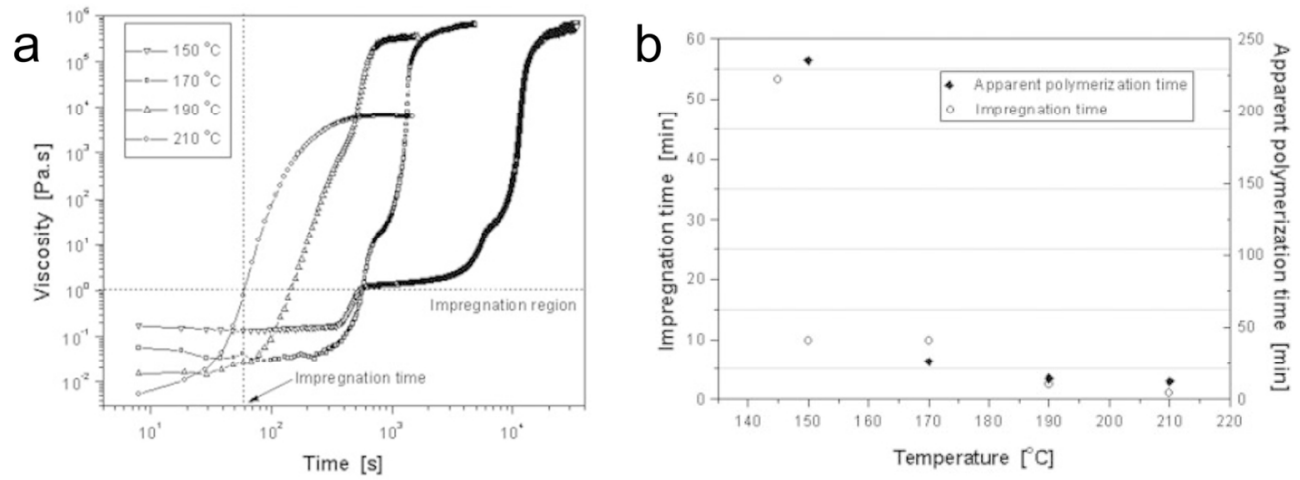

Fig. 13: Effect of testing temperatures on the variation of melt viscosity with time (a) and impregnation time and apparent polymerization time as a function of temperature (b). Reprinted with permission from Ref. 29. Copyright 2006 John Wiley and Sons. $65 \times 24 \mathrm{~mm}(600 \times 600 \mathrm{DPI})$ 

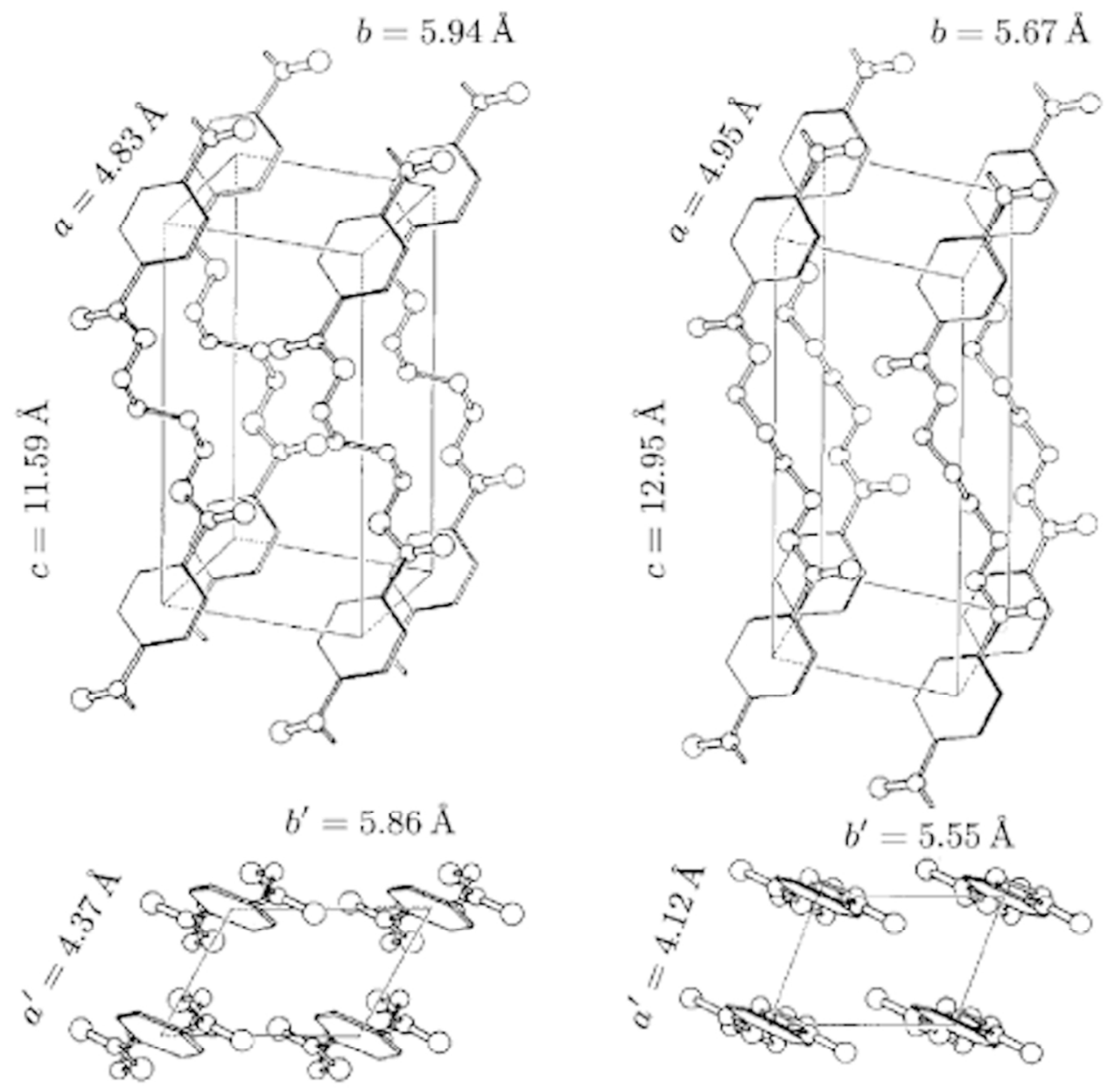

(a)

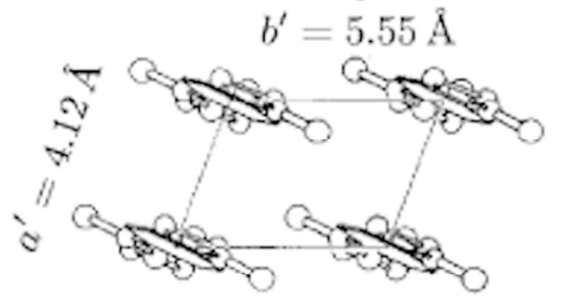

(b)

Fig. 14: Elementary cells of PBT: (a) $\alpha$-form and (b) $\beta$-form. Reprinted with permission from Ref. 58. Copyright 1976 American Chemical Society. $119 \times 123 \mathrm{~mm}(300 \times 300 \mathrm{DPI})$ 


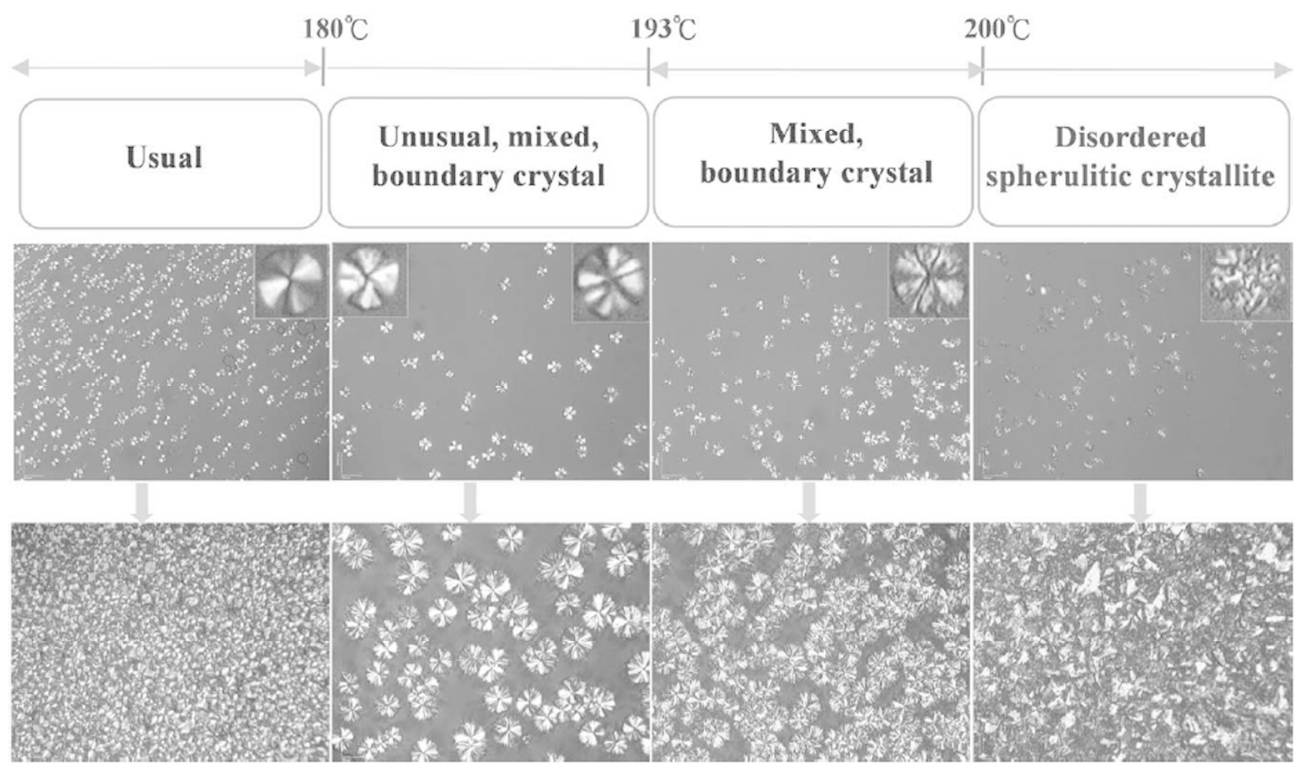

Fig. 15: PLM morphologies of PCBT corresponding to the crystallization temperature range of $190-215^{\circ} \mathrm{C}$. Reprinted with permission from Ref. 47. Copyright 2010 John Wiley and Sons.

$170 \times 99 \mathrm{~mm}(300 \times 300 \mathrm{DPI})$ 

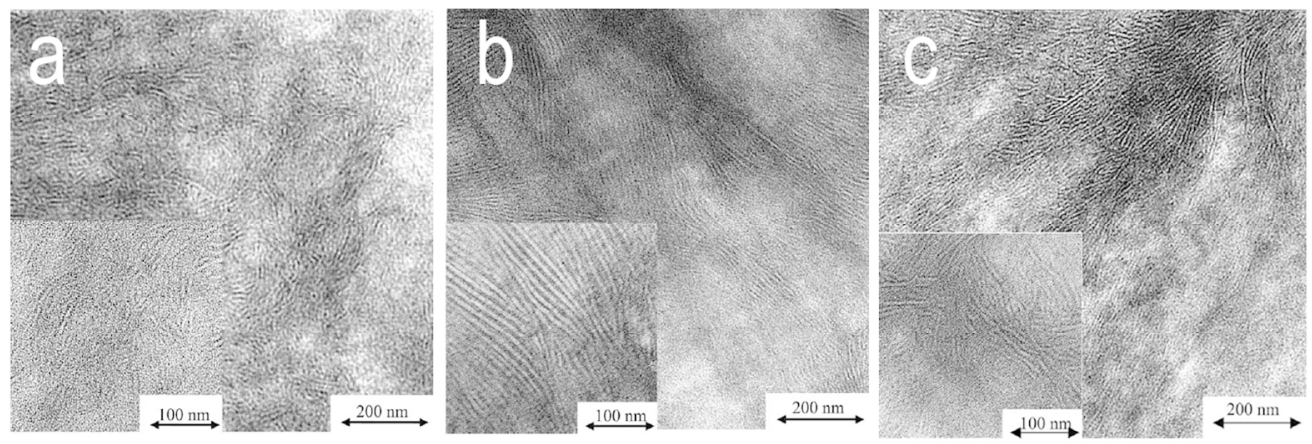

Fig. 16: TEM micrographs of PBT (a), PCBT (b) and reprocessed RP-pCBT (c). Reprinted from Ref. 63 with permission from Elsevier. $170 \times 56 \mathrm{~mm}(300 \times 300 \mathrm{DPI})$ 

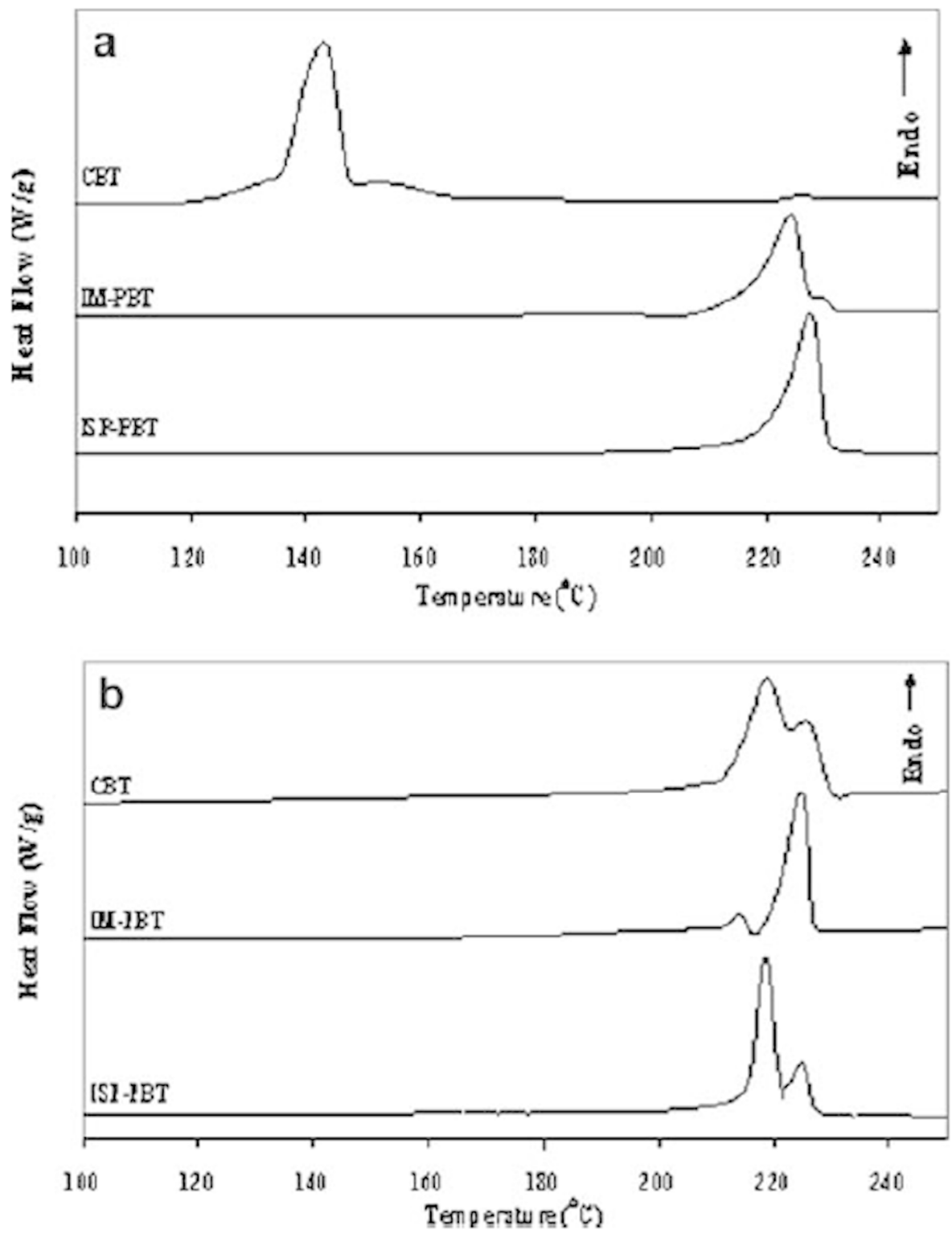

Fig. 17: DSC thermograms of CBT, injection moulded PBT (denoted as IM-PBT) and isothermally polymerized pCBT (denoted as ISP-PBT). First heating scan (a), second heating scan (b). Heating and cooling rates: $5^{\circ} \mathrm{C} / \mathrm{min}$. Reprinted from Ref. 66 with permission from Elsevier. $156 \times 203 \mathrm{~mm}(600 \times 600 \mathrm{DPI})$ 


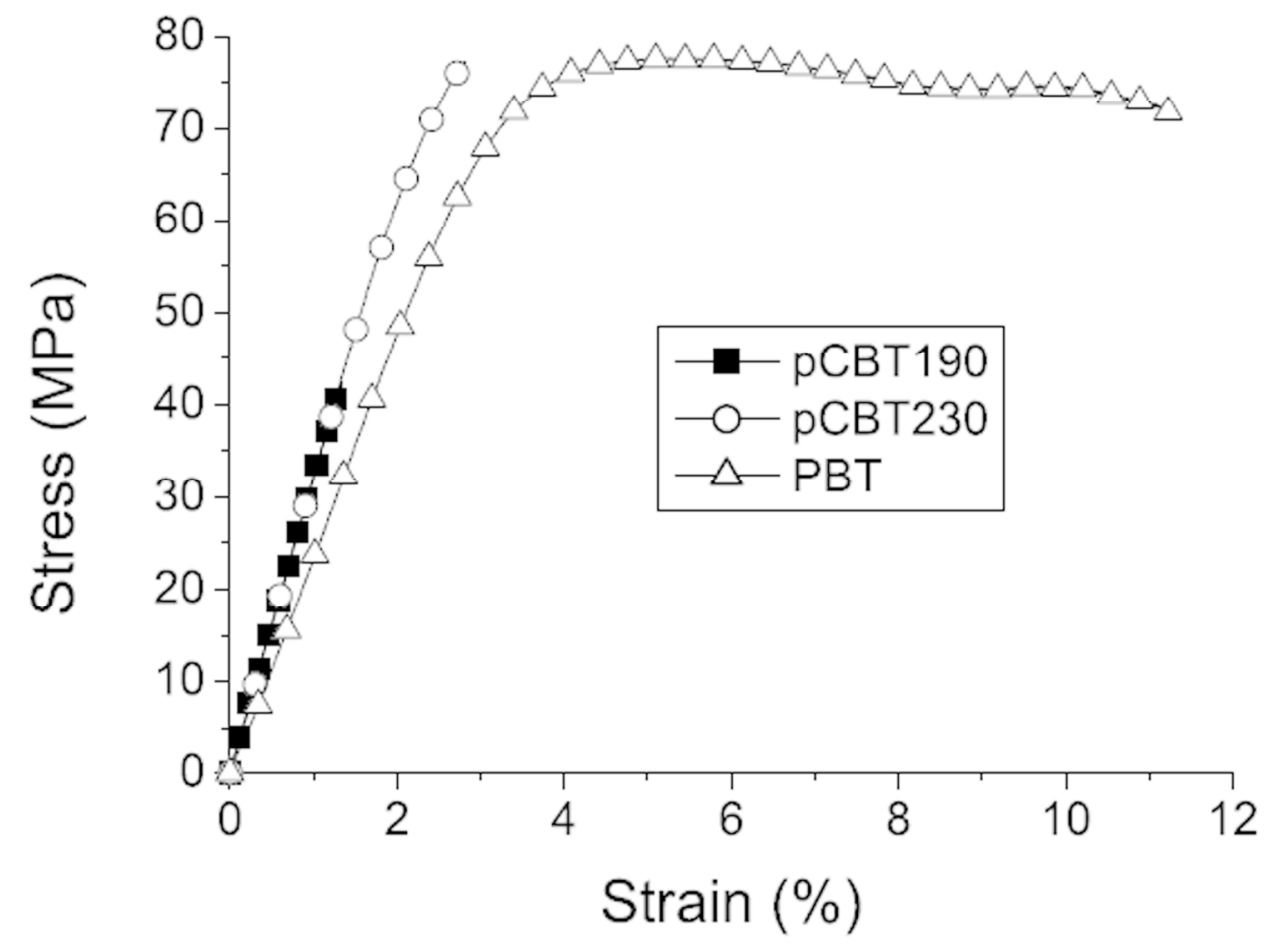

Fig. 18: Typical 3 point bending stress-strain curves for PCBT and PBT. Reprinted from Ref. 63 with permission from Elsevier.

$77 \times 59 \mathrm{~mm}(600 \times 600 \mathrm{DPI})$ 

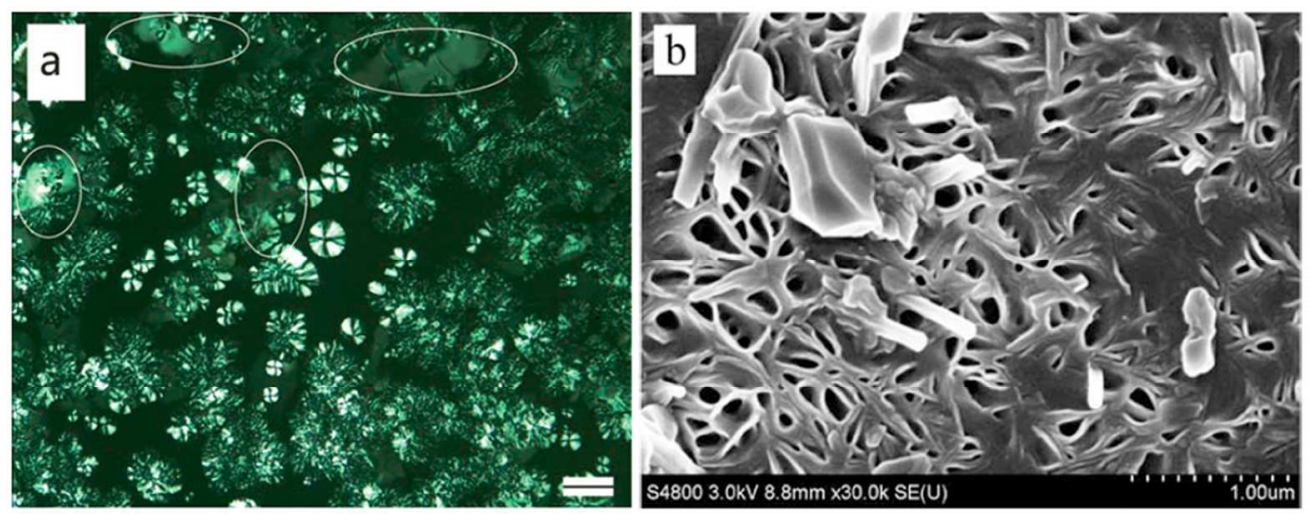

Fig. 19: Remaining cyclic oligomer crystals after polymerization at $190^{\circ} \mathrm{C}$ for $30 \mathrm{~min}$; PLM image (a) and SEM image (b). Reprinted from Ref. 40 with kind permission from Springer Science and Business Media. $150 \times 58 \mathrm{~mm}(300 \times 300 \mathrm{DPI})$ 

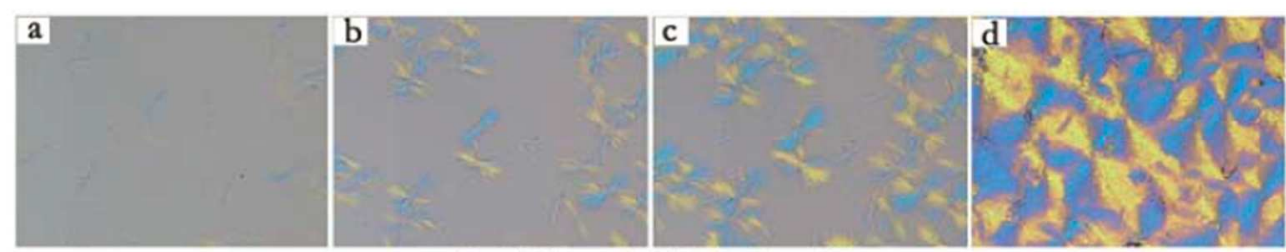

Evolution of pCBT spherulite

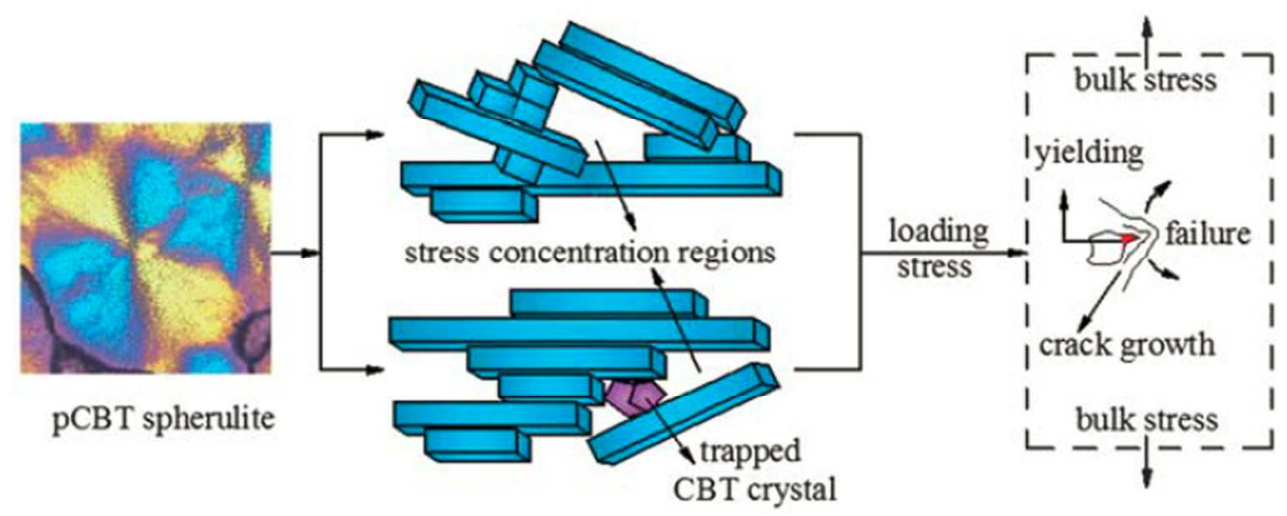

Fig. 20: Brittleness mechanism of remaining cyclic oligomer crystals in pCBT. Reprinted from Ref. 40 with kind permission from Springer Science and Business Media. $150 \times 95 \mathrm{~mm}$ (300 x 300 DPI) 
Carbodiimide

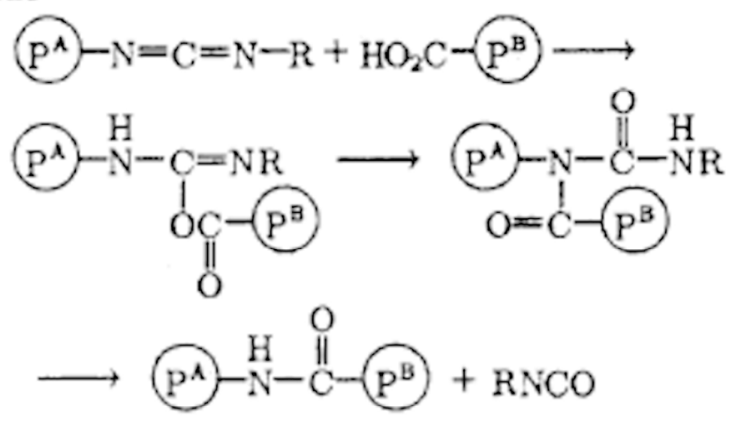

Isocyanate<smiles>O=C(Nc1ccccc1)OC(=O)Nc1ccc(C=[Po+][O-])cc1</smiles>

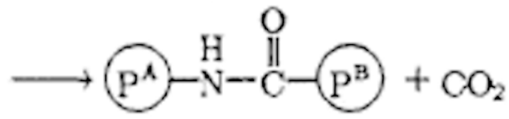

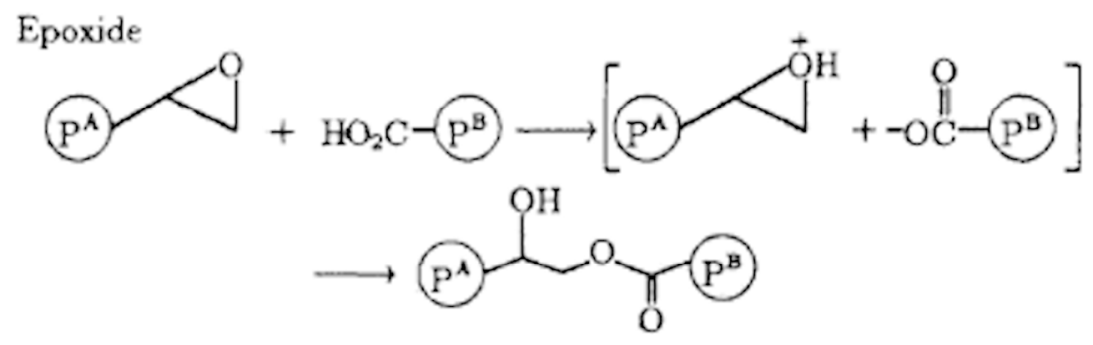<smiles>O=C(NCCOC(=O)c1ccccc1)c1ccc(C23C[C@H](CO2)CC(c2ccccc2)N3)cc1</smiles>

Fig. 21: Reactions of carboxylic groups with various electrophilic groups. Reprinted with permission from Ref. 87. Copyright 2005 John Wiley and Sons. $205 \times 280 \mathrm{~mm}(300 \times 300$ DPI) 

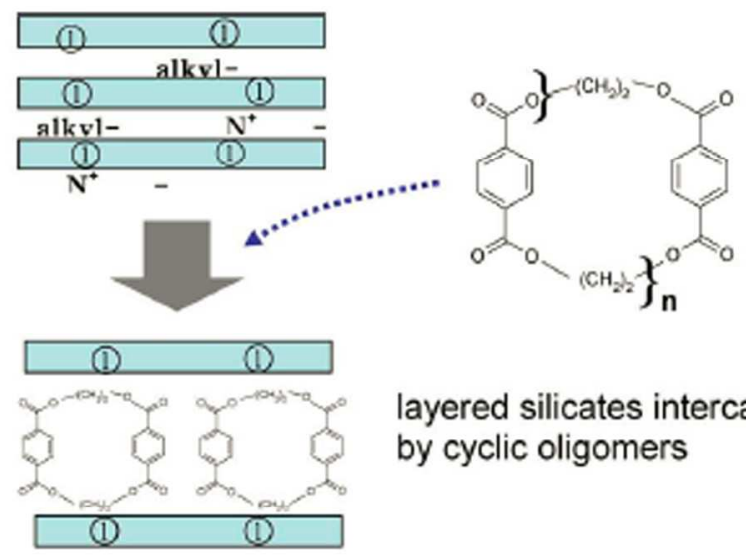

layered silicates intercalated by cyclic oligomers
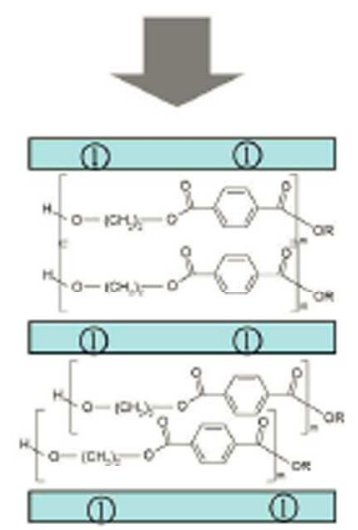

ring-opening polymerization of cyclic oligomers causing increase of interlayer distance along with disintegration of layered silicates

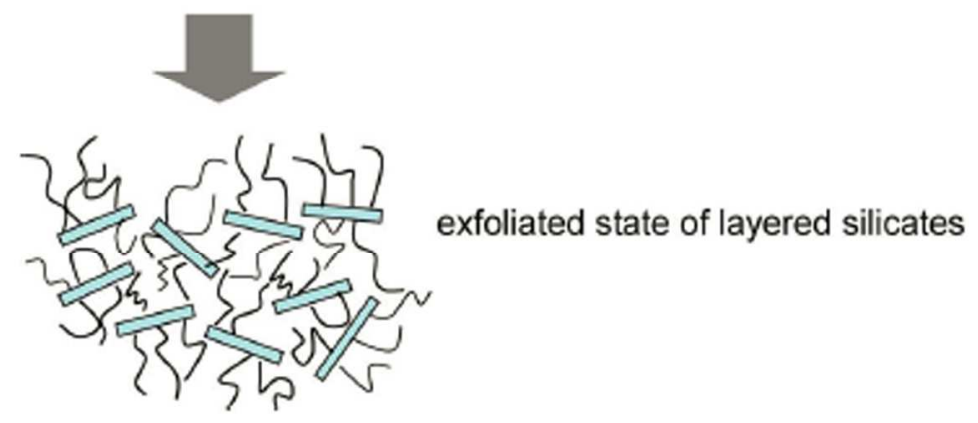

Fig. 22: Schematic representation of nanocomposite formation by ROP of cyclic ethylene terephthalate oligomers in between silicate layers. Reproduced from ref. 14 with permission of Elsevier Science Ltd., UK. $180 \times 271 \mathrm{~mm}(600 \times 600 \mathrm{DPI})$ 


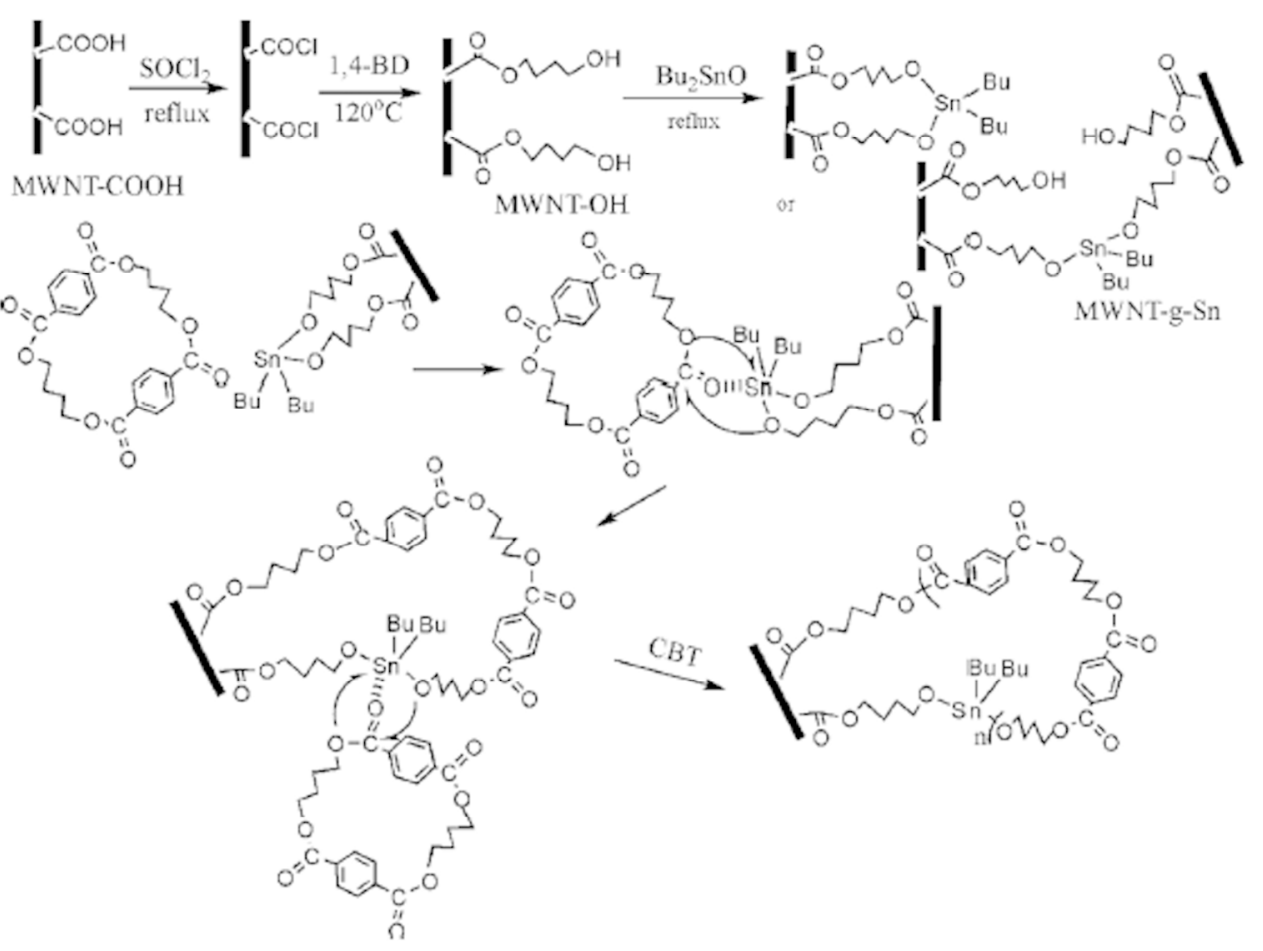

Fig. 23: Synthesis route of MWCNT-grafted PCBT. Reproduced from ref. 153 with permission of John Wiley and Sons. $109 \times 79 \mathrm{~mm}(600 \times 600$ DPI $)$ 
1

2

3

4

5

6

7

8

9

10

11

12

13

14

15

16

17

18

19

20

21

22

23

24

25

26

27

28

29

30

31

32

33

34

35

36

37

38

39

40

41

42

43

44

45

46

47

48

49

50

51

52

53

54

55

56

57

58

59

60
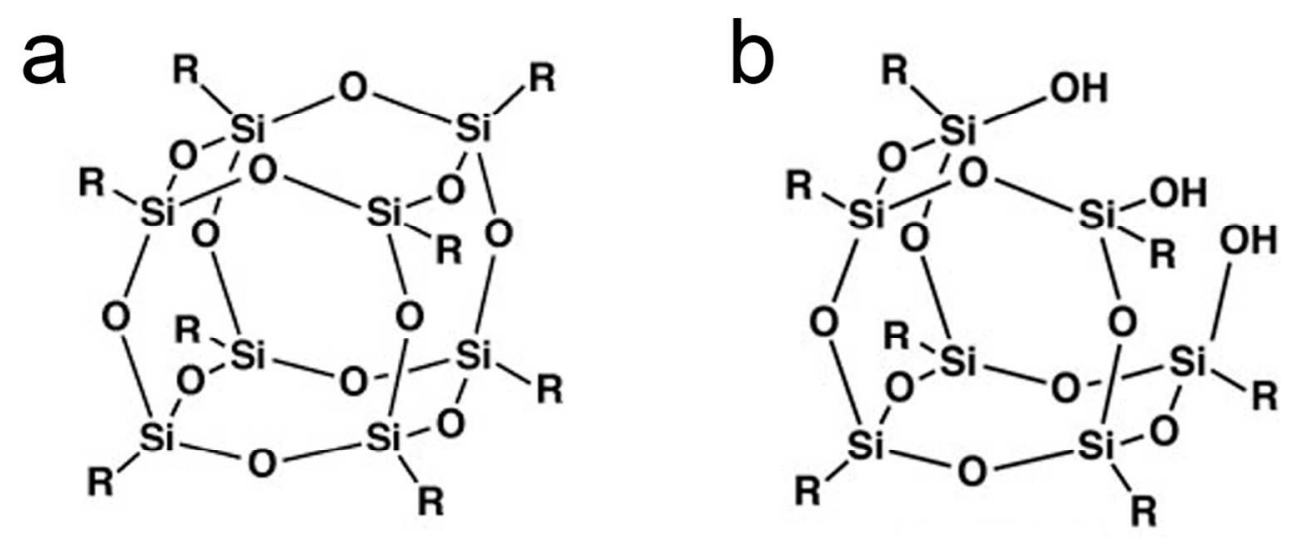

Fig. 24: Chemical structures of POSS; cage structure (a) and partial cage structure (b). Reproduced from ref. 133 with permission of Elsevier. $123 \times 53 \mathrm{~mm}(300 \times 300 \mathrm{DPI})$ 


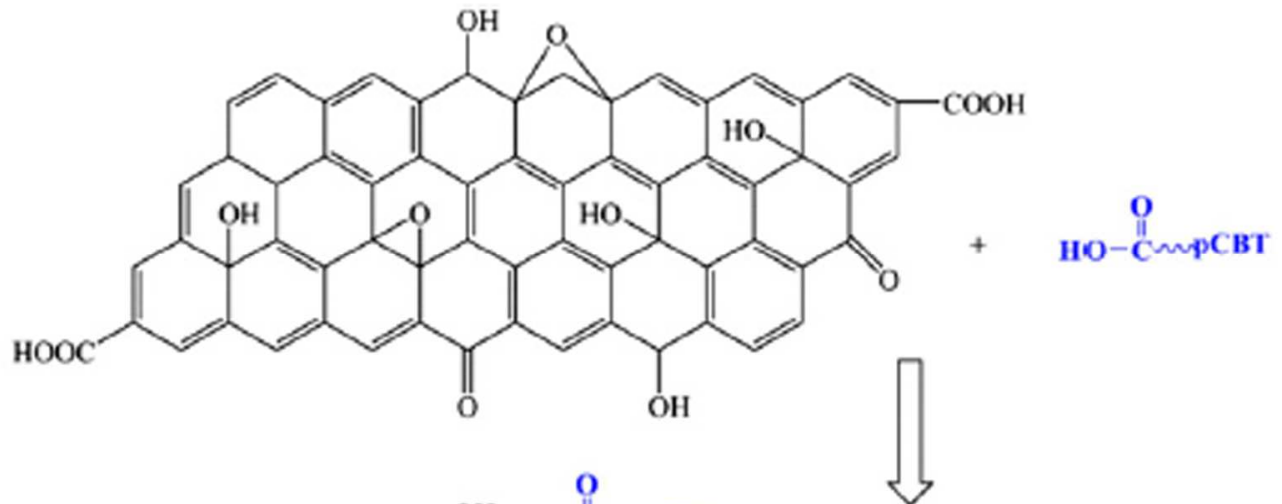

Fig. 25: Polymerization mechanism of TRGO and CBT. Reproduced from ref. 188 with permission of Elsevier. $137 \times 157 \mathrm{~mm}(600 \times 600 \mathrm{DPI})$ 


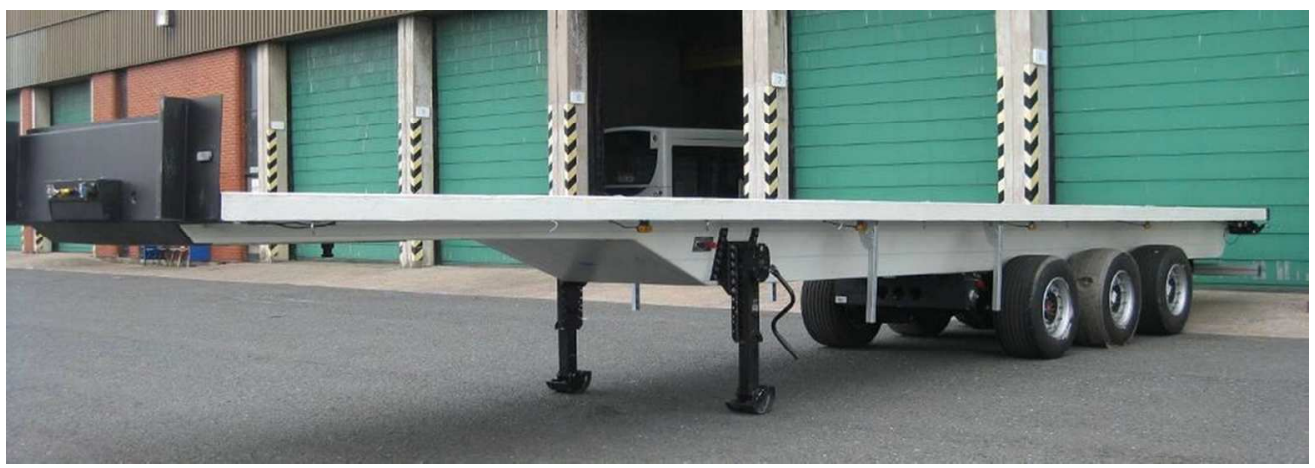

Fig. 26: World's first lightweight and aerodynamic thermoplastic composite trailer. Reproduced from ref. 219.

$52 \times 18 \mathrm{~mm}(600 \times 600 \mathrm{DPI})$ 


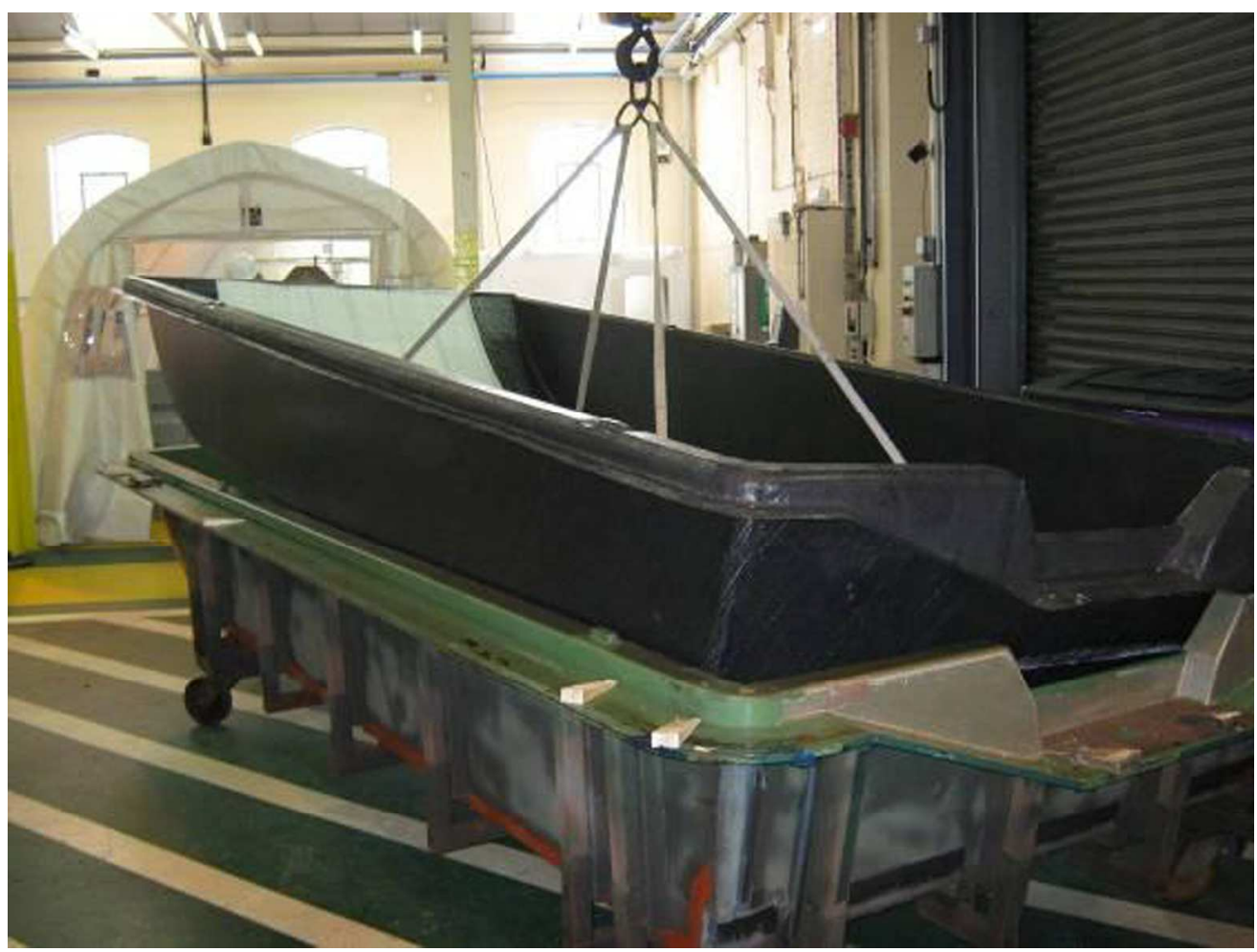

Fig. 27: Flat bottom boat case study manufactured from pCBT/GF composite and a balsa-cored sandwich panel. Reproduced from ref. 219. $112 \times 84 \mathrm{~mm}(600 \times 600 \mathrm{DPI})$ 

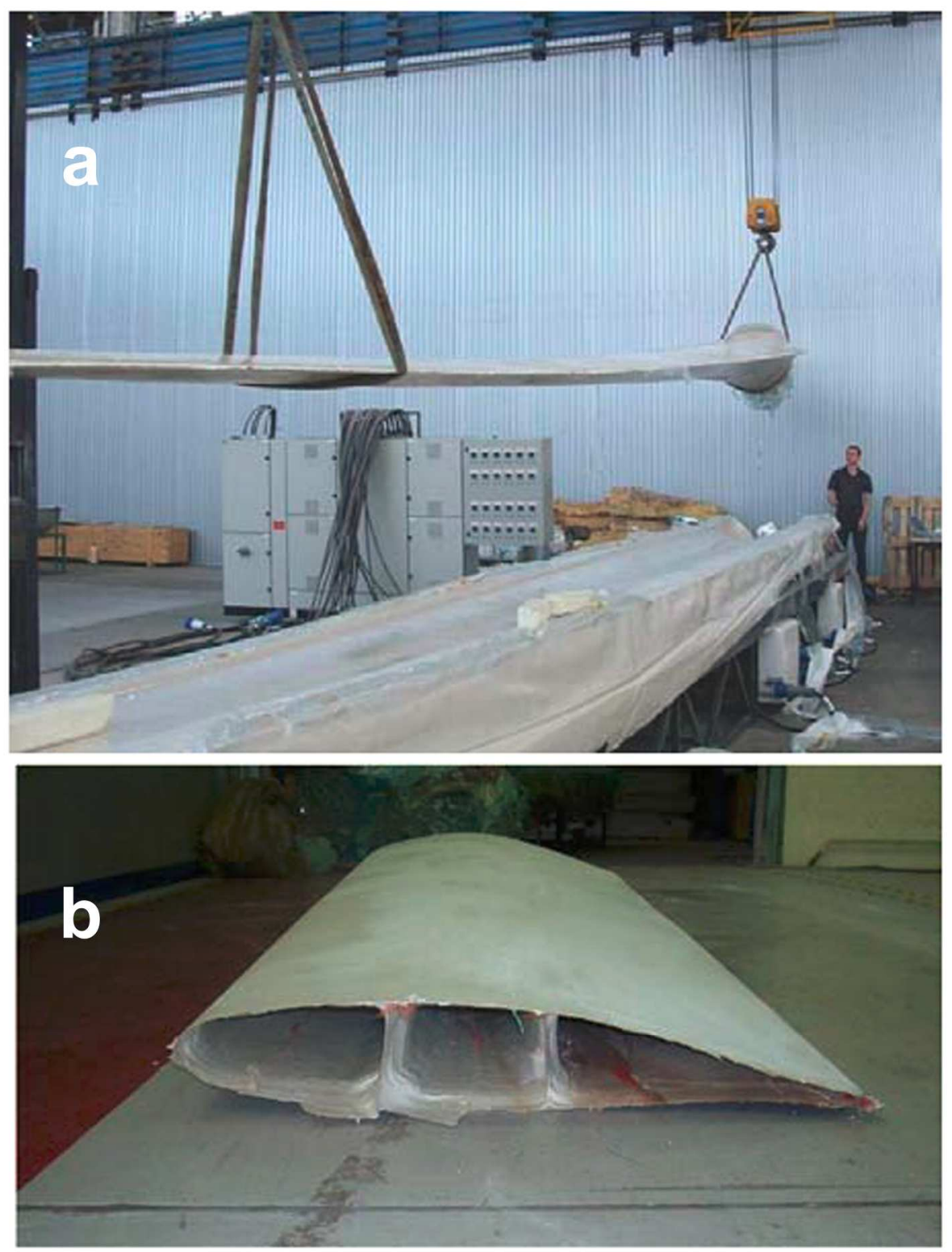

Fig. 28: $12.6 \mathrm{~m}$ long $\mathrm{pCBT/GF}$ wind turbine blade manufactured at $200{ }^{\circ} \mathrm{C}$, (a) removing moulded blade from tool; and (b) a $4.0 \mathrm{~m}$ moulded section of the blade, showing the spar-cap and shear-webs moulded in a "one-shot" process. Reproduced from ref. 223 $198 \times 262 \mathrm{~mm}(300 \times 300 \mathrm{DPI})$ 